\title{
INFORMATION ASYMMETRY, SHARE MISPRICING AND THE COORDINATION PROBLEM: INVESTOR PORTFOLIO CHOICE IN CZECH VOUCHER PRIVATIZATION
}

\section{Elena Yusupová}
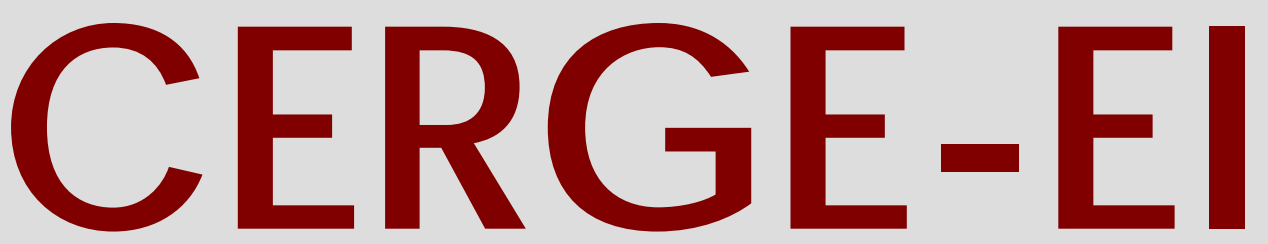

Charles University Centerfor Ec onomic Research and Graduate Educ ation Academy of Sciences of the Czech Republic Ec onomic s Institute 


\title{
Working Paper Series 301 (ISSN 1211-3298)
}

\section{Information Asymmetry, Share Mispricing and the Coordination Problem: Investor Portfolio Choice in Czech Voucher Privatization}

\author{
Elena Yusupová
}

\author{
CERGE-EI \\ Prague, July 2006
}


ISBN 80-7343-097-5 (Univerzita Karlova. Centrum pro ekonomický výzkum a doktorské studium) ISBN 80-7344-086-5 (Akademie věd České republiky. Národohospodářský ústav) 


\title{
Information Asymmetry, Share Mispricing and the Coordination Problem:
}

\section{Investor Portfolio Choice in Czech Voucher Privatization*}

\author{
Elena Yusupová
}

CERGE-EI**

\begin{abstract}
Voucher privatization in the Czech Republic presented a natural experiment of the ability of investors to construct their portfolios under conditions of asymmetric information and the absence of stock market prices. This paper provides a theoretical model of an optimal portfolio choice made by the investors maximizing their expected return and at the same time solving a coordination problem in a non-cooperative game with other investors. The perception of share misvaluation and private information are endogenized. The model offers an interpretation and theoretical justification of earlier empirical findings and explains the crucial role of the auctioneer, different optimal strategies for different types of investors and the redundancy of legal limits constraining ownership stakes in firms. The results provide implications for the design of voucher privatization, which should lead to more efficient share distribution and price setting.
\end{abstract}

\begin{abstract}
Abstrakt
Kupónová privatizace v České republice představuje přirozený experiment schopností investorů sestavit portfólio v podmínkách asymetrických informací a absence tržních cen akcií. Tento článek poskytuje teoretický model optimálního portfólia sestaveného investory maximalizujícími očekávaný výnos a současně řešícími problém koordinace v nekooperativní hře s dalšími investory. Vnímaní nesprávného ohodnocení akcií a soukromé informace jsou endogenní. Model umožňuje interpretace a teoretické zdůvodnění předcházejících empirických výsledků, vysvětluje rozhodující roli organizátora aukce, rozlišuje optimální strategie pro jednotlivé typy investorů a ukazuje nadbytečnost právního limitu omezujícího vlastnický podíl investorů ve firmách. Výsledky mají implikace pro nastavení kupónové privatizace, která by vedla k efektivnější distribuci akcií a stanovování cen.
\end{abstract}

Keywords: voucher privatization, asymmetric information, portfolio and strategic investors, portfolio choice, mispricing

JEL Classification: D81, D82, G11

\footnotetext{
* I am grateful to Randall Filer, Jan Hanousek, Evžen Kočenda, Jan Švejnar, Timur Yusupov and Peter Zemčík for useful comments, suggestion and constructive critique. The grant support from GAČR No.402/05/2018 is highly appreciated. The author would also like to thank Richard Stock for English editing.

E-mail: Elena.Yusupova@cerge-ei.cz. Address for correspondence: CERGE-EI, P.O. BOX 882, Politických věznu 7, 11121 Prague, Czech Republic

**CERGE-EI is a joint workplace of the Center for Economic Research and Graduate Education, Charles University, and the Economics Institute of the Academy of Sciences of the Czech Republic, CERGE-EI, P.O. Box 882, Politických vězñu 7, Prague 1, 111 21, Czech Republic.
} 


\section{Introduction}

The privatization of state-owned enterprises (SOEs) was a crucial point in the transformation of Central and Eastern European countries (CEECs) into market economies at the beginning of the 1990s. In spite of many political, social and economic issues related to privatization, there is a universal consensus among economists that privatization improves efficiency (Rees, 1988). However, privatizing in countries with under-developed or nonexistent domestic financial markets, suffering from a shortage of private capital for investment and a lack of useful asset-pricing signals, is a challenge. Consequently, the question arises which method of privatization is feasible and the most efficient when a large number of firms need to be privatized and their value is not known.

A natural outcome was the choice of voucher privatization in several CEECs and Russia. It has a number of advantages, such as (i) relative transparency, which mostly prevents corruption and helps political legitimacy (Tř́ska, 2002), (ii) equality, since it is available to all citizens over 18 , (iii) it gives a large cross-section of the population a sense of ownership in the economy and helps to overcome the dual legacies of communism (Hillion and Young, 1996), (iv) the ability to handle a huge number of SOEs in a relatively short time (Takla, 1994), (v) it initiates capital market development (Brzica, 1996), and (vi) governments can largely sidestep the valuation problems that plague privatization in transition economies. The privatized enterprises did not have a market track record on which valuation could be based and there were no expert institutions to fulfill this task. In voucher privatization, as Hillion and Young (1996) or Mejstrík et al. (1997) argue, investors need to assess only the enterprises' relative values, i.e. their values with respect to one another, rather than having to express each in monetary terms. In addition, Bennett et al. (2004) analyzed the impact of various privatization methods on economic growth and found that mass privatization is the only method with a significantly positive effect.

Governments in transition countries had more objectives than a mere transfer of assets from public to private ownership. First, a pattern of ownership that would ensure the efficient performance of firms was of interest. Second, a more concentrated ownership was, with nonfunctioning capital markets, a better guarantee of effective corporate governance. Voucher privatization, which all citizens would take part in, presented a risk that the resulting ownership structure would be so widely dispersed that it would impede the development of effective corporate governance and hamper improvement in economic performance. In 
addition, it was often criticized for its inability to provide firms with "real owners" who could improve performance. Fear of too-dispersed ownership, which might lead to considerable agency costs, low investor participation in firm control and a lack of professional management of investments were the main reasons why authorities supported the participation of investment funds in the mass privatization in several CEECs, such as the Czech Republic, Poland and Bulgaria. ${ }^{1}$

The Czech Republic was the first country in the region that initiated a widespread mass privatization program. The property value of privatized SOEs was substantially higher than the cumulated price of the voucher points assigned to the citizens: each got 1000 points for approximately 30 USD. The privatization thus seemed to be a lucrative investment opportunity and this fact motivated the rise of Investment Privatization Funds (IPFs). Voucher holders could entrust their voucher points (or some of them) to IPFs, which invested on their behalf. These entities thus became the predecessors of later professional institutional investors and mutual funds.

Lack of investment experience among citizens and large marketing campaigns enabled IPFs to collect a majority of the total voucher points. The participation of IPFs was supported, as the initial research shows, also in academic circles. As Švejnar (1993) argued, IPFs enabled citizens to get equal proportions of the privatized property and at the same time reduced citizens' exposure to risk. Hyclak and King (1993) concluded that the IPFs had the purpose to establish a model of a diversified portfolio of privatized firms and to raise consciousness about personal financial investing in market economies. Brzica (1996) also proposed that IPFs would contribute to developing financial markets and promoting collective investment.

In contrast to Poland, the individual investors and IPFs in the Czech Republic selected their portfolios based on their knowledge, experience and beliefs about the future performance of available securities. However, the problems IPFs faced during their portfolio choice, which resembled a price-setting, multiround iterative auction, were significantly different. Prices were set by the government, there was a limited supply of shares, no alternative use of the voucher points that served as a means of payment for the shares, and there was little or no experience with investing in and controlling firms.

Since the mid-1990s this phenomenon has been the focus of theoretical and especially empirical research. Investor strategies, determinants of share demand, differences between

\footnotetext{
${ }^{1}$ For evidence on the fear of too-dispersed ownership weakening the shareholder monitoring activity and strengthening the management see e.g. Carlin and Mayer (1992), Boycko et al. (1994), Takla (1994), Kraizberg (1999).
} 
individual investors and IPFs and between the privatization designs in individual CEE countries and, more generally, the efficiency of the bidding process were of large concern to researchers. The main aim of governments was to sell all shares and to have all points allocated (Tř́iska, 2002; Hanousek and Filer, 2001; Kraizberg, 1999). This seemed to be in conflict with finding optimal share prices and motivated a number of research questions such as: Did property go to those investors who valued it most? Was the bidding process optimal as a price discovery mechanism?

Though empirical studies provided interesting insights into the privatization process, they were mostly not based on any theoretical foundations. Švejnar and Singer (1994) found the existence of systematic factors in the voucher bidding system. They stressed that an empirical investigation of the determinants of bidding behavior and price setting is complicated by the lack of well-established theory. This comes as no surprise taking into account the complex nature of privatization and the bidding process, in particular the inconsistent behavior of some investors and their heterogeneity leading to diverse objective functions.

Our main objective is to fill this gap in the research and to build a model that enables studying this issue and tries to explain the determinants of the expected-return-maximizing investors' share demand. The model is based on the current knowledge of the bidding process. The study aims to identify investors' intentions, their perception of firms' misvaluation and their rationality by looking at their investment strategies. Providing insight into investors' motives and the level of perceived mispricing would allow policy-makers to set prices more precisely and, in general, to distinguish different groups of investors and regulate their activities. The model can assist in future privatization efforts. The analysis of differences in the decision-making of different types of bidders in an environment characterized by information asymmetry and in the absence of market prices should also contribute to the branch of economic literature focused on trading and auctioning mechanisms.

Theoretical analysis of the model shows how different incentives of investors affect their share demand. In particular, the IPFs might prefer to play the role of portfolio investors and, as classical mutual funds, bid for the most undervalued firms to benefit from an increase in their market value after the privatization and from the management fee. On the other hand, they might wish to be actively involved in management and undertake firm restructuring, attract foreign investors or in other active ways increase a firm's value. 
The paper proceeds as follows. In Section 2, we review the related studies, starting with the general literature on multi-unit auctions and proceeding with an overview of studies modeling different aspects of the Czech privatization process. In Section 3, based on the current level of knowledge we construct a model and derive the equations of the optimal share demand. In Section 4, the share demand and the weight of relevant factors are analyzed for portfolio investors and the investors intending to participate in firm management, and the impact of changes in relevant factors are outlined. The analyses also show how shortages in price-setting distort the investors' decisions and lead to an inefficient outcome. In Section 5, we discuss the findings. We conclude and derive some policy-making implications in Section 6.

\section{Literature Review}

Although many empirical studies were undertaken in the area of mass privatization in the Central and Eastern European countries, the bidding process as an auction with a specific institutional structure has not received much attention. This section is divided into two subsections. First, we review the up-to-date research on auctions and their relevance for the bidding process that took place during voucher privatization; second we look at the theoretical studies of the bidding process in the Czech Republic. ${ }^{2}$ We stress important questions and conclusions of the research, which lead to the foundations of our model presented in Section 3.

\subsection{The related auction theory literature}

Mass privatization is often compared to an auctioning mechanism, which efficiently distributes shares and drives the prices to their equilibrium value. Therefore, before looking at the research efforts to model the privatization process, it is useful to have a look at general auction theory and to assess how much insight it actually brings for the design of mass privatization. $^{3}$

The objective of an auction is to elicit enough information about a bidder's preferences to realize an efficient or approximately efficient allocation. Auctions have recently come into the spotlight because of their use in deregulation, privatization and on the

\footnotetext{
${ }^{2}$ In this section we are primarily interested in exploring the nature of the bidding process from the theoretical point of view.

${ }^{3}$ As the auction theory literature is vast and goes far beyond the scope of our research, we limit ourselves to the studies related to multiple-item multiple-unit bidding.
} 
Internet. They have the convenient property of aggregating information. Even if no information on bidders' valuations of an item is available, the auctioneer can achieve the sale of the item to the bidder who values it most. When multiple items are for sale, this task becomes more complex. In response to this problem, combinatorial auctions emerged in the academic literature. Rassenti et al. (1982) and Banks et al. (1989) are the earliest works on the topic.

Combinatorial auctions are simultaneous multiple-item auctions that allow the submission of combinations of the items being sold. Bids on combinations of items are important to bidders whose value for combinations is greater than the sum of their values for the individual items. This can be the result of cost savings in procurement and synergies between assets or when winning alternative items can meet the same need (Pekeč and Rothkopf, 2003). The distinctive features of these auctions are:

the complexity of winner determination as individual bidders are bidding for different combinations of items and the highest bids are not guaranteed to win and

the cooperative flavor of bidding stemming from the way auction winners are determined.

Bykowski et al. (1995) present examples in which allowing combinatorial bids increases both revenue and efficiency. Harstad and Rothkopf (1995) support the efficiency argument. Krishna and Tranaes (2002), though admitting the higher efficiency of combinatorial bidding, find that when there is a sufficient number of bidders, full bundling with a winner-take-all format brings less revenue.

Next to potential gains, there are also disadvantages connected with allowing combinatorial bids. The first is the difficulty of finding the best revenue maximizing set of winning bids given by two main factors. Computational complexity, which rapidly increases with the number of items, is a central reason for difficulties in designing such auctions. There were a number of ways proposed to deal with this issue, such as algorithmic approaches surveyed by de Vries and Vohra (2003), limiting biddable combinations discussed by Park and Rothkopf (2001) or limiting the use of combinatorial bids to reduce the intersecting structure of all biddable combinations (FCC, 2000). ${ }^{4}$ Some structures of combinatorial bids that are computationally manageable are discussed in Rothkopf et al. (1998). Also, as Pekeč and Rothkopf (2003) argue, the determination of the auction winner may be also opaque. Transparency is therefore important in auctions since it simplifies bidders' understanding of

\footnotetext{
${ }^{4}$ Sometimes, limiting the use of combinatorial bids can interact favorably with concerns about bidders' incentives.
} 
the situation and increases their trust in the auction process. Generally, there is no clear-cut way to deal with the complexity of winner determination and the trade-off between some unwanted consequences depends on the choice of the auction designer.

The second is the "threshold" or "free-rider" problem discussed in Milgrom and Wilson (1993), when the diseconomies of scale dominate and the bids on combinations exceed higher bids for individual units. The problem is magnified when many items are being sold and large combinations are sought. The combinatorial auctions can be conducted as single round sealed bid auctions, progressive auctions, Vickrey-Clarke-Growe mechanism, uniform price mechanism ${ }^{5}$ or iterative combinatorial auctions. Each has advantages and drawbacks, and the final choice is determined by the most optimal outcome given the predefined priorities of the auction.

Since the iterative combinatorial auctions best reflect the voucher privatization bidding process, we will elaborate more on this topic. This type of auctions are predominant in e-business (Pekeč and Rothkopf, 2003). They come in two varieties. In the first type, quantity setting, bidders submit prices on various allocations in each round. The auctioneer makes a provisional allocation of the items that depends on the submitted prices. Bidders are allowed to adjust their price offers from the previous rounds and the auction continues. The aim is to ensure rapid progress and encourage competition. In the second type, price setting, the auctioneer sets the price and bidders announce which bundles they want at the posted prices. The auctioneer observes the requests and adjusts the prices, governed by the need to balance demand with supply. The practical use of quantity setting prevails over price setting, also due to the freedom given to the bidders.

Compared to other formats, for example sealed bid auctions, iterative combinatorial auctions have a number of advantages that are listed in de Vries and Vohra (2003): (i) It saves bidders from specifying their bids for every possible combination, so the bid submission burden is significantly lower. (ii) Such methods can be adapted to dynamic environments where bidders and objects arrive and depart at different times. (iii) It allows information to be revealed (the prospective participants can learn about their rivals' evaluations through the bidding process) and creates a space for collusive behavior. Though the total bid preparation process might be lengthy and burdensome and many shortages of single round combinatorial auctions are not eliminated, this is the most popular combinatorial auction format in practice.

\footnotetext{
${ }^{5}$ For more details on the listed auctioning mechanism see Robinson (1985), Krishna and Tranaes (2002), Harstad and Rothkopf (2000), Vikrey (1961), Clarke (1971), Groves (1973), Rothkopf et al. (1990), Yokoo et al. (2004), Parks (2001), Ausubel and Milgrom (2002), de Vries and Vohra (2003).
} 
There are some problems related to combinatorial auctions, especially to their iterative auctioning mechanism. The exposure problem involves the risk of bidders winning unwanted items. For example if the bidder wants to win $\{a\}$ or $\{b\}$, but not both, the bidder might be reluctant to submit competitive bids for both. Allowing (or imposing) budget or capacity constraints (e.g. Hohner et al. 2003) on bids or both (e.g. Elmaghraby and Keskinocak, 2003) can mitigate this problem.

Ties in auctions lead to arbitrary allocations. There are some ways to deal with this, however, no one way is fully satisfactory. Combinatorial auctions usually place a much higher information and communication burden on both bidders and the auctioneer. Bidders can evaluate and bid on all combinations; the auctioneer processes the bids, determines the winning allocations and prices and provides feedback after each bidding round. Based on this, the bidders process the new information and submit new bids. The complexity flows from many combinations and the cooperative aspect of combinatorial bidding. Even the multiround format might not be able to overcome these issues.

Nissan and Segal (2002) consider the communication bottleneck even more severe than the computational one, since it becomes an issue already with a smaller number of items when the computational complexity is still manageable and cannot be sidestepped by transferring it to the bidders themselves. Nissan and Segal (2002) and Rothkopf et al. (1998) propose some technical procedures to mitigate this problem. For example, the structure of biddable combinations can be limited or the auctioneer should provide some tools that help bidders in bid preparation.

\subsection{Previous work in the theoretical modeling of privatization}

Though auction theory provides a lot of insightful information and intuition for the design of the mass privatization, the auction literature does not offer a model resembling the unique character of mass privatization. Czech voucher privatization can be described as an iterative combinatorial price-setting auctioning mechanism conducted in a multiround format, where bidders' choices are limited by their budget constraints and restrictions on bids.

However, in some respects it critically differs from the described auctioning mechanisms. First, regarding the main criteria of the auction assessment, the government did not strive for revenue maximization. The aim was possibly just a fair distribution of shares of privatized firms to the citizens. 
Second, the auctioneer adjusted prices after every round to distribute all shares and the bidders made efforts to allocate all their voucher points. The allocative efficiency in the classical sense to sell the shares to the bidders with highest private values was limited. This was because all bidders with a reservation price exceeding the voucher price could bid and receive the shares and also the prices might not reflect the value perceived by the bidders due to (i) different private valuations of different types of bidders and their interests and (ii) an auctioneer who might not adjust prices efficiently.

Third, while in classical combinatorial auctions, multiple indivisible items are distributed, every item in the voucher privatization (shares of one firm) consisted of multiple units (in the context of auction theory one can speak about divisible objects). As a result, researchers mostly chose their own approaches to the theoretical modeling of the bidding process.

Brada (1992) and Hillion and Young (1996) looked for an analogy between the voucher scheme and a resource allocation mechanism similar to the one proposed by Walras, where bidding for goods or financial instruments would eventually converge to a set of prices that would equate supply and demand. However as Brada (1992) and Filer and Hanousek (2001) pointed out, the process differed from Walras' tatonnement in the asymmetry of the distribution process. In the Walras procedure the goods are not delivered until the price is found, when supply equaled demand. Hillion and Young (1996) also do not consider price discovery as a main motive of the auctioneer. Therefore Brada (1992) proposed the concept of an asymmetric distribution of shares, which is supported by bidders' different value distributions of the same shares and leads to investors' strategic behavior. Brada (1992) interprets strategies according to the Cournot and Stackelberg model, where the players who are maximizing their profits or some form of utility function, are not cooperating and have equal power in a competitive game (Stackelberg, 1952). However, this solves static models, whereas the voucher privatization was a sequential bidding mechanism, where the past round's strategies and bidding behavior can have a direct influence on the current bidding opportunity and behavior. ${ }^{6}$

Ma (1994) drew on the theoretical literature and his dissertation presents the first profound theoretical analysis of the dynamics of the voucher process. Ma (1994) focused on

\footnotetext{
${ }^{6}$ Besides, as Wendelová and Bukáč (1993) indicated there might be some level of cooperation among IPFs. Therefore the models of Prescott (1973) and Kydland (1977), who assume that the players determine their best decisions on the current state of the system and the decisions of the other players, might be better points of departure.
} 
the assessment of price development. He also made inferences about IPFs' objectives for the acquisition of voucher points from actual behavior and strategies in the bidding system using a game-theoretic analysis, in particular two models: a simultaneous bidding and sequential bidding model with Markov strategies, where behavior is characterized by the likelihood of a bidder's winning of shares. The simulations suggested that the behavior and strategies were consistent with the second model. Comparing the bidding of firms and individuals, he concluded that (i) IPFs had a lot of power in determining the results of the auction; (ii) IPFs were risk-averse (whereas individuals were more risk-takers) and (iii) IPFs wanted active involvement in management decisions. So their investments were motivated by higher ownership stakes, low share price and positive future prospects. The shortage of the model is that the investor maximizes only the number of shares won, regardless of the price. The subjective probability of oversubscription, which is a function of the misvalued price, is an unknown parameter.

Brzica (1996) and Hillion and Young (1996) expressed the view that one of the attractive features of voucher privatization was the fact that investors needed to assess only firms' relative values, instead of expressing their absolute value in monetary terms. Rational investors would bid on relatively undervalued shares and avoid relatively overvalued shares. Tř́ska (2002) did not believe that investors had a clear view of firm quality, however Hingorani et al. (1997) as well as Filer and Hanousek (2001) showed a positive relationship between the first-round demand and later stock market prices, which supports the use of share demand to measure relative share values. This led Hingorani et al. (1997) to the conclusion that investors' behavior was profit-maximizing.

Though the main aim of the government was the fast transfer of ownership, the main interest of researchers concerned the efficiency of the process. Did the bidding mechanism assign the highest stakes in the firms to the investors who valued them most? Katz and Owen (1997) combined the unique features of voucher privatization and derived its Nash solution. It implies that in equilibrium, IPFs should acquire more ownership in those firms in which their relative skills are higher under the assumption that the points are exogenously assigned to the IPFs. The main result is that the future market performance of the firm is endogenous and cannot be predicted by the investors. According to Katz and Owen (1997), efficient privatization requires the most skilled and credible IPFs to extract the most voucher points of 
individuals, which was in the Czech case hardly possible. ${ }^{7}$ This led them to the conclusion that the design of the Czech privatization was flawed. ${ }^{8}$ Similarly, Boycko et al. (1994) found out that in an environment with significant wealth constraints, assets might not end up in the hands of the highest-value users. In response to this problem Maskin (2000) constructed an auction where budget-constrained investors with private values win the shares that they value most. But, as Filer and Hanousek (2001) correctly argued, the price was set at a supposed approximation of the true equilibrium rather than a price higher than the reservation price; a bidder with the highest value was therefore not necessarily a winner. This leads to the question how efficient the Czech voucher privatization was and consequently how might its efficiency have been improved.

The next question relates to the efficiency of the bidding process as a price discovery mechanism. Filer and Hanousek (2001) undertook an empirical study where they investigated whether prices in a limited number of adjustments based on excess demand and supply are able to fully reflect all available information. Though their results are positive, the auctioneer might still inappropriately process the correct signals sent by investors. This holds mainly for small firms. Kraizberg (1999) showed inefficiency in price discovery, which might have a distortive impact on the allocation of resources in the economy. This argument is further strengthened by the primary aim of the government to sell all the shares and absorb all the available voucher points, which led to a mispricing bias (Hingorani et al., 1997). Hillion and Young (1996, p. 2-3) stressed this point stating, "in later rounds, bidding behavior can be best described as the search for mispriced securities. The prices obtained in the auction therefore, were unlikely to be reliable signals of relative value, thereby questioning the usefulness of the auction as a price-discovery mechanism". One should also keep in mind that investors might modify their information set depending on others' revealed information.

Finally, if one wants to assess efficiency, it is necessary to know the objective function of investors. As Anderson (1994) argues, the objective function varies according to the desirable functions of the fund. This has further implications for the optimal portfolio choice. Marcinčin and Shemetilo (1995) asserted that the initial structure of the investor's portfolio reflected the willingness to monitor the enterprise. In other words, portfolio investors have different motivations to invest than investors who want to be involved in management and

\footnotetext{
${ }^{7}$ The main reason is that the citizens were often attracted by the different marketing measure of the IPFs backed by a strong financial or non-financial institution. Their financial strength was however not always correlated with their skills as return-maximizing investors.

${ }^{8}$ In their next paper, Katz and Owen (2002) show that even under full information there is no guarantee that the distribution of voucher points between funds of different skills will be profit-maximizing for privatized firms.
} 
therefore their investment strategies should differ. This was however distorted by some inefficiencies, as Egerer (1996) pointed out, the initiative of IPFs to control the firms seemed to be determined by the size of the stake they managed to get. In addition, as Kraizberg (1999) argued, inefficiency was partially due to the very short investment horizon of cash-poor investors, who were maximizing the first official market value of funds to obtain a large proportional management fee.

The reviewed work helps us to clarify the basic assumptions and constraints of the model. Efficient investors with a longer-term horizon maximize the future expected value of the firms bidding for the most undervalued firms. The deviations from this strategy were caused by the asymmetric knowledge of investors, by different intended functions of the IPFs as Anderson (1994) proposed and distortions in price-setting (Kraizberg, 1999). We will include in our model all these factors. The aim is to infer the IPFs' objective for the acquisition of voucher points and the extent of learning from their behavior and strategies in the bidding process.

\section{Model}

The model draws on the current knowledge presented in the literature review. The main target of the model is to show how the heterogeneity of investors determined the variety of investment strategies. Though our aim is to model the privatization process as generally as possible, defining the bidding rules and constraints on which the model is based, we depart from the design of Czech voucher privatization. Therefore, as a first step, we proceed with a brief illustration of the bidding mechanism.

The voucher privatization was organized in two waves and each had several privatization rounds. In the first round prices were uniform, $p_{i 1}=p_{1}$ voucher points per share in the both waves. In the second and all consequent rounds, the share price of firm $i$ was adjusted according to the ratio of the aggregate demand of all investors in a given round $r$, $s d_{i r}=\sum_{j} s d_{j i r}$, and share supply $s s_{i r}$. The share demand was handled in the following manner: 
If $s d_{i r} / s s_{i r}<1$, the demand was satisfied at a price valid in a given round and the price of the unsold shares was lowered if there was a lot of shares left or increased if only few shares stood out. ${ }^{9}$

If $s d_{i r} / s s_{i r}=1$, the demand was satisfied and the firm was completely sold out.

If $s d_{i r} / s s_{i r} \in(1,1.25\rangle$, the demand of individual investors was fully satisfied at the price valid in the given round and the share demand of IPFs was proportionally rationed.

If $s d_{i r} / s s_{i r}>1.25$, the shares were not distributed but offered in the next round at a higher price, which was a function of excessive demand.

After every round the Center for Coupon Privatization (CCP) processed the bidding information for each round and published the results, but a special working group appointed by a deputy minister in the Ministry of Finance, the Price Committee, performed the repricing task according to the excess demand for shares in the previous round weighted by the last price, shares unsold and points left. This group will be referred to as the auctioneer. The number and price of shares for each firm were announced. As the points could be used only for buying shares in the voucher privatization, everybody made an effort to allocate points completely and no alternative use biased the process.

This mechanism was supposed to drive prices to their equilibrium values. However, it had some limits, in particular, the number of shares to sell and the number of voucher points left so the prices had to be adjusted in such a manner to decrease the probability of repeated overbidding and to divide the available points among the available shares.

After becoming familiar with the main features of the privatization process, we can proceed with constructing the model. We focus on big investment companies and for simplicity we refer to them below as "investors".

There are $N$ firms to be privatized, $i \in\{1, \ldots, N\}$, and $M$ investors, $j \in\{1, \ldots, M\}$. The stake which investor $j$ has in firm $i$ is denoted $q_{j i}$. The bidding process takes place during a number of privatization rounds $r \in\{1, \ldots ., R\} .{ }^{10}$ In each round $r$ each investor $j$ chooses his/her portfolio of shares. His/her decisions are based on two assumptions:

Assumption 1: All investors maximize their expected utility, using all the available private and public information and knowledge they have at their disposal subject to budget and legal constraints.

\footnotetext{
${ }^{9}$ For details on the price-setting mechanism see Tříska (2002) or Krčmář (1992).

${ }^{10}$ Investors did not know the exact number of rounds $R$ at the beginning of the bidding process. This forced them to maximize their expected return in every round and give a bigger weight to the negative impact of overbidding.
} 
Assumption 2: The portfolio choice has the character of a non-cooperative game. The investors incorporate into their decisions only the expected strategies of other investors. This gives rise to a coordination problem among investors. ${ }^{11}$

Three constraints limit investors' maximizing behavior.

The budget constraint: the amount of points allocated to firms in individual rounds $b_{j i}$ must be smaller or equal to all points the investor has at her or his disposal $B_{j}$.

The stake of investor $j$ in firm $i, q_{j i}$, must not exceed the legal limit $l$ imposed on investment companies. $^{12}$

The investors are not allowed to short-sell the shares, which implies that share demand $s d_{j i r}$ must be equal to or higher than 0.

The maximization problem of every investor $j$ can be specified as follows (since the problem is specified for one investor, we can skip the subscript $j$ ):

$$
\operatorname{Max} \sum_{r=1}^{R} \sum_{i=1}^{N} E\left(U_{i r} \mid \Omega_{i r}\right)
$$

subject to $\quad \sum_{r=1}^{R} \sum_{i=1}^{N} b_{i r} \leq B$

$$
\begin{array}{ll}
\sum_{r=1}^{R} q_{i r} \leq l \quad \text { in every } i \in\{1, \ldots, N\} \\
-s d_{i r} \leq 0 \quad \text { in every } r \in\{1, \ldots, R\} \text { and every } i \in\{1, \ldots, N\},
\end{array}
$$

where $E\left(U_{i r} \mid \Omega_{i r}\right)$ is the investor's expected utility from investing in selected firms, according to her or his private information on firms, public information and information received during the previous rounds from the behavior of other investors, which are part of the investor's information set $\Omega_{i r}$.

The first constraint specifies that the sum of all the points allocated in individual firms and rounds, $b_{i r}$, for every investor cannot exceed his/her budget consisting of $B$ points. ${ }^{13}$ The

\footnotetext{
${ }^{11}$ The first assumption is based on the general consensus reached in previous empirical studies and the second is a reasonable simplification of the problem taking into account the number of firms and investors.

12 There were more legal limits constraining investment stakes of investors in firms (see Act No. 92/1991 and No. 248/1992 Collection for detail). However, two of them are relevant for our model: first, the limit on the stake of the investment company in a firm and second, the limit on the proportion of the investor's entrusted points invested in one firm. For simplification, we consider large investors, so only the first limit is binding. This legal limit was in the first round $20 \%$ and in the second round $10 \%$.

${ }^{13}$ We should also mention the constraint that in each round $\sum_{j=1}^{M} \sum_{i=1}^{N} s s_{j i r} \cdot p_{i r} \leq \sum_{j=1}^{J} B_{j r}+I_{r}$ for $r=1, \ldots R$, where $B_{j r}$ is the number of points of a particular investor in round $r$ and $I_{r}$ is the sum of the points held by individuals.
} 
second constraint (1b) stipulates that the proportion of shares held by any investor in any firm $q_{i r}$ cannot exceed the legally allowed limit $l$. Finally, the constraint (1d) prohibits shortselling, i.e. the bids can be higher than or equal to 0 .

The question then follows what in the given circumstances determines the investor's utility function. Ma (1994) assumed in his model that investors maximized the number of shares they are able to get. However, for a rational, return-maximizing investor, not only the quantity of shares matter but also their quality, i.e. their potential to generate profit. Filer and Hanousek (2001) found that during the first round of bidding almost all professional bidders knew which shares were undervalued at given voucher prices. Denoting the stock value of firm $i$ for investor $j$ in a given round $r$ as $E_{j r}\left(V_{i}\right)$ and the voucher price of the firm's stock in a given round as $p_{i r}$, rational investors prefer firms with a higher expected gross return in a given round compared to another firm $k$ in the portfolio:

$$
\frac{E_{j r}\left(V_{i}\right)}{p_{i r}} \geq \frac{E_{j r}\left(V_{k}\right)}{p_{k r}} .
$$

As the inequality shows, the ratio can differ across investors and rounds according to their future price expectation $E_{j r}\left(V_{i}\right)$, which can be based on new information, and according to the price development. This explains the varying interest of individual investors with different information sets in particular firms.

However, investors can possess some private information, which enables them to draw private benefits. These can flow from several sources:

the investor wants to be involved in the management of the firm and its decisionmaking;

the articles of association which determine the division of power in the firm between the executive board and the supervisory board and specifies their structures, the investor can sell a block of shares of a firm with good prospects for a price that is higher than the price would be in the case when the investor has only a small stake.

Therefore his expected return exceeds the one expected by portfolio investors benefiting solely from a price increase and dividends. ${ }^{14}$

Therefore the auctioneer must take into account the number of unsold shares and the number of points left. This limits share prices being fully adjusted to the demand/supply ratio in the previous round. As this constraint is incorporated into the share prices it is exogenous for the investor.

${ }^{14}$ We have in mind mostly firms with growth potential but bad governance. This division has further impacts on the second constraint. In voucher privatization, the legal constraint was $20 \%$ in the first wave and $10 \%$ in the 
We incorporate this possibility into the model through the parameter $c_{j i r} \geq 1$ which accounts for the possible benefits from higher concentration or active participation in a particular firm. The parameter affects the expected share value $E_{j r}\left(V_{i}\right)$, which becomes $E_{j r}\left(V_{i}\right)^{c_{j i r}}$ and enables us to distinguish two types of investment interests. First, if the investor prefers solely financial portfolio management, his stakes in firms are smaller than $10 \%$ and he does not intend to intervene in firm governance; parameter $c_{j i r}=1$. We refer to these investors as portfolio investors. Second, if the investor wants to be involved in the firm management, and consequently strives for stakes equal to or bigger than $10 \%$ of the firm, the parameter $c_{j i r}>1$ increases the share value for investor $j$, and thus increases the expected return above the value for portfolio investors. We refer to the second group as strategic investors. This parameter serves as an additional factor explaining the differences in investors' interest in particular firms. ${ }^{15}$ However, given the budget constraint and risk of overbidding, one has to keep in mind that investors have mostly dual interests: strategic interests in some firms and portfolio interests in the rest of the received firms. Therefore when we speak about strategic investors, we refer to those trying to receive bigger stakes in more firms and according to their success to actively perform their ownership rights.

The expected return is expressed per share, so for every firm $i$, it has to be multiplied by the number of shares demanded $s d_{j i r}$. Given Assumption 2 that investors do not collude and the possibility that their information can be to some extent symmetric, i.e. more investors are aware of undervalued firms, a fixed limited number of shares in individual firms might lead to a situation where share demand considerably exceeds share supply. Based on the description of the privatization process, these shares are not allocated but offered in the next round at a higher price. This situation is called in the literature overbidding or oversubscription and its extent determines the price for the next round. ${ }^{16}$ Rational investors are responsive to the described lost opportunity costs: going for the most lucrative- " the first best “-investment opportunity, they can face overbidding, the points are not allocated and

second wave. Given that strategic investors need higher stakes for effective control, the legal limits amounting to $10 \%$ and $20 \%$ were binding in both waves, mainly in the second one.

${ }^{15}$ In addition, showing an interest in a bigger share in the firm can signal to the market active monitoring, which might further increase its market value. Though Katz and Owen (1997) argued that the value of the firm is endogenous, determined by the investors and volume of their stakes, we assume here that the firm value is based on the beliefs of the relevant investors concerning its future value.

${ }^{16}$ If the extent of overbidding is smaller than $25 \%$, the bids of investment companies are proportionately cut and the shares are distributed. Therefore when we speak about the probability of overbidding, we refer to overbidding exceeding $125 \%$ of supplied shares when the shares are offered again in the next round. For details on the rules of bidding see the literature review and cited references. 
"the second best" firms might have been sold out in the same round. Therefore, investors diversify their bidding and choose a number of shares in a particular firm in each round $s d_{j i r}$ to balance the maximizing of the expected return and the minimizing of the risk of overbidding. This behavioral feature is captured by the parameter $\mu_{j i r}$, which approximates the probability, given by the subjective beliefs of investor $j$, that overbidding will not take place and shares will be distributed. So the number of demanded shares is adjusted by the probability that the shares will be won.

Additionally, we assume (consistent with the rules of the bidding process) that the investors did not know at the beginning how many rounds the bidding process will consist of. This rule should prevent the strategic behavior of big investors and protect small investors. As a result, in every round investors make a simultaneous decision which firms to invest in and how many shares to bid on to maximize their expected utility subject to their constraints based on the publicly available information, private knowledge and personal beliefs and expectations. Consequently, investor $j$ solves in every round $r$ the same maximization problem. $^{17}$

$$
\sum_{i=1}^{N} E\left(U_{i r} \mid \Omega_{i r}\right)=\sum_{i=1}^{N} s d_{i r}^{\mu_{i r}} \frac{E_{r}\left(V_{i}\right)^{c_{i r}}}{p_{i r}} \text { in every } r \in\{1, \ldots, R\}
$$

subject to $\quad \sum_{i=1}^{r} \sum_{i=1}^{N} b_{i t} \leq B$

$$
\begin{aligned}
& \sum_{t=1}^{r} q_{i t} \leq l \quad \text { in every } i \in\{1, \ldots, N\} \\
& -s d_{i r} \leq 0 \quad \text { in every } r \in\{1, \ldots, R\} \text { and every } i \in\{1, \ldots, N\} .
\end{aligned}
$$

The main disadvantage of this specification is the presence of unobserved factors. Expected market value and the subjective probability of overbidding threaten the feasibility of empirical verification and further analysis of the model. Therefore we replace them with the parameters.

First, the expected market value of the firm shares is not observed. However, investors mostly had expectations on which they based their investment decisions (see inequality (2)). We can distinguish three possible cases: the shares are perceived by investor $j$ as undervalued

\footnotetext{
${ }^{17}$ In terms of constraints we still need to take into account the previous rounds. The bidding mechanism had an intermediate allocation of shares after every round, which means that the budget and legal constraints were influenced by the performance in previous rounds.
} 
$E_{j r}\left(V_{i}\right)^{c_{j i r}}>p_{i r}$, overvalued $E_{j r}\left(V_{i}\right)^{c_{j i r}}<p_{i r}$, or accurately valued $E_{j r}\left(V_{i}\right)=p_{i r}$. We can drop the unobserved variable - the expected value of the firm - and at the same time account for the mispricing of the firm's shares through the parameter $v_{j i r}$ replacing $E_{j r}\left(V_{i}\right) / p_{i r}$ by $p_{i r}^{c_{j i r} / v_{j i r}} / p_{i r}=p_{i r}^{c_{j i r} / v_{j i r}-1}$. The extent of overvaluation (undervaluation) is reflected in $v_{j i r}>1\left(0<v_{j i r}<1\right)$ which decreases (increases) the expected return from the share of the firm $i{ }^{18}$ For a correctly priced firm, $v_{j i r}=1$, assuming that $c_{j i r}=1$, the expected gross return would be equal to 1 . In addition, when the share is overvalued or undervalued, $p_{i r}^{c_{j i r}} v_{j i r}-1$ will be, in the case of share overvaluation, reduced to a larger extent for more expensive shares than for cheaper shares and, in the case of undervaluation, on the contrary, the term will grow faster for more expensive shares than for cheaper shares at the same level of undervaluation.

Second, the probability that shares might be oversubscribed and transferred to the next round as a consequence of the coordination problem mattered for investment decisions. Ma (1994) argued that IPFs were risk-averse in their bidding behavior, which contributed to the stability of the system. Generally, the more substantial the undervaluation of firm $i$, the higher the probability that the shares will be oversubscribed and the smaller the chance of getting them at a given price. This implies a decrease in $\mu_{j i r}$.

In addition, as Hillion and Young (1996) argue, the valuation of the firm relative to other firms mattered in the voucher privatization more than its absolute value. We can apply their argument to our problem. Undervaluation does not automatically mean a higher risk of overbidding. One would instead expect that investors are comparing a misvaluation of a particular firm $i$ with a misvaluation of the residual shares in the portfolio and based on this they assess the relative risk of overbidding. Denote the misvaluation parameter of other shares in the portfolio $\bar{v}_{j p r}=\sum_{p=1, p \neq i}^{N} s s_{p r} v_{j p r} / \sum_{p=1, p \neq i}^{N} s s_{p r}$, where $s s_{p r}$ denotes the amount of supplied shares in the firms $p \in\{1, \ldots, i-1\} \cup\{i+1, \ldots, N\}$. The probability that investor $j$ wins the shares, $\mu_{j i r}$, is expressed as a function of the ratio of the relative misvaluation of the shares the investor is considering buying, $i$, to the average misvaluation of residual shares in the portfolio $\mu_{j i r}=f\left(v_{j i r} / \bar{v}_{j p r}\right)$, such that the probability of receiving the shares declines as

\footnotetext{
${ }^{18} \mathrm{We}$ assume, in line with the real development, that the share price of each firm in every round is equal to or bigger than 1 .
} 
the relative undervaluation of firm $i$ deepens, i.e. $\partial \mu_{j i r} / \partial\left(v_{j i r} / v_{j p r}\right)>0$. Therefore we express the probability that the shares will be distributed using a logistic function as

$$
\mu_{j i r}=1-2 /\left(1+\exp \left(v_{j i r} / \bar{v}_{j p r}\right)\right) .
$$

We can see that in extreme cases, when $v_{j i r} / \bar{v}_{j p r}$ converges to $0, \mu_{j i r} \rightarrow 0$, which implies a close to null probability of receiving very strongly relatively undervalued shares. When the value of $v_{j i r} / \bar{v}_{j p r}$ tends to plus infinity, i.e. the shares of firm $i$ are relatively overvalued, $\mu_{j i r} \rightarrow 1$. It can also be observed that a decrease in utility resulting from a high probability of overbidding relatively increases with the size of the bid $s d_{j i r}{ }^{19}$

This leads us to a more precise specification of the maximization problem of every investor $j$ which he or she solves in every round $r$ :

$$
\max _{\left\{s d_{i r}\right\}} \sum_{i=1}^{N} s d_{i r}{ }^{1-2 /\left[1+\exp \left(v_{i r} / \bar{v}_{p r}\right)\right]} p_{i r}^{\left(c_{i r} / v_{i r}\right)-1}
$$

subject to $\quad I(r) \sum_{i=1}^{N} \sum_{t=1}^{r-1} s a_{i t} \cdot p_{i t}+\sum_{i=1}^{N} s d_{i r} \cdot p_{i r} \leq B_{j}$

$$
\begin{aligned}
& \frac{I(r) \sum_{t=1}^{r-1} s a_{i t}+s d_{i r}}{S_{i}} \leq l, \text { for all } i \in\{1, \ldots, N\}, \text { where } I(r) \sum_{t=1}^{r-1} s a_{i t}<l S_{i} \\
& -s d_{i r} \leq 0 \quad \text { for all } i \in\{1, \ldots, N\},
\end{aligned}
$$

where

$S_{i}$ denotes the number of shares of firm $i$ and $s a_{i r}$ denotes the shares of firm $i$ received by investor $j$ in the round.

$I(r)$ is the index function such that $I(r)=\left\{\begin{array}{l}0 \text { if } r=1 \\ 1 \text { if } r>1\end{array}\right.$.

As one cannot ex ante identify which constraints (5b)-(5d) will be binding for which investors, our problem contains inequality constraints. For the purpose of correctly solving the maximization problem containing inequality constraints and identifying possible irregularities on the boundaries of the feasible set we use Kuhn-Tucker conditions (KT conditions). The

\footnotetext{
${ }^{19}$ For modifying the price and the number of shares to account for the expected utility and the probability that the shares will be received, we choose the exponential form, as we assume that the investors are more sensitive to more extreme values of misvaluation. For example the relationship between the extent of misvaluation and the expected probability of overbidding is not linear, instead the expectation that overbidding occurs becomes stronger as relative misvaluation increases. A similar argument holds for expressing the unobserved expected share value to account for the expected gross returns. The determination with which informed investors make efforts to avoid overvalued shares is much stronger than the determination to buy undervalued shares.
} 
Necessity Theorem stipulates that the KT conditions are necessary conditions for a local optimum if the constraint qualification is satisfied. This is always the case if all constraints are linear (Vinogradov, 1999, p. 50).

Denoting the objective function of investor $j$ in round $r$ as $f_{j r}\left(s d_{1}, s d_{2}, \ldots, s d_{N}\right)$, the partial derivative $\partial f_{j r}\left(s d_{i}\right) / \partial s d_{i}$ for $i \in\{1, \ldots, N\}$ evaluated at $s d_{i}=0$ is not defined, therefore KT conditions do not apply in this case and we specify them only for $s d_{i}>0$, i.e. when the third constraint is not binding. ${ }^{20}$ Coming back to our problem (5a)-(5d), we write the Lagrangian for investor $j$ in round $r$ as follows:

$$
\begin{aligned}
& L_{j r}=\sum_{i=1}^{N} s d_{i r}^{1-2 /\left(1+\exp \left(v_{i r} / \bar{v}_{p r}\right)\right)} p_{i r}^{c_{i r} / v_{i r}-1}-\lambda_{1 r}\left(I(r) \sum_{i=1}^{N} \sum_{t=1}^{r-1} s a_{i t} \cdot p_{i t}+\sum_{i=1}^{N} s d_{i r} \cdot p_{i r}-B\right)- \\
& \left.-\sum_{i=1}^{N} \lambda_{2, i r}\left(I(r) \sum_{t=1}^{r-1} s a_{i t}+s d_{i r}\right) / S_{i}-l\right) \quad \text { in every } r \in\{1, \ldots, R\},
\end{aligned}
$$

and derive FOC and complementary slackness conditions

$$
\begin{aligned}
& \frac{\partial L_{j r}}{\partial s d_{i r}}=\mu_{i r} s d_{i r}^{\mu_{i r}-1} p_{i r}^{c_{i r} / v_{i r}-1}-\lambda_{1 r} p_{i r}-\lambda_{2 i r} / S_{i} \leq 0, \\
& s d_{i r} \geq 0 \text { and } s d_{i r} \frac{\partial L_{j r}}{\partial s d_{i r}}=s d_{j i r}\left(\mu_{i r} s d_{i r}^{\mu_{i r}-1} p_{i r}^{c_{i r} / v_{i r}-1}-\lambda_{1 r} p_{i r}-\lambda_{2 i r} / S_{i}\right)=0
\end{aligned}
$$

for all $i \in\{1, \ldots, N\}$.

$$
\begin{aligned}
& \frac{\partial L_{j r}}{\partial \lambda_{1 r}}=\left(I(r) \sum_{i=1}^{N} \sum_{t=1}^{r-1} s a_{i t} \cdot p_{i t}+\sum_{i=1}^{N} s d_{i r} \cdot p_{i r}-B\right) \leq 0, \\
& \lambda_{1 r} \geq 0 \text { and } \quad \lambda_{1 r}\left(I(r) \sum_{i=1}^{N} \sum_{t=1}^{r-1} s a_{i t} \cdot p_{i t}+\sum_{i=1}^{N} s d_{i r} \cdot p_{i r}-B\right)=0 \\
& \frac{\partial L_{j r}}{\partial \lambda_{2 i r}}=\left(\frac{I(r) \sum_{t=1}^{r-1} s a_{i t}+s d_{i r}}{S_{i}}-l\right) \leq 0 \\
& \lambda_{2 i r} \geq 0 \text { and } \lambda_{2 i r}\left(\frac{I(r) \sum_{t=1}^{r-1} s a_{i t}+s d_{i r}}{S_{i}}-l\right)=0 \text { for all } i \in\{1, \ldots, N\} .
\end{aligned}
$$

\footnotetext{
${ }^{20}$ We have to keep in mind that there are two possible reasons why the share demand falls to 0. First, the shares are largely overvalued and the investors expect a price decline, however, as the non-negativity constraint applies, short positions cannot be taken and the share demand is simply 0. Second, the investors' possibilities are limited by wealth and the legal constraint, and there is no space for further investment in firm $i$, and $s d_{i}=0$ even though the non-negativity constraint is not binding.
} 
If $\lambda_{1 r} \neq 0$ and $\lambda_{2 i r} \neq 0$ for any $i \in\{1, \ldots, N\}$ and $r \in\{1, \ldots, R\}$, we get binding constraint conditions. In the opposite cases when $\lambda_{1 r}=0$ and/or $\lambda_{2 i r}=0$, the constraint does not have to hold. The specification (7a)-(7c) takes care of all cases.

In every single round $r$, we solve for the vector $\left\{s d_{1}, \ldots, s d_{N}, \lambda_{1}, \lambda_{21}, \ldots, \lambda_{2 N}\right\}$, however as the derivations are analogous, we present the possible solutions for a representative share demand $s d_{j i r}$ of investor $j$, firm $i$ and round $r$.

For every combination $\{i, r\}$ we derived four possible solutions. The results are presented in the Appendix. However, before deriving the optimal demand functions when individual constraints are or are not binding, we first have to make sure that KT conditions are sufficient conditions for $f_{s d_{i r}}^{\prime}\left(s d_{1 r}^{*}, \ldots, s d_{N r}^{*}\right)=0$ to be a local maximum at $s d_{i r}^{*}$ for all $i \in\{1, \ldots, N\}$.

The Sufficiency Theorem stipulates that KT conditions are sufficient conditions for $x^{*}$ to be a local optimum of a maximization program if the following assumptions are satisfied:

the objective function is differentiable and quasi-concave, each constraint is differentiable and quasi-convex (Vinogradov, 1999, p. 51).

The twice-differentiable function is concave if and only if its second derivative is everywhere negative semidefinite (Vinogradov, 1999, p.39). Our function fulfils this condition (this statement is proven in the Appendix).

As all our constraints are linear functions, they automatically fulfill the second condition. We can conclude that $s d_{i r}^{*}$, for which $f_{s d_{i r}}^{\prime}\left(s d_{i r}^{*}\right)=0$ holds, is a local maximum of our maximization problem.

Now we can proceed with deriving the optimal share demand equations for consequent theoretical analyses and empirical testing. Keeping in mind that the result of every round for every investor is a vector of shared demand in all firms $i \in\{1, \ldots, N\},\left\{s d_{1}, \ldots, s d_{N}\right\}$, we point out and analyze four possible situations with different combinations of binding constraints. $^{21}$ This is relevant for further theoretical analysis, where we discuss how the constraints affected share demand factors and for the empirical testing that helps us to identify the prevailing investor type and the heterogeneity of investor strategies.

\footnotetext{
${ }^{21}$ For details on derivations see the Appendix.
} 
First, since the objective function is strictly increasing in each argument, when neither the budget constraint nor the legal constraint for the share demand of firm $i$ in round $r$ needs to be binding, the only solution consistent with the equations in (7a) is $s d_{i r}=0$. As a zero vector cannot be a solution, at least one constraint other than the non-negativity one must be binding. Therefore the situation $\lambda_{1 r}=0$ and $\lambda_{2 i r}=0$ is not possible.

Second, only the legal constraint is binding $\left(\lambda_{2 i r} \neq 0\right)$; in the case of the budget constraint $\left(\lambda_{1 r}=0\right)$, this does not need to hold. This situation is characteristic for investors who are in possession of a large amount of points and make efforts to allocate them to the greatest extent possible. The share demand can be specified as $s d_{i r}=l S_{i}-I(r) \sum_{t=1}^{r-1} s a_{j i t}$.

However, for the purpose of empirical testing, we do not derive $\lambda_{2 i r}$. Instead, we maximize (6) with respect to $s d_{i r}$ and make its logarithmic transformation. The optimal share demand equation of investor $j$ is the following:

$$
\ln s d_{i r}^{*}=-\frac{1}{\mu_{i r}-1} \ln \left(\frac{\mu_{i r}}{\lambda_{2 i r}}\right)-\frac{c_{i r} / v_{i r}-1}{\left(\mu_{i r}-1\right)} \ln p_{i r}-\frac{1}{\mu_{i r}-1} \ln S_{i} .
$$

As $\mu_{i r}-1=-2 /\left(1+\exp \left(v_{j i r} / \bar{v}_{j p r}\right)<0\right.$, the size of the firm has a positive impact on the share demand and at the same time the price elasticity is moderate (positive if $c_{i r} / v_{i r}>1$ ); it is difficult to assess if the legal constraint is binding due to voucher point abundance or the control interests of the investor.

Third, only the budget constraint is binding, $\left(\lambda_{1 r} \neq 0\right)$; for the legal constraint this is not necessarily the case $\left(\lambda_{2 i r}=0\right)$. This situation is characteristic for investors focused on a diversified allocation of all their points, but since the legal constraint is not binding, they are also without obvious control interests. The share demand can be expressed, using the budget constraint, as $s d_{j i r}=\left(B_{j}-I(r) \sum_{i=1}^{N} \sum_{t=1}^{r-1} s a_{i t} \cdot p_{i t}-\sum_{k=1, k \neq i}^{N} s d_{k r} \cdot p_{k r}\right) / p_{i r}$, i.e. only the budget constraint is binding.

We derive the optimal share demand in this situation as a function of price

$$
\ln s d_{i r}^{*}=-\frac{1}{\mu_{i r}-1} \ln \left(\frac{\mu_{i r}}{\lambda_{1 r}}\right)-\frac{c_{i r} / v_{i r}-2}{\left(\mu_{i r}-1\right)} \ln p_{i r} .
$$

Compared with (8a), the size of the firm is not important any more for portfolio investors, who are on the other hand more sensitive to prices. 
Fourth, both constraints are binding $\left(\lambda_{1 r} \neq 0, \lambda_{2 i r} \neq 0\right)$, which might indicate investors in firms where they have strategic interests and at the same time, efficiency in point allocation matters for them. ${ }^{22}$ The share demand can be computed using constraints. The optimal share demand can be expressed as

$$
\ln s d_{i r}^{*}=\frac{1}{\mu_{i r}-1}\left[\frac{\lambda_{2 i r}}{\lambda_{1 r} S_{i} p_{i r}}-\ln \left(\frac{\mu_{i r}}{\lambda_{1 r}}\right)\right]-\frac{c_{i r} / v_{i r}-2}{\left(\mu_{i r}-1\right)} \ln p_{i r} .
$$

Plugging in $\mu_{i r}=1-2 /\left(1+\exp \left(v_{i r} / \bar{v}_{p r}\right)\right)$, we get

$$
\ln s d_{i r}^{*}=\frac{1+\exp \left(v_{i r} / \bar{v}_{p r}\right)}{2}\left[\ln \left(\frac{\mu_{i r}}{\lambda_{1 r}}\right)-\frac{\lambda_{2 i r}}{\lambda_{1 r} S_{i} p_{i r}}\right]+\frac{1+\exp \left(v_{i r} / \bar{v}_{p r}\right)}{2}\left(\frac{c_{i r}}{v_{i r}}-2\right) \ln p_{i r} .
$$

For details on the derivation of (8c) see the Appendix.

Compared to the previous situation, the negative impact of prices is even stronger, since there is a negative additional term which declines when the relative overvaluation declines. On the other hand the negative impact of the last factor in absolute value declines with growing prices and the size of the firms and grows in the case of small firms with cheap shares. This term might account for the effect of liquidity on share demand.

This result determines the optimal amount of share demand as a function of share prices, the size of firms and the combination of firm and investor characteristics weighted by the share demand elasticity to given variables. Elasticities are given by the subjective probability of overbidding, which is a function of the perceived relative misvaluation of the shares and by the control interests of investors. In this respect the model provides more information compared to the model of Ma (1994) who derived the optimal share demand as a function of subjective probability that shares will be won, regardless of their quality.

The model has the following advantages, which distinguish it from previous attempts at formalizing bidding behavior. First, we do not make any strong assumptions about the asymmetry of parameters $c_{j i r}, v_{j i r}$ and $\bar{v}_{j p r}$. They can differ not only among investors and firms but also can evolve and change during individual rounds. Endogenizing heterogeneous beliefs of investors, their learning and updating available knowledge after each round enables good insight into the investor's bidding behavior.

Second, characteristics of firms, such as their profitability, liquidity and indebtness, are incorporated into the expected share value $E_{j r}\left(V_{i}\right)$, and consequently in parameter $v_{j i r}$,

\footnotetext{
${ }^{22}$ Of course we can express conclusions about the strategic interests of investors with binding legal constraints only after having information about the value of the legal constraint stipulated as a proportion of all shares in the firm.
} 
and need not be included separately. Besides, the empirical studies of Švejnar and Singer (1994) and Aggarwal and Harper (2000) confirmed that after the first rounds the firm characteristics became incorporated into voucher prices and their significance as share demand factors disappeared. Third, the model allows direct empirical verification and reveals differences between individual types of investors and development across rounds.

As the main share demand factors are independent of investor characteristics, if investors had identical information sets, each one should have bid for the same portfolio with respect to his/her budget constraint. However, it is an empirical fact that the bidding of investment companies significantly differed. The different private knowledge of investors, their subjective perception of firm mispricing, the different sizes of wealth (points entrusted), various preferences (including the strategic intentions) and the level of overbidding fear most probably are the most relevant factors that affected the sensitivity of share demand to exogenous variables and caused differed demand patterns.

The impact of the relevant variables has the expected sign in all cases. However, the effects differ across investor types. In the case of investors and firms where the budget constraint is binding, the share price elasticity is negative even for undervalued shares, whereas for investors where the budget constraint does not need to be binding, the impact of prices is positive in the case of relatively undervalued shares. Similarly, the impact of firm size can be also positive when the budget constraint is not binding, or growing firm size can moderate the negative effect of other variables when the budget constraint is binding.

Equations (8a)-(8c) indicate that the size and significance of the coefficients matter for portfolio construction. The impact of firm $i$ 's relative undervaluation $v_{j i r} / \bar{v}_{j p r}$ on the share demand of a utility-maximizing investor is ambiguous. On the one hand, the extent of undervaluation increases the probability of overbidding if other investors are well informed. ${ }^{23}$ This leads to a decrease in share demand. On the other hand, it enables getting shares at prices below their fundamental values, which is reflected in a lower sensitivity of share demand to the price. A positive price elasticity of share demand in the case of the undervaluation of firm $i$ 's shares is an example. ${ }^{24}$ The impact of the average misvaluation of shares $\bar{v}_{j p r}$ co-

\footnotetext{
${ }^{23}$ The awareness of investor $j$ of the knowledge of other investors is also unobserved, and instead of bringing it explicitly to the model we assume that it will be absorbed by the more extreme value of parameter $v_{j i r}$. Though there is no explicit empirical proof that investors were considering the expected reactions of their rivals into their decisions, there are case studies that support this possibility (Otradovec, 1995a and 1995b).

${ }^{24}$ What extent of firm $i$ 's undervaluation is necessary for a positive impact of its price on share demand depends also on the type of investor, namely if the budget constraint is binding or not.
} 
determines the perceived probability of overbidding and consequently affects the strength of the impact of relevant variables.

In addition, whereas the strength of the price impact is determined by the relative undervaluation of firm $i$ to the other shares, the sign of the impact is given purely by the ratio $c_{j i r} / v_{j i r}$.

The parameter $c_{j i r}$ mitigates the impact of price $p_{i r}$ on share demand. As we can see in Figure 11, growing $c_{j i r}$ increases the negative price coefficient, which can reach positive values for investors with stronger control interests resulting in a positive impact of prices on share demand. The intuition is straightforward; investors with an ambition to be involved in the firm management are not that sensitive to small price changes. According to our model, information revealed through excessive or little demand enters prices through their adjustment. If learning in the privatization process takes place, the convergence of $v_{j i r}$ and $\bar{v}_{j p r}$ to 1 should bring a convergence in the sensitivity of individual types of investor to price changes and variations in the coefficients of equations (8a)-(8c) across individual investors should become smaller.

The main consequence is that the bidding mechanism leads to a wide price differential caused primarily by initially undervalued shares (whose prices go up) and overvalued shares (whose prices go down) and Ma's (1994) conclusion, that the main reason for price differential is a higher demand of IPFs in the former group of shares, is only the consequence of their undervaluation.

Tř́ska (2002) stated that elasticity was important information for the auctioneer, because it indicated the expected reaction of investors to price changes. Lower elasticity makes the price-setting problem easier whereas high elasticity causes switching from one firm to another when the price adjusts. Švejnar and Singer (1994) also argued that an important assumption underlying the thinking of the authorities about the optimal price adjustment between rounds was that the overall demand for the shares of a given firm has unit elasticity. ${ }^{25}$ This means a stable amount of points were invested, which was, however, mostly not the case. The model also illustrates that the price elasticity can be largely variable among investors, reflecting their perception of share misvaluation and the extent of control interests.

\footnotetext{
${ }^{25}$ They concluded that this underlying assumption was insufficient and besides, officials relied heavily on their own intuition.
} 
In the following parts we are interested in how the size and mutual interactions between the parameters affect the optimal share demand of different groups of investors and how much learning took place between rounds.

\section{Analysis of the share demand factors}

In this section, we proceed with the analysis of what determines the size and the sign of the variable impact and how this can help us in clarifying the motivations of different investment strategies.

We start with Assumption 1 which says that investors maximize their utility and bid to the greatest possible extent for firms which are less overvalued (more undervalued) compared to the residual shares in a portfolio, i.e.

$v_{j i r} / c_{j i r}<\bar{v}_{j p r} / \bar{c}_{j p r}$.

The misvaluation parameters absorb the extent of overvaluation and undervaluation. As we argued in Section 3, investors could choose the firms for two reasons:

The firm is substantially undervalued relative to its expected market value or, according to the investor's knowledge, it has substantial growth potential; the investor sees the firm as a profitable opportunity. The investor thus makes a portfolio investment without any intentions to be involved in the firm governance, $c_{j i r}=1$.

The investor's interest goes beyond benefiting from the underpricing of the firm. This investor is attracted mainly by the intention to benefit from firm control or from a later sale of a block of shares to an outside investor. Of course, a combination of these two reasons is possible.

The difference between these two types of incentives is reflected in the value of parameter $c_{j i r}$, which has in (i) a value of 1 and in (ii) a value bigger than 1 . However, as parameter $c_{j i}$ is not observed, we need an additional factor that distinguishes the two groups of investors. If the legal constraint (LC) limiting the stake of an investor in the firm is specified around the threshold value which creates a border between the portfolio and strategic investments (when the investors intend to participate in firm governance), the two groups can be distinguished by a binding LC.

In Section 3, we specified three specifications (8a)-(8c) for the three following situations of share demand: 
(i) (8a) when only the legal constraint is binding;

(ii) (8b) when only the budget constraint is binding;

(iii) (8c) when both legal and budget constraints are binding.

As the LC in the Czech voucher privatization was $20 \%$ and $10 \%$ in the first and second waves, respectively, we can base our analysis on the general assumption that if the legal constraint is binding, we assume that $c_{j i r}>1$ and call this group strategic investors, otherwise $c_{j i r}=1$ and we refer to this group as portfolio investors.

Following this argument, further analyses will be performed for two types of investors separately and it will be shown that the same misvaluation of firms leads to a different impact for portfolio investors and strategic investors.

\subsection{Bidding behavior of portfolio investors}

Portfolio investors are characterized by a lower level of ownership concentration and no involvement in firm management. Out of the three specifications, (8b) captures the bidding of investors for whom the legal constraint, in contrast to the budget constraint (BC), is not binding, which allows us to assume that $c_{j i r}=1$ and consider their bids as portfolio investments. In addition, we also analyze the situation specified in (8a). Although it does not follow our argument presented above because the LC is binding, this can be the result not only of control interests in firm, but also the result of an abundant wealth of entrusted voucher points. The non-binding BC justifies this argument. Therefore, we are not able to say if their parameter $c_{j i r}=1$ or $c_{j i r}>1$ and therefore include this group also in analyzing portfolio investors.

\section{The impact of firm i's share price}

Let us firstly have a look at the effect of the price of firm $i$ determined by the coefficient

$$
\frac{\partial \ln s d_{j i r}}{\partial \ln p_{i r}}=\frac{\partial s d_{j i r}}{\partial p_{i r}} \frac{p_{i r}}{s d_{j i r}}=\left(1 / v_{j i r}-1\right)\left(\frac{1+\exp \left(v_{j i r} / \bar{v}_{j p r}\right)}{2}\right)
$$

for investors with a non-binding budget constraint and

$$
\frac{\partial \ln s d_{j i r}}{\partial \ln p_{i r}}=\frac{\partial s d_{j i r}}{\partial p_{i r}} \frac{p_{i r}}{s d_{j i r}}=\left(1 / v_{j i r}-2\right)\left(\frac{1+\exp \left(v_{j i r} / \bar{v}_{j p r}\right)}{2}\right)
$$

for investors with a binding budget constraint. 
The coefficient determining the size of the price impact on share demand consists of two terms:

$\left(1 / v_{j i r}-1\right)$ for investors with a non-binding legal constraint and $\left(1 / v_{j i r}-2\right)$ for investors with a binding legal constraint. This term captures the price sensitivity of the share demand for investors given by share mispricing, and it is lower for investors with binding legal constraints.

$1+\exp \left(v_{j i r} / \bar{v}_{j p r}\right) / 2$ is always positive and affects only the significance of the former term, without an impact on the coefficient sign.

Distinguishing the two types of investors described above, we come to the conclusions summarized in the following proposition.

Proposition 1: The price elasticity of the share demand of the expected-utilitymaximizing portfolio investor $j$ becomes positive when $v_{j i r}<1$ in the case of a non-binding budget constraint and when $v_{j i r}<0.5$ in the case of a binding budget constraint. Its absolute value grows with the ratio of relative misevaluation $v_{j i r} / \bar{v}_{j p r}$.

The value of the price elasticity decreases with the misvaluation parameter $v_{j i r}$ and decreases with the coefficient $\bar{v}_{j p r}$ when the price impact of share demand is positive and increases when the price impact is negative. An increase in the relative undervaluation of firm $i, v_{j i r} / \bar{v}_{j p r}$, has a negative impact on the absolute value of the coefficient.

(The proof of Proposition 1 can be found in the Appendix.)

The important result of this part is that, first, the price impact on the share demand can be positive when the shares are sufficiently undervalued. While for investors with a nonbinding $\mathrm{BC}$, it is enough when $v_{j i r}<1$, investors with a binding $\mathrm{BC}$, who are naturally more sensitive to prices, require a higher extent of undervaluation $v_{j i r}<0.5$ to react to prices positively.

The next statement in the proposition stipulates what determines the price elasticity. As the Proof of Proposition 1 shows, investors with a binding BC are more price-elastic in the case of overvalued shares and less price-elastic in the case of strongly undervalued shares compared to their counterparts with a non-binding BC. The stronger impact is given by the double impact of growing $v_{j i r}$, which decreases the negative value of $\left(1 / v_{j i r}-2\right)$ (due to the 
low attractiveness of overvalued shares) and at the same time increases the positive value of $1+\exp \left(v_{j i r} / \bar{v}_{j p r}\right) / 2$ (due to the lower probability of overbidding). As a result, the price elasticity becomes stronger. However, in the case of low $v_{j i r},\left(1 / v_{j i r}-1\right)$ and $\left(1 / v_{j i r}-2\right)$ increase and after achieving some threshold $v_{j i r}$, they become positive; at the same time $1+\exp \left(v_{j i r} / \bar{v}_{j p r}\right) / 2$ declines. We can say that whereas low $v_{j i r}$ encourages share demand due to the profitable opportunity, it also increases the probability of overbidding and therefore mitigates the overall positive impact. This holds especially for investors with a binding $\mathrm{BC}$, who consequently tend to diversify to a larger extent.

This result contrasts with the hypothesis of Ma (1994) that IPFs have an inelastic demand for higher-priced firms because of their predatory strategy and intense bidding. We are saying that not the price itself but its distance from the expected future market value (or even higher private value) matters. So, higher prices were the result of intense bidding by investors who perceived the firms as undervalued. In Figure 1, we plot the relationship between the values of $v_{j i r}$ and the corresponding price elasticity of share demand at different values of $\bar{v}_{j p r}$ for portfolio investors.

Generally we can conclude that the size of price elasticity is determined by:

(i) The extent of mispricing: the stronger the overvaluation or undervaluation of the shares, the larger the sensitivity of investors to prices.

(ii) The extent of relative mispricing: the more undervalued the shares of firm $i$ are perceived relative to the other supplied shares, the less sensitive to prices investors are. $^{26}$

Plotting the value of the coefficient as a function of $v_{j i r}$, we can see that the coefficient declines with $v_{j i r}$ (Figures 1 and 2), i.e. the more overvalued the shares are, the lower the coefficient is. This is an interesting finding showing that when the shares are undervalued, the effect of a good investment opportunity is stronger than the effect of the overbidding risk. ${ }^{27}$

Regarding the impact of the misvaluation of residual shares, the price coefficient grows with $\bar{v}_{j p r}$ when the price impact is negative, meaning that when the shares are

\footnotetext{
${ }^{26}$ This is caused primarily by a higher probability of overbidding.

${ }^{27}$ Though looking closer at the Proof, one can see that the relationship might have the opposite direction if the shares of the firm $i$ are strongly undervalued and at the same time they are to a bigger extent relatively overvalued, which is a rather improbable scenario.
} 
overvalued (or weakly undervalued) and decline with $\bar{v}_{j p r}$, the price impact is positive. In both cases it mitigates the absolute value of the price elasticity. In the case of share overvaluation, growing $\bar{v}_{j p r}$ drops the absolute value of the price elasticity due to the lack of other investment opportunities, while in the case of a stronger share undervaluation, a smaller amount of other investment opportunities increases the risk of overbidding and the positive price impact is therefore diminished (Figure 3).

In the specified model, only the misvaluation of the firm itself determines the sign of the price coefficient, the misvaluation of the other firms relative to the misvaluation of the specific firm $i$ affects only the magnitude of the impact. 
Figure 1 Price elasticity of portfolio investors with non-binding budget constraint, as a function of $v_{j i r}$

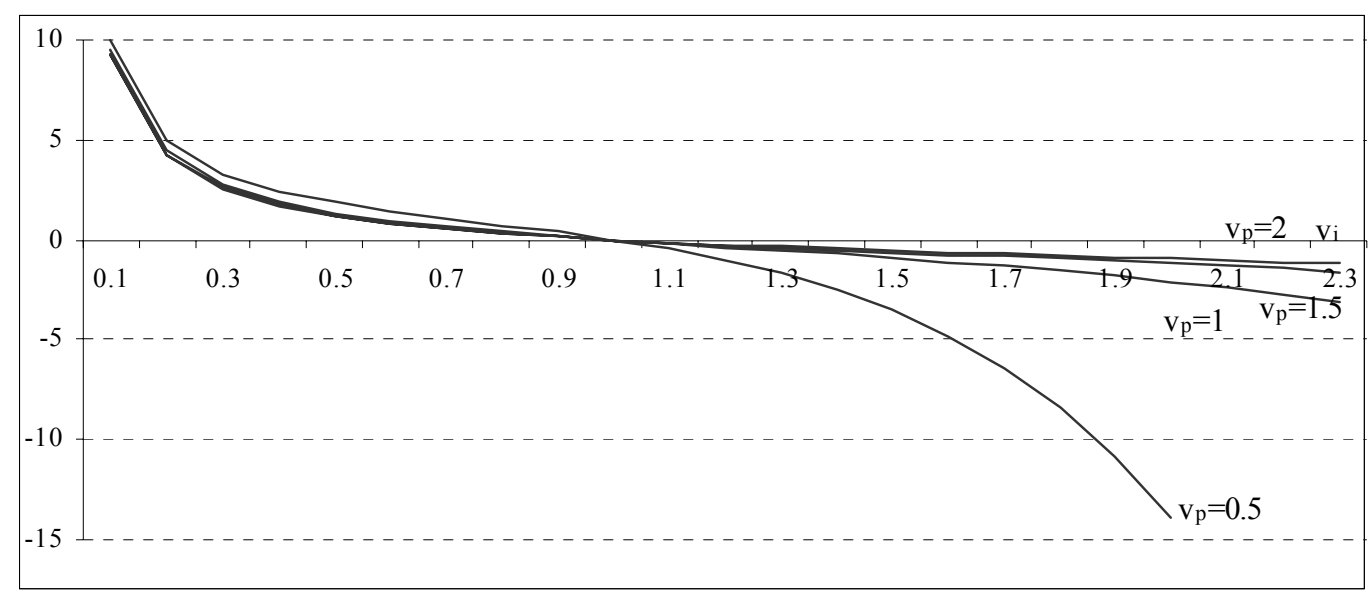

Figure 2 Price elasticity of portfolio investors with binding budget constraint, as a function of $v_{\text {jir }}$

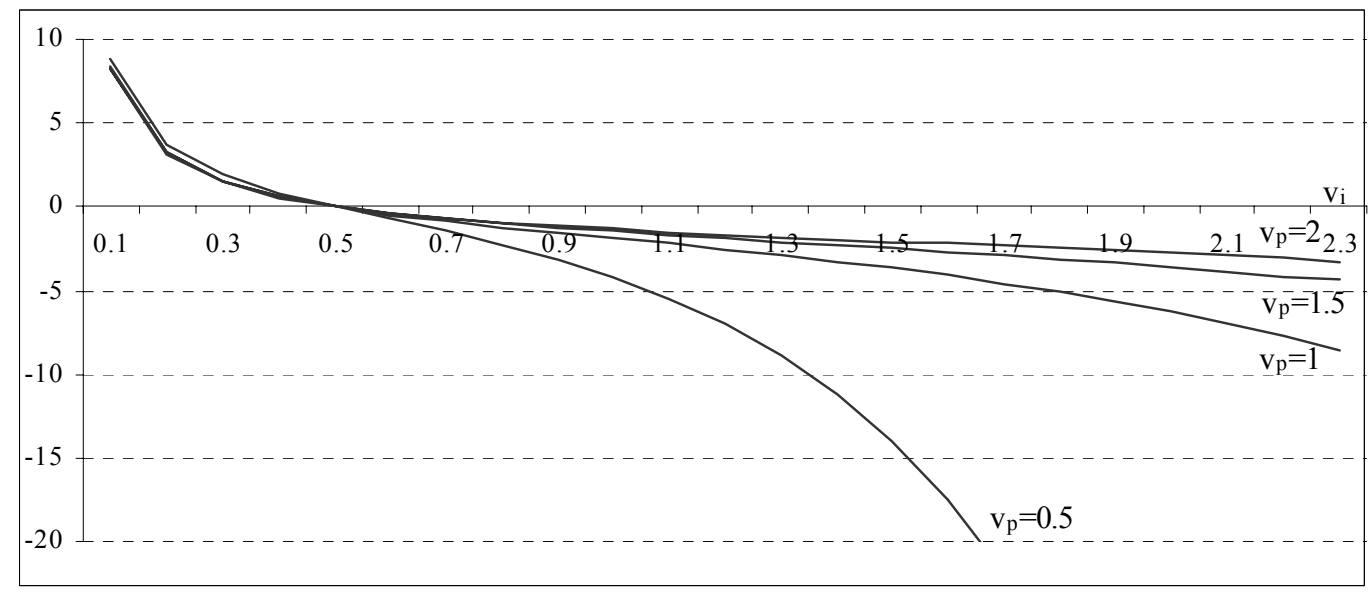

Figure 3 Price elasticity of portfolio investors with binding budget constraint, as a function of $v_{j p r}$

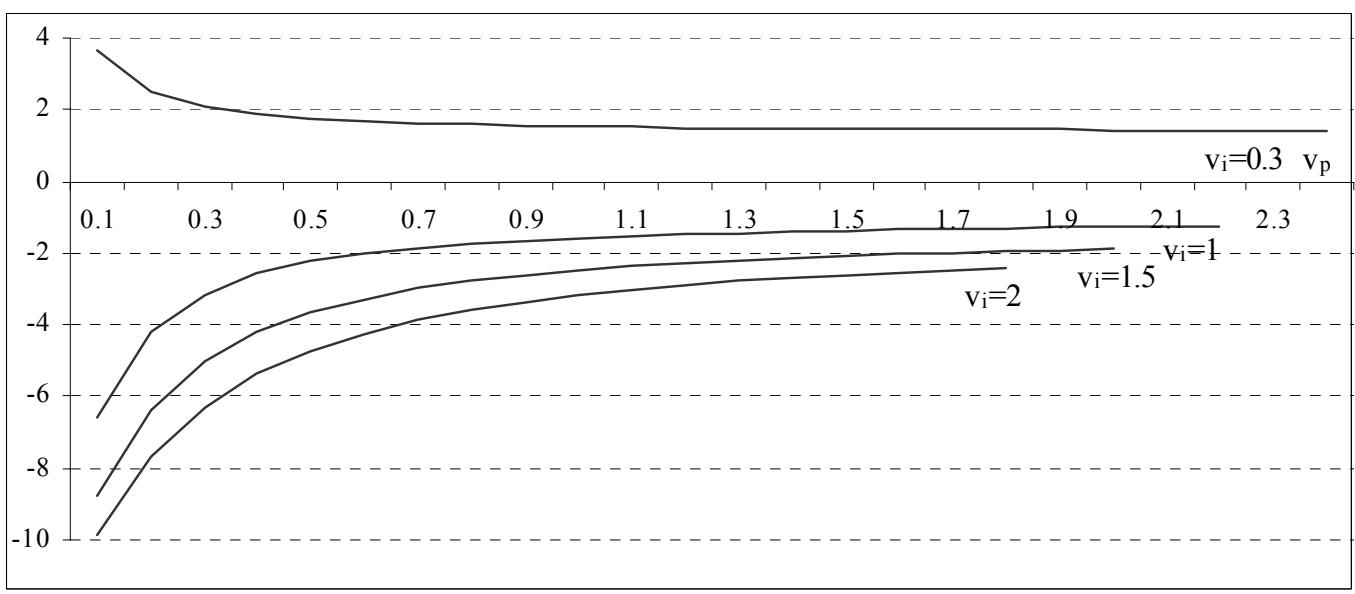




\section{The impact of firm i's size}

The size of a preferred firm $i$ in the portfolio of supplied shares also enters the decision-making process of investors with a non-binding budget constraint as the variable $S_{i}$ denoting the number of shares of firm $i$. The coefficient determining the size of it for investors with a non-binding $\mathrm{BC}$ is the following:

$$
\frac{\partial \ln s d_{j i r}}{\partial \ln S_{i}}=\frac{\partial s d_{j i r}}{\partial S_{i}} \frac{S_{i}}{s d_{j i r}}=\frac{1+\exp \left(v_{j i r} / \bar{v}_{j p r}\right)}{2} .
$$

For the bidding decisions of portfolio investors for whom their BC is binding, the firm size is not relevant, which indicates that they tend to diversify points over firms of all sizes.

As (11) shows, the impact is always positive, decreasing with firm $i$ 's relative undervaluation, i.e. as $v_{j i r} / \bar{v}_{j p r}$ decreases. The economic intuition of this result is straightforward. The investors have many voucher points and as these have null value after the bidding process, they try to allocate them to the greatest extent possible. The legal constraint, when expressed as the number of shares in firm $i$ an individual investor can buy, is not so restrictive in bigger firms. Therefore these are more attractive for "wealthy" investors.

To sum up, the impact of firm $i$ 's size for the share demand of investors with a nonbinding $\mathrm{BC}$ is always positive and its magnitude is mitigated only by a higher probability of overbidding, which increases when firm $i$ 's relative undervaluation deepens, i.e. as $v_{j i r} / \bar{v}_{j p r}$ declines.

\section{The investor and firm effect}

The optimal share demand of investor $j$ in firm $i$ is also determined by the characteristics of the firm, namely firm $i$ 's relative undervaluation and the investor's characteristics. This effect also differs for investors with a non-binding BC derived in (8a)

$$
\frac{1+\exp \left(v_{j i r} / \bar{v}_{j p r}\right)}{2} \ln \left(\frac{1-2 /\left(1+\exp \left(v_{j i r} / \bar{v}_{j p r}\right)\right)}{\lambda_{2 i r}}\right)
$$

and for investors with a binding $\mathrm{BC}$, whose optimal share demand is derived in (8b)

$$
\frac{1+\exp \left(v_{j i r} / \bar{v}_{j p r}\right)}{2} \ln \left(\frac{1-2 /\left(1+\exp \left(v_{j i r} / \bar{v}_{j p r}\right)\right)}{\lambda_{1 r}}\right) \text {. }
$$


If the specifications (8a) and (8b) are econometric equations, the investor effect is their intercept and it tells us how many shares the investor demands in a given firm $i$ after controlling for other variables.

The overall effect, which consists only of unobserved parameters, has two parts. First, $1+\exp \left(v_{j i r} / \bar{v}_{j p r}\right) / 2$ grows when the relative undervaluation of firm $i$ 's shares diminishes. As the coefficient is always positive and determines only the magnitude of the overall effect, the sign of the effect is determined by its second part, which is the log form of the parameter $\mu_{j i r}$, denoting the probability perceived by investor $j$ that shares of firm $i$ will be distributed in round $r$, divided by the marginal value of the LC $\lambda_{2 i r}$, in the case of investors with a nonbinding $\mathrm{BC}$, and by the marginal value of the investor's BC $\lambda_{1 r}$ (i.e. the points entrusted and available in the given round), in the case of investors for whom the $\mathrm{BC}$ is binding.

The effect of $\mu_{j i r}\left(v_{j i r} / \bar{v}_{j p r}\right)$ has an ambiguous effect on the share demand which can be determined only in interaction with $\lambda$. On the one hand, large mispricing discourages investors who are reluctant to overbid and so their share demand decreases, which is reflected in the smaller coefficient value. On the other hand, misvaluation raises the interest of investors who are attracted by a profitable investment opportunity. The final effect, formulated in Proposition 2, is therefore determined by the interaction of the subjective probability that shares will be distributed and the marginal value of investor $j$ 's wealth $\lambda_{1 r}$ for investors with a binding $\mathrm{BC}$ or the marginal value of investor $j$ 's LC $\lambda_{2 i r}$ for investors with a non-binding BC.

Proposition 2: The investor effect on the share demand is positive:

for investors with a non-binding budget constraint, when $\mu_{j i r}>\lambda_{2 i r}$, i.e. the probability that shares are distributed exceeds the marginal value of the legal constraint. The probability of this event grows with the legal constraint $l$, with firm $i$ 's relative share undervaluation and with the share price when the shares are overvalued. The probability declines with the amount of shares in firm $i$ received in previous rounds. The impact of firm size is ambiguous.

for investors with a binding budget constraint, when $\mu_{j i r}>\lambda_{1 i}$, i.e. when the probability that shares are distributed exceeds the marginal value of the budget constraint. The probability of this event grows with investor $j$ 's endowment of voucher points and firm 
$i$ 's relative share undervaluation. The probability declines with the voucher points allocated in previous rounds and in other firms and with the share price in the case $v_{j i r} \leq 0.5$.

The effect declines as the relative undervaluation of firm $i$ 's shares, $v_{j i r} / \bar{v}_{j p r}$, deepens. (Proof of Proposition 2 can be found in the Appendix.)

For investors with a non-binding budget constraint, this term mitigates the impact of the price and size variables due to the bidding constraints. It grows when the legal limit increases and declines with the amount of shares of firm $i$ received in previous rounds, as the legal constraint limits further investment in this firm.

Firm $i$ 's relative undervaluation $v_{j i r} / \bar{v}_{j p r}$ has a double impact. It mitigates the overall positive (due to a higher risk of overbidding) or negative (due to a good investment opportunity) impact. However, an increasing ratio of $v_{j i r} / \bar{v}_{j p r}$ positively effects the second term of (12a).

There are additional factors that affect the share demand through $\lambda_{2 i r}$. The impact of firm size is uncertain and negative when the probability that the shares are distributed $\mu_{j i r} \rightarrow 1$ is high and positive otherwise. This means that the firm size increases the investorspecific part of the share demand only when there is a more significant threat of overbidding. If this is not the case, increasing size diminishes its value and in this manner it compensates the firm size effect defined in (11).

Finally, the share price affects the term positively if the shares are overvalued and negatively when they are undervalued. Intuitively, one would expect the opposite. We can interpret this result as a counterbalance to the impact of the price variable, and is justified by the efforts of investors to avoid overbidding and a too-concentrated portfolio.

Regarding investors with a binding budget constraint, term (12b) grows when the shadow price of wealth declines, which can be the result of a large endowment of voucher points or good investment opportunities, i.e. low $v_{j i r} / \bar{v}_{j p r}$. The price has a negative impact on the investor effect as long as the share price as a factor of share demand affects it positively, i.e when $v_{j i r} \leq 0.5$. The impact of $v_{j i r} / \bar{v}_{j p r}$ has, like in the previous category, an ambiguous effect on share demand. Its lower value increases $\ln \left(\mu_{j i r} / \lambda_{1 i}\right)$, but this is 
mitigated by the lower coefficient $1+\exp \left(v_{j i r} / \bar{v}_{j p r}\right) / 2$. The interpretations are similar as for the previous group.

We can see that the investor-specific effect captures primarily investors' reluctance to overbid while the share price variable reflects looking for profitable opportunities. This effect has more aspects. First, the reluctance of portfolio investors to overbid plays an important role in their decision-making. Large mispricing of the firms in the portfolio mitigates a positive as well as negative investor effect on share demand.

Second, profitable investment opportunities increase the share demand in the selected firms and at the same time they contribute to the positive sign of the investor effect, as wider investment opportunities reduce the risk of overbidding. Third, firm size matters only for investors with a non-binding $\mathrm{BC}$ and affects their share demand (i) positively as one of the share demand factors and (ii) indirectly as a part of the investor-specific effect (this part of the effect is ambiguous). Therefore, bigger portfolio investors are first attracted to bigger firms and second expected to diversify more to allocate all their points. This result justifies also the argument of Koleva and Vincensini (2002) that one of the reasons why big bank-sponsored IPFs diversified their portfolios was to allocate all their points.

Fourth, a bigger investor size raises the share demand of investors with a binding BC in the selected firms. The increase in the share demand of investor $j$ is caused by a lower shadow price of wealth $\lambda_{1 r}\left(B_{j}\right)$ due to a bigger endowment of voucher points $B_{j}$.

As we showed in Section 3, the analyzed variables shape the share demand in firm $i$ when the demand is strictly larger than 0 . The constraint (1d) requires that the share demand in any firm or round must be bigger than or equal to 0 . If the variables should have caused negative demand, for example due to a strong firm overvaluation that causes a highly negative price effect, as short-selling is not possible, the non-negativity constraint is binding and $s d_{j i r}=0$. On the other hand, the low share demand can be caused by the limited amount of voucher points to allocate and by attractive investment opportunities in other firms. In this case, one does not consider the non-negativity constraint as binding. This brings us to one important problem of the bidding process. According to the mechanism, the prices for the next round were modified according to the number of shares left, outstanding voucher points and in particular the ratio of excess demand to supply for the shares of individual firms (e.g. Tř́iska, 2002 and Filer and Hanousek, 2001). Due to the non-negativity constraint (1d), the auctioneer was not able to precisely quantify the actual extent of investors' perception of share overvaluation. As a result, the prices of weakly demanded small firms with low liquidity 
might have been unjustifiably decreased, especially if only portfolio investors would have participated. Filer and Hanousek (2001, p. 1635) also found that the "voucher process did a better job in each wave of predicting the market price of the large and medium capitalization stakes than it did of predicting the value of the firms with fewer shares involved". ${ }^{28}$ As a result, overshooting and undershooting in price adjustment, pointed out in the empirical study of Aggarwal and Harper (2000), might be one of the reasons why investors were not "loyal" to firms they bid for in a previous round, as Tříska (2002) pointed out. Lack of loyalty can be explained by the fact that the prices of shares in very high and very low demand did not converge to the "correct" value with $v_{j i r}=1$, instead they tend to overshoot and undershoot. Investors reacted to rapid price movements between rounds with switching among firms. The imbalances calmed down in later rounds, when switching from one firm to another also decreased (Kraizberg, 1999).

This part provides an intuition for how one can distinguish strategies and the misvaluation perception of portfolio investors based on the coefficients of their share demand. As we argue in Section 3, if all investors would have identical information about firm misvaluation, the information would be symmetrically distributed, investment strategies would be the same, and investors would end up with the same composition of their portfolios. On the other hand, the bigger the differences in the perceptions of the share value are among investors, the bigger the differences in the value of coefficients can be expected. This holds mostly at the beginning of the bidding process. The speed of convergence shows the pace of investors' learning and the efficiency of the price setting.

The model suggests that when shares are correctly priced, portfolio investors prefer a fully diversified market portfolio. Share concentration is mainly the result of mispricing, asymmetric information and of intentions to participate in the corporate governance of privatized firms. We deal with this last point in the next part.

\subsection{Bidding behavior of strategic investors ${ }^{29}$}

As we outlined at the beginning of this section, apart from portfolio investors, one could identify another type of investor intending to obtain a higher amount of shares and play

\footnotetext{
${ }^{28}$ The reason is, according to Filer and Hanousek (2001), related to the fact that in efficient markets, prices incorporate information to the extent that the analyzing cost can be recouped through the excess return.

${ }^{29}$ As explained in Section 3, referring to the investors as strategic does not automatically imply that they have strategic interests in all firms, just that there are firms in their portfolio for which they make efforts to receive higher stakes and to actively perform their ownership rights.
} 
a part in corporate governance or in some other way benefit from firm control. We distinguish them from portfolio investors by the parameter $c_{j i r}>1$ in firm $i$. The parameter increases the expected return from investing into a particular firm compared to portfolio investors. A higher value of the parameter can be the outcome of (i) concentrated ownership and firm control, (ii) winning a block of shares that can be sold with a higher profit margin to another investor or (iii) the confidence of investors regarding the future prospects of the firm, and their intentions to restructure it, or on the contrary, to loot it. Superior information and interest in the firm can come from a previous relationship, for example as a firm creditor, supplier, customer, director or simply from better know-how in the field of firm restructuring and evaluation.

We assume that, as in case of portfolio investors, strategic investors are expectedreturn-maximizing and all have some beliefs and expectations about the firm's future market value. Rational investors are always bidding for a subset of shares, which are undervalued more than residual shares in the portfolio. This can be expressed as in the previous part as:

$$
v_{j i r} / c_{j i r}<\bar{v}_{j p r} / \bar{c}_{j p r} .
$$

As $c_{j i r}>1$ the investor's interest goes beyond benefiting from the difference between the expected future market price and the current voucher price. Although the investor chooses firms comparing $v_{j i r} / c_{j i r}$ and $\bar{v}_{j p r} / \bar{c}_{j p r}$, the coefficient that mitigates price elasticity in the case of high mispricing, $\mu_{j i r}=1-2 /\left(1+\exp \left(v_{j i r} / \bar{v}_{j p r}\right)\right)$, does not contain $c_{j i r}$. Capturing the risk of overbidding thus does not take into account possible control interests.

The value of parameter $c_{j i r}$ is not observed and we need an additional indicator distinguishing strategic and portfolio investors. As we argued above, when the legal constraint is specified at the level that creates a border between portfolio and strategic investments, the binding legal constraint can fulfill this role. From the derived functions of optimal share demand (8a)-(8c) in Section 3, (8a) and (8c) express the optimal share demand of investors with a binding legal constraint. Therefore, we consider those for whom these two specifications capture best their share demand as strategic investors: (8a) covers investors with a non-binding $\mathrm{BC}$ and $(8 \mathrm{c})$ covers investors with a binding $\mathrm{BC}$.

We know from the previous part that the price elasticity of the share demand grows with share overvaluation. In this part we proceed with an analysis of how the extent of control interest and private information of strategic investors affects the impact of the relevant variables on share demand to identify the main differences between the two types of investors. 


\section{The impact of firm i's price}

First we look at the effect of the most important variable: the voucher price of the shares determined by the coefficient

$$
\frac{\partial \ln s d_{j i r}}{\partial \ln p_{i r}}=\frac{\partial s d_{j i r}}{\partial p_{i r}} \frac{p_{i r}}{s d_{j i r}}=\left(\frac{1+\exp \left(v_{j i r} / \bar{v}_{j p r}\right)}{2}\right)\left(\frac{c_{j i r}}{v_{j i r}}-1\right)
$$

for investors with a non-binding budget constraint and

$$
\frac{\partial \ln s d_{j i r}}{\partial \ln p_{i r}}=\frac{\partial s d_{j i r}}{\partial p_{i r}} \frac{p_{i r}}{s d_{j i r}}=\left(\frac{1+\exp \left(v_{j i r} / \bar{v}_{j p r}\right)}{2}\right)\left(\frac{c_{j i r}}{v_{j i r}}-2+\frac{\lambda_{2 i r}}{\lambda_{1 r} S_{i} p_{i r}}\right)
$$

for investors with a binding budget constraint. ${ }^{30}$

The price coefficient consists of two terms: (i) $\left(c_{j i r} / v_{j i r}-1\right)$ for investors with a nonbinding $\mathrm{BC}$ and $\left(c_{j i r} / v_{j i r}+\lambda_{2 i r} / \lambda_{1 r} S_{i} p_{i r}-2\right)$ for investors with a binding BC. This term affects the attractiveness of the share demand for investors due to their undervaluation. (ii) $1+\exp \left(v_{j i r} / \bar{v}_{j p r}\right) / 2$ is always positive and affects only the significance of the first term. We can easily see that the first term is higher compared to portfolio investors, which indicates a lower sensitivity to prices.

The conclusions of the analysis of the price factor on the share demand are summarized in Proposition 3.

Proposition 3: The price elasticity of the share demand of the expected-utilitymaximizing strategic investor $j$ with a non-binding budget constraint becomes positive when $v_{j i r}<c_{j i r}$ and with a binding budget constraint when $v_{j i r}<c_{j i r} /\left(2-\lambda_{2 i r} / \lambda_{1 r} S_{i} p_{i r}\right)$. The absolute value of price elasticity grows with the ratio of relative misvaluation $v_{j i r} / \bar{v}_{j p r}$. The value of the price elasticity decreases with the misvaluation parameter $v_{j i r}$. It decreases with the parameter $\bar{v}_{j p r}$ when the price impact of share demand is positive and increases when the price impact is negative. The extent of the control interest of strategic investors mitigates the negative price impact. A smaller size of the firm and a low voucher price of its shares have a positive impact on the share demand for investors with a binding BC. (Proof of Proposition 3 can be found in the Appendix.)

\footnotetext{
${ }^{30}$ For details on the derivations of (13b) see the Appendix.
} 
The main difference between portfolio and strategic investors is that while for portfolio investors firm $i$ 's absolute misvaluation was crucial for the sign of the price coefficient, here the difference between $v_{j i r}$ and $c_{j i r}>1$ determines its sign. As a result, the price coefficient is generally higher, in particular for investors with a non-binding BC.

Investors with a binding $\mathrm{BC}$, who are naturally more sensitive to prices, require a stronger undervaluation $v_{j i r}<c_{j i r} /\left(2-\lambda_{2 i r} / \lambda_{1 r} S_{i} p_{i r}\right)$ to react to prices positively. However, the necessary threshold value of firm undervaluation grows with the parameter of control interests $c_{j i r}$, which mitigates the occurrence of the negative price impact.

An additional point in which the group of strategic investors differs from portfolio investors is the relevance of the price and the size of the firm for the price coefficient. While the price elasticity of portfolio investors is determined solely by the value of the misvaluation parameters, here the value of the voucher price itself affects the price impact. Though for big firms with higher voucher price $\lambda_{2 i r} / \lambda_{1 r} S_{i} p_{i r} \rightarrow 0$, the relevance of this term becomes negligible, for small firms traded at a low voucher price, a higher value of $\lambda_{2 i r} / \lambda_{1 r} S_{i} p_{i r}$ increases the term $\left(c_{j i r} / v_{j i r}-2+\lambda_{2 i r} / \lambda_{1 r} S_{i} p_{i r i r}\right)$, and thereby the value of the coefficient. This indicates that in small, cheap and presumably illiquid firms, the bidding of strategic investors differs to a greater degree from the portfolio investors, compared to the bidding in big firms. In particular, strategic investors tend to decrease their price sensitivity when it comes to small and cheap firms, while portfolio investors diversify across firms of all sizes.

As the proof of Proposition 3 stipulates, investors with a binding BC are generally more price-elastic in the case of overvalued shares and less price-elastic in the case of strongly undervalued shares compared to their counterparts with a non-binding BC. The stronger elasticity is given by the double impact of growing $v_{j i r}$, which decreases the negative value of $\left(c_{j i r} / v_{j i r}-1\right)$ and $\left(c_{j i r} / v_{j i r}-2+\lambda_{2 i r} / \lambda_{1 r} S_{i} p_{i r}\right)$, given by the low attractiveness of overvalued shares, and at the same time increases the positive value of $1+\exp \left(v_{j i r} / \bar{v}_{j p r}\right) / 2$, due to a lower probability of overbidding. As a result, the price elasticity rises. On the other hand, in the case of low $v_{j i r}$, the misvaluation parameter affects the two parts of the coefficient in opposite directions. The rationale behind this is that whereas low $v_{j i r}$ encourages share demand due to a profitable opportunity, it also increases the probability of overbidding and therefore mitigates the overall positive impact. This holds especially for investors with a binding $\mathrm{BC}$, who also to a larger extent tend to diversify. 
Figures 4-11 illustrate our argument that the price elasticity coefficient, ceteris paribus, generally declines with $v_{j i r}$ and declines (increases) with $\bar{v}_{j p r}$, when the price impact is positive (negative) and increases with $c_{j i r}$.

Investors with a non-binding budget constraint

Figure 4 Price elasticity of share demand, $c_{j i r}=1.5$

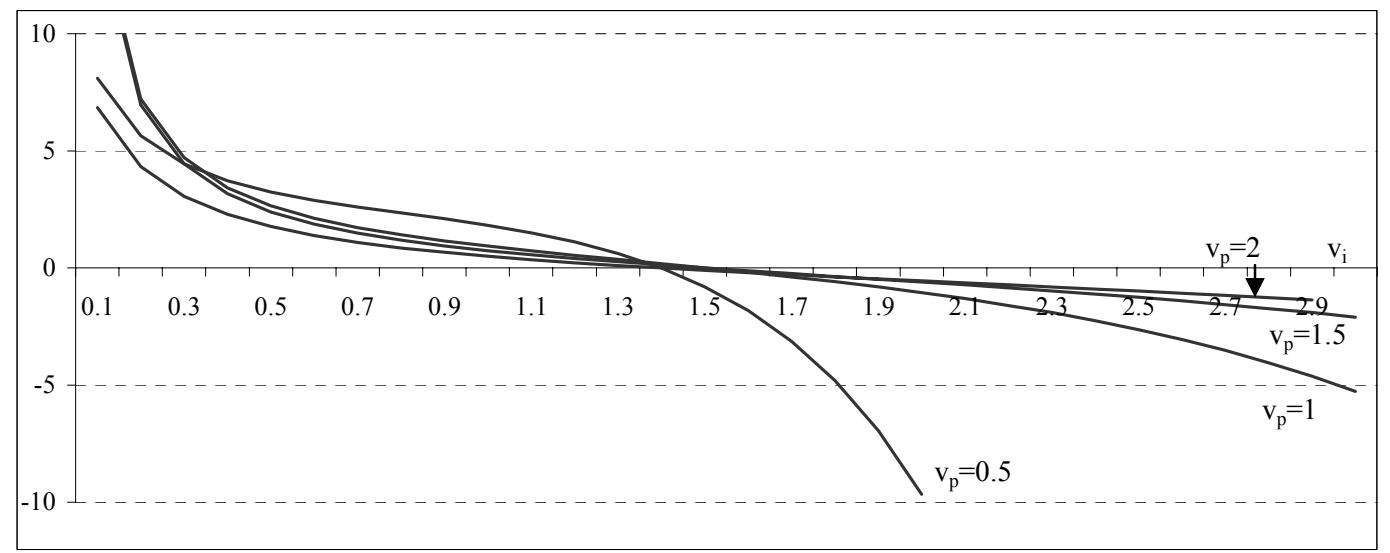

Figure 5 Price elasticity of share demand, $c_{j i r}=2$

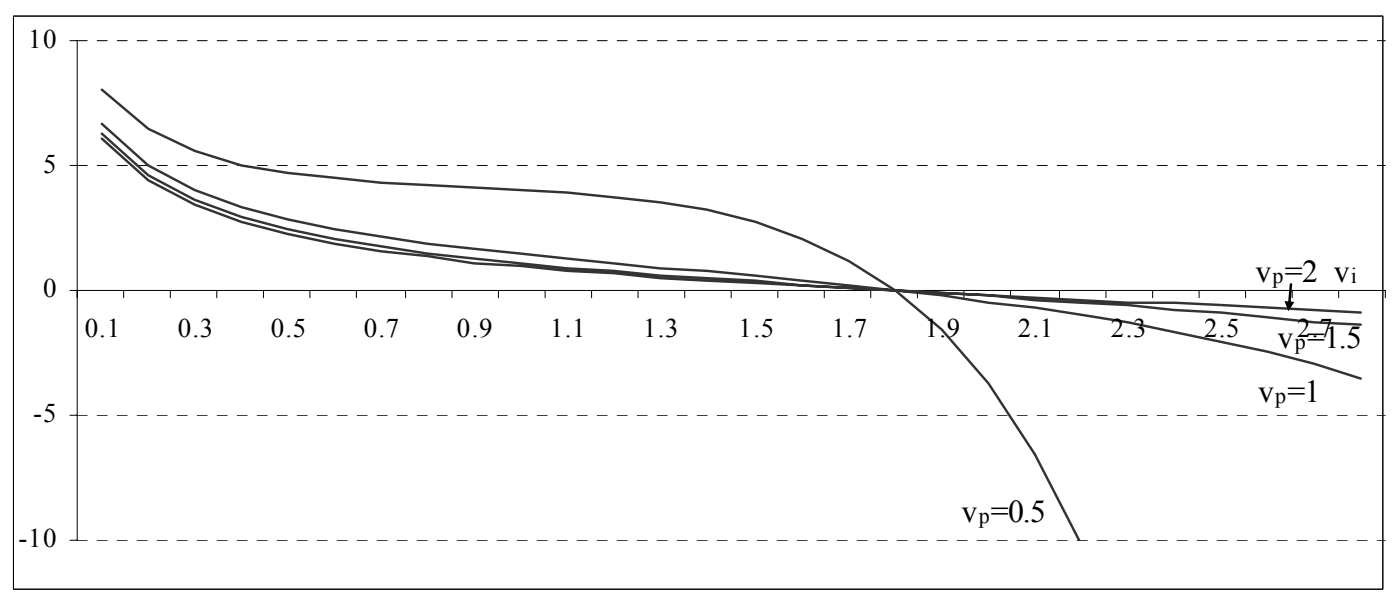


Figure 6 Price elasticity of share demand, $c_{j i r}=2.5$

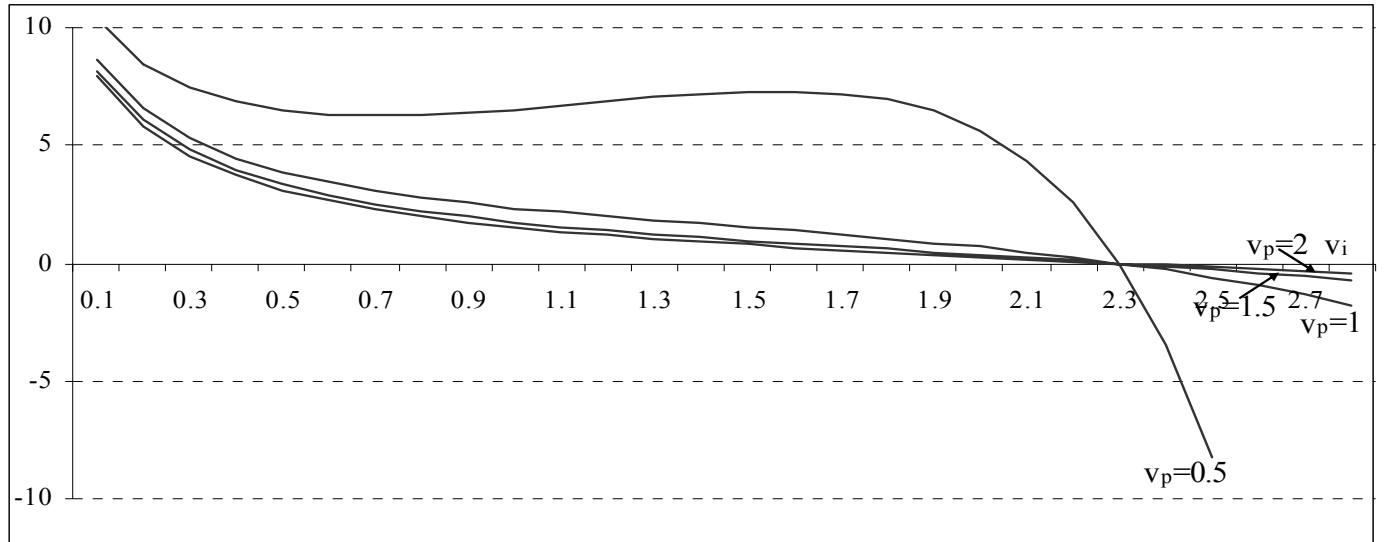

Figure 7 Price elasticity of share demand, $\bar{v}_{j p r}=2$

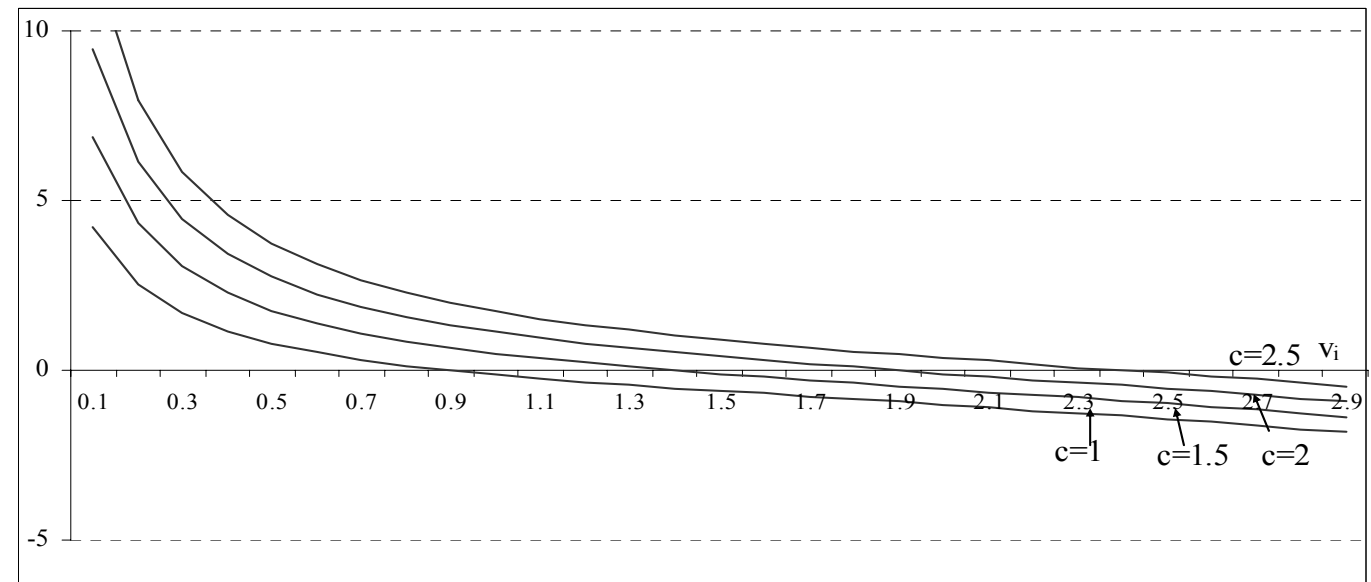

Figures 4-7 present the price elasticity for strategic investors with a non-binding BC. According to the extent of their control interests the price impact is positive especially when the control interests grow, monotonically decreasing with $v_{j i r}$. This outcome suggests that the effect of the lower attractiveness of more overvalued shares prevails over the effect of the reluctance to overbid. The only exception is the situation when the overall portfolio is largely undervalued and the investors have high control interests in firm $i$ (see Figure 6 at $\bar{v}_{j p r}=0.5$ ). As $v_{j i r}$ increases, the lower attractiveness of less undervalued shares causes a lower positive price effect, but at $v_{j i r}=0.5$ it gains momentum and in the interval from 0.5 to cca 1.6 , the price coefficient increases with $v_{j i r}$, which means that the efforts to avoid overbidding prevail over the factor of a less profitable investment opportunity. This development can be observed 
only in the case of the investors with a non-binding BC. However, after some threshold value of $v_{j i r}$, the price coefficient starts to continue its declining trend.

In Figure 7, we plot price coefficients as functions of $v_{j i r}$, when the residual shares are on average overvalued $\bar{v}_{j p r}=2$, for different levels of control interests $c_{j i r}=1,1.5,2$ and 2.5. We can see that the importance of this factor of the share demand is more pronounced mainly in the interval where the price impact is positive.

Investors with a binding budget constraint

Figure 8 Price elasticity of share demand, $c_{j i r}=1.5$

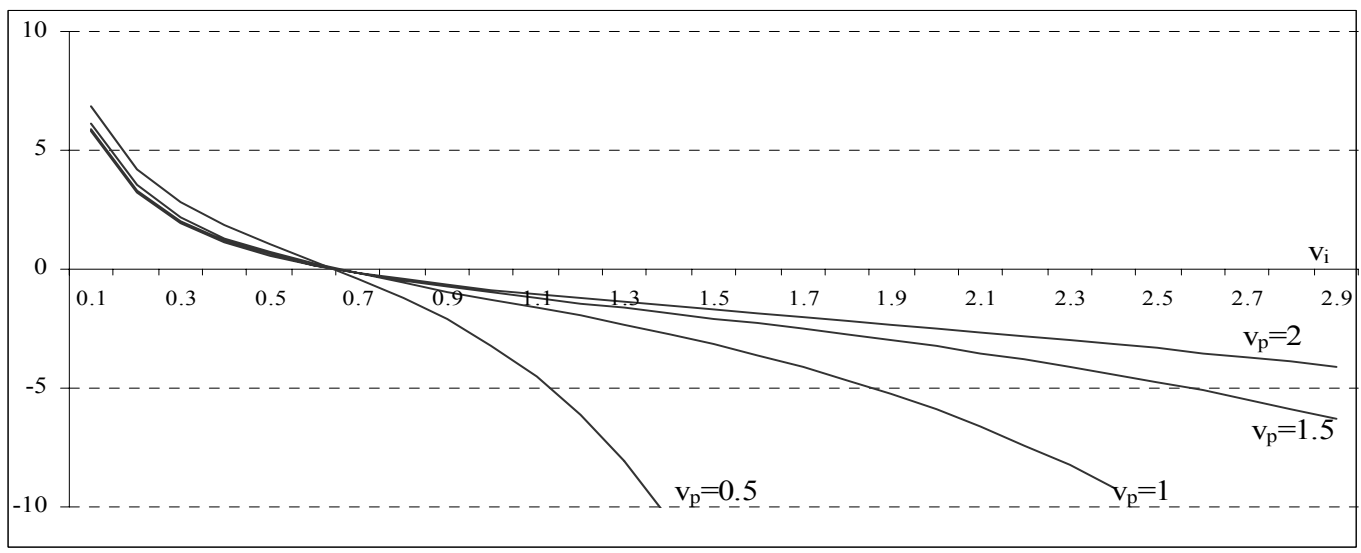

Figure 9 Price elasticity of share demand, $c_{j i r}=2$

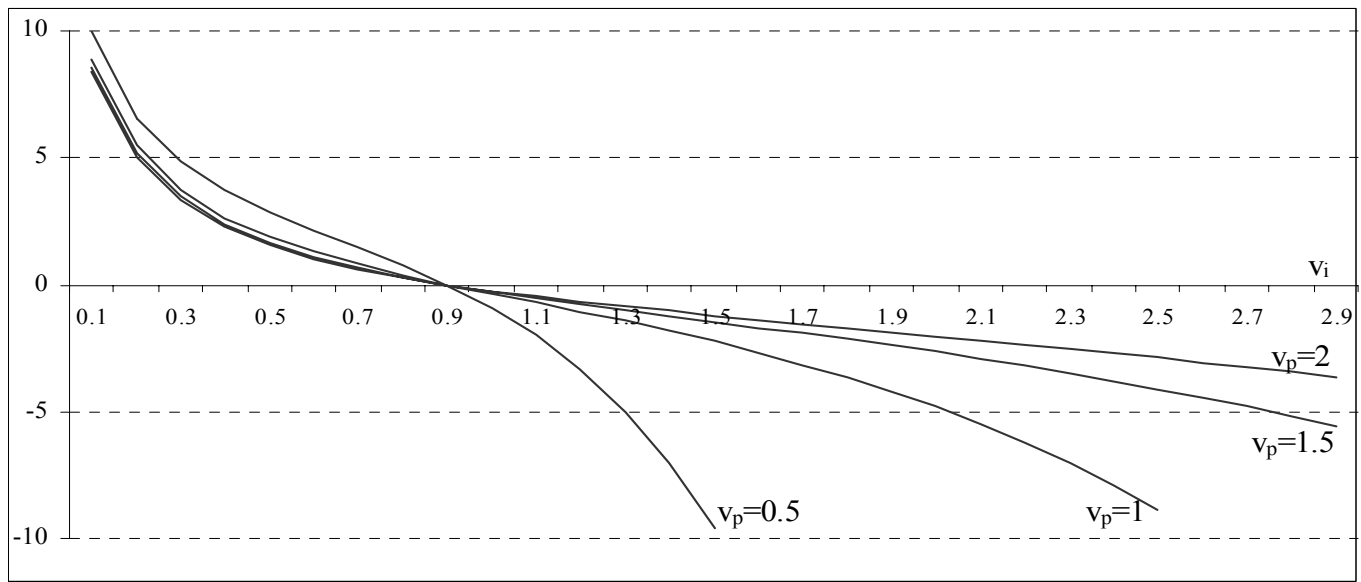


Figure 10 Price elasticity of share demand, $c_{j i r}=2.5$

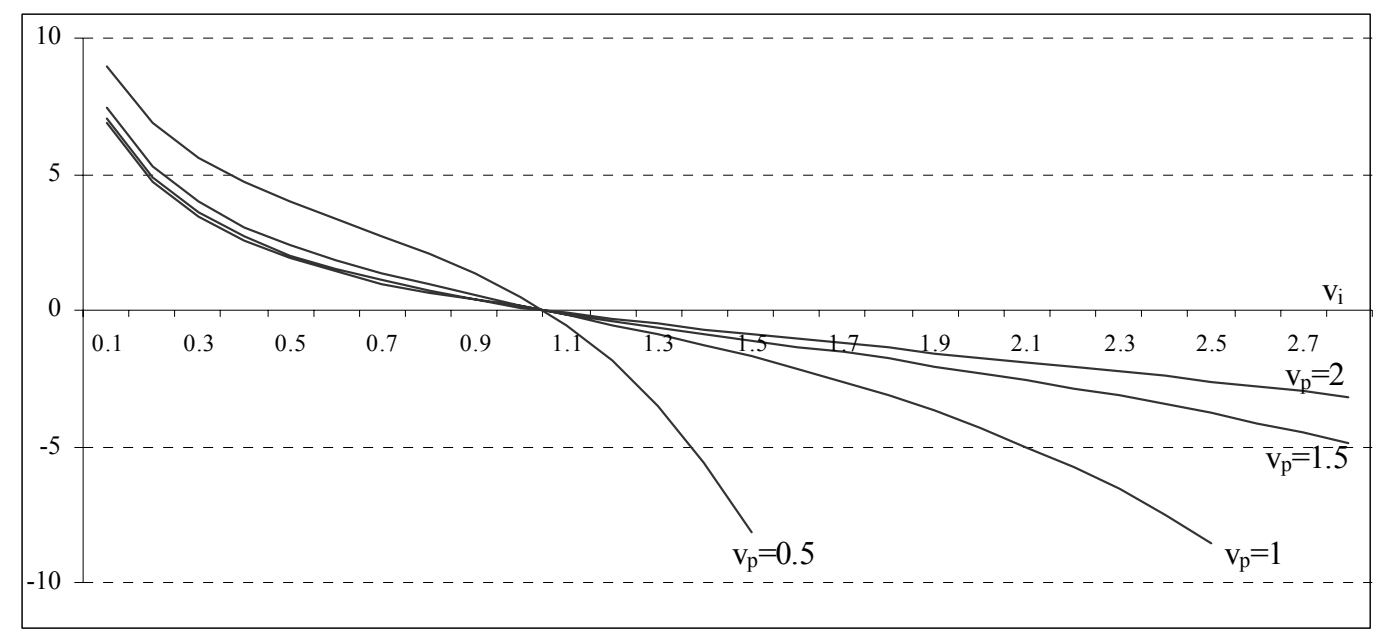

Figure 11 Price elasticity of share demand, $\bar{v}_{j p r}=2$

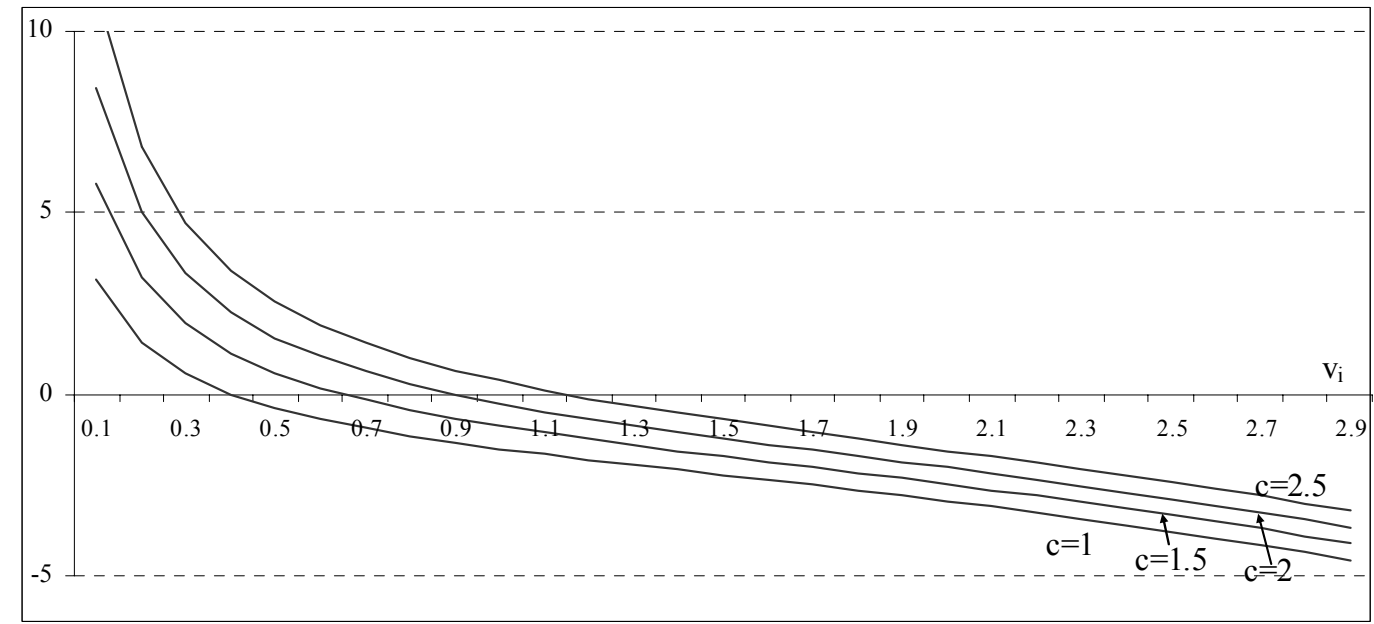

Figures 8-11 illustrate the relationship between the values of $v_{j i r}$ and the price elasticity of share demand at different values of $\bar{v}_{j p r}$ and $c_{j i r}$ for strategic investors with a binding $\mathrm{BC}^{31}$

Generally, the development differs from investors with a non-binding BC only in two points: (i) when the price impact is positive, firm $i$ 's misvaluation primarily matters for the value of the coefficient, while the impact of $\bar{v}_{j p r}$ does not change the result much and (ii) the misvaluation of the residual shares $\bar{v}_{j p r}$ has on the other hand a stronger impact when the price impact is negative, where it raises the price elasticity. This can be explained by a faster

\footnotetext{
${ }^{31}$ Please note that, in plotting coefficient (18b), we simplified it assuming that $\lambda_{2 i r} / \lambda_{1 r} S_{i} p_{\text {ir ir }} \approx 0$, which is a reasonable approximation, given that (i) even in smaller firms traded at low values, the fraction is very small and (ii) this part of the price impact comes from the investor effect and is available only in the interaction with the other three factors.
} 
reaction to price changes compared to investors with a non-binding $\mathrm{BC}$ and might indicate that strategic investors do not tend to compete for the same shares with their counterparts with stricter financial constraints.

We can conclude that the price elasticity of strategic investors is determined similarly as for portfolio investors by the following items.

The extent of mispricing: the stronger the overvaluation or undervaluation of the shares, the bigger sensitivity of investors to prices we can expect.

The extent of relative mispricing: the more undervalued the shares of firm $i$ are perceived relative to the other supplied shares, the less sensitive to prices the investors are. $^{32}$

The control interests: the more the investor is interested in active participation in firm governance, the higher the coefficient value.

The value of the coefficient generally decreases with $v_{j i r}$. This is an interesting finding, meaning that the effect of a better investment opportunity is stronger than the effect of an overbidding risk. Though the proof of Proposition 3 shows that the relationship might have the opposite direction under certain circumstances (strong control interests, an absolute undervaluation of firm $i$ and at the same time its relative overvaluation $v_{j i r} / \bar{v}_{j p r}>1$ ), the charts indicate these are very rare scenarios, supported only for investors with a non-binding $\mathrm{BC}$ where a higher fear of overbidding can be expected.

Regarding the impact of the misvaluation of the portfolio consisting of residual shares, the price coefficient grows with $\bar{v}_{j p r}$ when the price impact is negative. This means that when shares are overvalued (or weakly undervalued) and decline with $\bar{v}_{j p r}$, the price impact is positive. Generally speaking, in both cases it mitigates the price elasticity and its economic interpretation is the same as in the case of strategic investors. The misvaluation of the other firms relative to the misvaluation of the specific firm $i$ affects only the magnitude of the impact, not its sign.

In contrast to portfolio investors with a binding $\mathrm{BC}$, not only the misvaluation of firm $i$ itself and of the residual shares determine the price coefficient of the strategic investors with a binding $\mathrm{BC}$, but also the voucher price of firm $i$ matters, although it matters very little. This is partially consistent with the argument of Ma (1994) that the voucher prices account for the share demand.

\footnotetext{
${ }^{32}$ This is caused primarily by higher probability of overbidding.
} 


\section{The impact of firm i's size}

The size of preferred firm $i$ in the portfolio of supplied shares also enters the decision making process of strategic investors with a non-binding $\mathrm{BC}$ as the variable $S_{i}$, denoting the number of shares of firm $i$. In contrast to portfolio investors, the firm size matters regardless of whether the $\mathrm{BC}$ is binding. However, its impact differs for investors with a non-binding $\mathrm{BC}$

$$
\frac{\partial \ln s d_{j i r}}{\partial \ln S_{i}}=\frac{\partial s d_{j i r}}{\partial S_{i}} \frac{S_{i}}{s d_{j i r}}=\frac{1+\exp \left(v_{j i r} / \bar{v}_{j p r}\right)}{2}
$$

and for investors with a binding BC

$$
\frac{\partial \ln s d_{j i r}}{\partial \ln S_{i}}=\frac{\partial s d_{j i r}}{\partial S_{i}} \frac{S_{i}}{s d_{j i r}}=\frac{1+\exp \left(v_{j i r} / \bar{v}_{j p r}\right)}{2} \lambda_{2 i r} / \lambda_{1 r} S_{i} p_{i r},{ }^{33}
$$

where it is a part of the overall investor effect. In both cases the impact is positive, i.e. when the size of the firm increases by $1 \%$, the share demand increases by a positive increment. The impact grows with $v_{j i r}$ and decreases with $\bar{v}_{j p r}$, which means that the term captures the efforts of investors to avoid overbidding. However, there are differences between investors with a binding and non-binding $\mathrm{BC}$ in the impact and its economic meaning.

For investors with a non-binding BC, the firm size elasticity (14a) is determined solely by firm $i$ 's relative misvaluation, i.e. every increase in the firm size brings an identical increase in the share demand, which is the same as for portfolio investors, and can be explained by the same economic intuition. These investors have many voucher points (which have a null value after the bidding process) and they try to allocate them to the greatest extent possible. The legal constraint, when expressed as an amount of shares, is not so restrictive in bigger firms, which are consequently more attractive for "wealthy" investors. Therefore, the impact of firm $i$ 's size is always positive and its magnitude is mitigated only by a higher probability of overbidding, which increases when firm $i$ 's relative undervaluation deepens, i.e. as $v_{j i r} / \bar{v}_{j p r}$ declines.

The firm size effect for the investors with a binding BC is more complex. First, the term (14b) is positive, i.e. share demand grows with firm size, but the impact itself contains the firm size, which diminishes the effect. Second, the component of the share demand contained in the firm size in the equation $(8 \mathrm{c})$ has a negative sign. The negative effect of the firm size on the share demand is in absolute terms growing with firm overvaluation and

\footnotetext{
${ }^{33}$ For the derivation, see the procedure described in Appendix for the derivation of (18b), which is very similar to this case.
} 
declining with firm size. Third, firm size affects share demand only in the interaction with the shadow prices of both constraints and the voucher price; therefore its individual effect is difficult to distinguish. One can conclude that the term compensates for the lower share demand of strategic investors in small and cheap firms.

\section{The investor and firm effect}

The optimal share demand of investor $j$ in firm $i$ is also determined by the characteristics of the firm, in particular relative to firm $i$ 's undervaluation and the investor's characteristics, which are not captured by observable factors. This term also differs for investors with a non-binding $\mathrm{BC}$ derived in (8a)

$$
\frac{1+\exp \left(v_{j i r} / \bar{v}_{j p r}\right)}{2} \ln \left(\frac{1-2 /\left(1+\exp \left(v_{j i r} / \bar{v}_{j p r}\right)\right)}{\lambda_{2 i r}}\right)
$$

and for investors with a binding $\mathrm{BC}$ derived in $(8 \mathrm{c})$

$$
\frac{1+\exp \left(v_{j i r} / \bar{v}_{j p r}\right)}{2}\left(\ln \left(\frac{1-2 /\left(1+\exp \left(v_{j i r} / \bar{v}_{j p r}\right)\right)}{\lambda_{1 r}}\right)-\frac{\lambda_{2 i r}}{\lambda_{1 r} S_{i} p_{i r}}\right) .
$$

If the specifications (8a) and (8c) are econometric equations, the investor effect is their intercept and tells us how many shares investor $j$ demands in firm $i$ after controlling for other relevant variables.

The overall effect consists mainly of unobserved parameters and has two parts. The

coefficient $\left(1+\exp \left(v_{j i r} / \bar{v}_{j p r}\right)\right) / 2$ grows with the relative overvaluation of firm $i, v_{j i r} / \bar{v}_{j p r}$. The coefficient is always positive and determines only the magnitude of the overall effect. The second part differs for investors with a non-binding BC $\ln \left(\mu_{j i r} / \lambda_{2 i r}\right)$ and for investors with a binding $\mathrm{BC} \ln \left(\mu_{j i r} / \lambda_{1 r}\right)-\lambda_{2 i r} /\left(\lambda_{1 r} S_{i} p_{i r}\right)$.

The effect of perceived mispricing $\mu_{j i r}$ has an ambiguous effect on the share demand which can be determined only together with $\lambda^{\prime} s$. On the one hand, large mispricing discourages investors who are reluctant to overbid, as they do not want to lose when overbidding occurs and their share demand decreases, which is reflected in a smaller coefficient value. On the other hand, misvaluation raises the interest of investors who are attracted by a profitable investment opportunity. The final effect, formulated in Proposition 2, is therefore determined by the interaction of the subjective probability that the shares will be 
distributed, the marginal value of investor $j$ 's wealth $\lambda_{1 r}$ and/or the marginal value of investor j's legal constraint $\lambda_{2 i r}$.

Proposition 4:

The investor effect on the share demand is positive for investors with a non-binding budget constraint when $\mu_{j i r}>\lambda_{2 i r}$. I.e. the probability that shares are distributed exceeds the marginal value of the legal constraint and the probability of this event grows with legal constraint $l$, with firm $i$ 's relative share undervaluation and with the share price if the shares are overvalued, and declines with the amount of shares in firm $i$ received in previous rounds.

The investor effect on the share demand is positive for investors with a binding budget constraint when $\mu_{j i r}>\lambda_{1 i} \exp \left(\lambda_{2 i r} / \lambda_{1 i} S_{i} p_{i r}\right)$, and the probability of this event decreases with investor $j$ 's shadow price of legal constraint $\lambda_{2 i r}$, with investor $j$ 's shadow price of budget constraint $\lambda_{1 r}$, if $\lambda_{1 r}>\lambda_{2 i r} / S_{i} p_{i r}$ and with firm $i$ 's relative share undervaluation.

The investor effect declines as the relative undervaluation of firm $i$ 's shares, $v_{j i r} / \bar{v}_{j p r}$, deepens.

(Proof of Proposition 4 can be found in the Appendix.)

For investors with a non-binding $B C$, this term mitigates the impact of the price and size variables given the bidding constraints. The impact is determined by the same factors and in the same way for portfolio investors and their economic interpretation is identical.

Regarding investors with $a$ binding $B C$, term (15b) grows when the shadow price of the LC declines, which can be the result of a larger size of the firm, a higher level of the legal constraint or a higher risk of overbidding given by a stronger relative undervaluation of firm $i$. Term (15b) grows with the shadow price of the investor's wealth only if $\lambda_{1 r}<\lambda_{2 i r} / S_{i} p_{i r}$. Otherwise term (15b) declines with $\lambda_{1 r}$.

Generally, the higher $\lambda_{2 i r}$, i.e. the more the LC limits the investor's choices, the smaller the share demand after controlling for all other factors. The impact of the shadow price of wealth is determined together with the shadow price of the LC. The summarized results imply that the higher the shadow prices, i.e. the more investors perceive the constraints 
as limiting their investment possibilities, the smaller the share demand after controlling for other relevant factors.

We can see that this term firstly reflects the investor's individual situation, especially the size of the budget relative to the quality of investment opportunities and the extent of control interests that determine the restrictiveness of the $\mathrm{BC}$ and the $\mathrm{LC}$ on individual stakes in one firm.

Secondly, the term captures the reluctance of investors to overbid. In the case of investors with a non-binding $\mathrm{BC}$, the situation is identical for strategic and portfolio investors, while in the case of investors with a binding BC, the effect is smaller, and while for portfolio investors the investor effect declines with $\lambda_{1 r}$, in the case of strategic investors the same holds only if $\lambda_{1 r}>\lambda_{2 i r} / S_{i} p_{i r}$.

Thirdly, portfolio investors' reluctance to overbid is partially replaced by the strategic investors' interest to get bigger blocks to be able to control firms. This tactic held predominantly in smaller firms with lower voucher prices, where it did not cost so much to receive a controlling amount. This strategy is consistent with our earlier results that the investors are waiting for a price decrease when their demand, controlling for other variables, increases.

\section{Relevance of the legal constraint}

The main reason why the LC was imposed, was to prevent investment companies from receiving too much control in firms. However, was the LC essential in fulfilling this objective? First, we argue that for only some investors the LC was binding, as the rest were not interested in larger stakes in firms. Portfolio investors preferred to diversify their investments and there was no effect of the LC on their investment strategies. Second, we show that there were other bidding factors that prevent rational investors from too-high bids on one firm.

As a result of the controversy and problem of the LC, its size and its impact on the bidding strategies of investors deserves a short discussion. The theoretical model implies the following consequences of removing the LC.

Proposition 5: Lifting the legal constraint increases the share demand of investors with a non-binding budget constraint. For investors with a binding budget constraint, the 
effect on the share demand will be ambiguous. (Proof of Proposition 5 can be found in the Appendix.)

The investor effect captures the changes in the share demand caused by removing the legal constraint on the stakes of investors in individual firms, or in other words, increasing $l$ to 1 . As Proposition 5 states, the impact is different for strategic investors with a non-binding and with a binding BC. As the KT problem solved in the Appendix indicates, an increase in $l$ causes a decrease in the shadow price of the LC, $\lambda_{2 i r}$ for every $i \in\{1, \ldots, N\}$. In the case of investors with a non-binding $\mathrm{BC}$, a decline in $\lambda_{2 i r}$ brings an increase in the value of term (15a), which means a higher share demand, controlling for the other factors. This group of investors, regardless of if they have strategic interests or not, due to their large wealth, makes efforts to allocate all their points. Lifting the LC therefore creates for them further investment opportunities.

However, for investors with a binding BC, the situation is more complex. As their investor effect (15b) includes both $\lambda^{\prime} s$, which are determined together, a decrease in $\lambda_{2 i r}$, which increases the value of term (15b), must be, ceteris paribus, compensated by an increase in $\lambda_{1 r}$. Depending on the mutual position of $\lambda_{1 r}$ and $\lambda_{2 i r}$, if $\lambda_{2 i r}>\lambda_{1 r} S_{i} p_{i r}$, both a decrease in $\lambda_{2 i r}$ and an increase in $\lambda_{1 r}$ have a positive effect on (15b), and the share demand increases. However, $\lambda_{2 i r}<\lambda_{1 r} S_{i} p_{i r}$ is a more probable scenario, given a decline of the shadow price of the LC $\lambda_{2 i r}$ and an increase in the shadow price of the BC $\lambda_{1 r}$ multiplied by the firm size and the voucher price considerably increases the RHS of the inequality. To sum up, a decrease in $\lambda_{2 i r}$ positively affects (15b), but an increase in $\lambda_{1 r}$ causes a decline in (15b), when $\lambda_{2 i r}<\lambda_{1 r} S_{i} p_{i r}$ and the overall effect is ambiguous. The binding BC, which puts limits on the investors' bids, gives an economic rationale to these results. In addition, assuming that an increase in $\lambda_{1 r}$ was implicitly caused by a higher probability of overbidding due to unlimited stakes (i.e. lower $\mu_{i r}$ ), a decrease in the share demand flows also from the reluctance of investors to overbid.

Generally, Proposition 5 indicates that the effect of lifting the LC might not have an essential impact on the share demand of investors depending on which investor type prevails and how much their BC is binding. There are more factors at play and the share demand becomes more concentrated only if the benefits of wider investment opportunities dominate 
the increased risk of overbidding. The relative misvaluation, determining the perceived probability that shares are distributed, therefore matters more than the undervaluation or overvaluation of the selected firm $i$ and the extent of control interest.

\subsection{The impact of variable changes and consequences of inefficient price-setting}

The price adjustment causes changes in the parameters of perceived firm misevaluation $v_{j i r}, \bar{v}_{j p r}$ and potentially also $c_{j i r}$, the size of the coefficient changes. $\frac{34}{\text { This }}$ implies that (i) the auctioneer should not base price changes on the price elasticity in the previous round and (ii) the coefficient change must be incorporated in the calculation of the overall effect.

As we derived in the Appendix, the impact of the change in explanatory variables on the change in the share demand between periods $r-1$ and $r$ is given by the weighted average of the coefficient levels in both periods, the weights determined by the size and the direction of the variable changes. When the share is overvalued, its price should decrease, so the coefficient from the earlier round has a stronger weight. In the case of undervalued shares it is vice versa. Generally speaking, the more elastic impact prevails, which leads to the conclusion that the impact of variable changes is stronger than the impact of variables expressed in levels.

Table 1 shows the sign of the impact and the direction in which the expected price movement changes the share demand. ${ }^{35}$ If the auctioneer sets prices efficiently, the prices of absolutely overvalued shares are lowered and the prices of absolutely undervalued shares are raised. In addition, among the shares that are absolutely overvalued (undervalued), the price of those more overvalued (undervalued) decrease (increase) faster to converge together to the expected future price. However, in case of Czech voucher privatization, we can point out some features that potentially led to inefficiencies in share distribution and pricing:

In the case when a small amount of shares are left, their price was increased in spite of their excess supply in the previous round.

The auctioneer could be informed only about relatively overvalued vs. undervalued shares with respect to other shares according to the investors' demand, therefore

\footnotetext{
$\underline{34}$ The change of the last parameter can be caused by the fact that investors are not able to get a larger stake anymore as most of the shares were sold, or another similar event can change their ability to benefit from a higher stake in a firm.

${ }^{35}$ All possible situations when the sign of the impact differed are analyzed. As we are interested primarily in the direction of misvaluation, the regions of elastic vs. inelastic demand are not distinguished.
} 
price setting without knowledge of absolute misvaluation might not go in the desired direction.

The bidding of strategic investors for absolutely overvalued shares might also give wrong signals for price setting, lead to a further price increase of these shares and revert the bidding of strategic investors.

The aim of the following analysis is to show how these imperfections affected the pricing decisions of the auctioneer and consequently through the price and investor effect the bidding of investors.

In the second column of the Table 1 we present all the possible intervals of $v_{j i r}$ with a different impact of the price change on the share demand for individual investor types. As the analysis shows, it is difficult to directly compare portfolio and strategic investors, because the price elasticity of portfolio investors is determined by the absolute value of the misvaluation parameters whereas in the case of strategic investors, the price elasticity is determined by the value of $v_{j i r}$ relative to the extent of control interests in a given firm captured by $c_{j i r}$. 
Table 1 Comparative analysis of the impact of variable changes on the optimal share demand

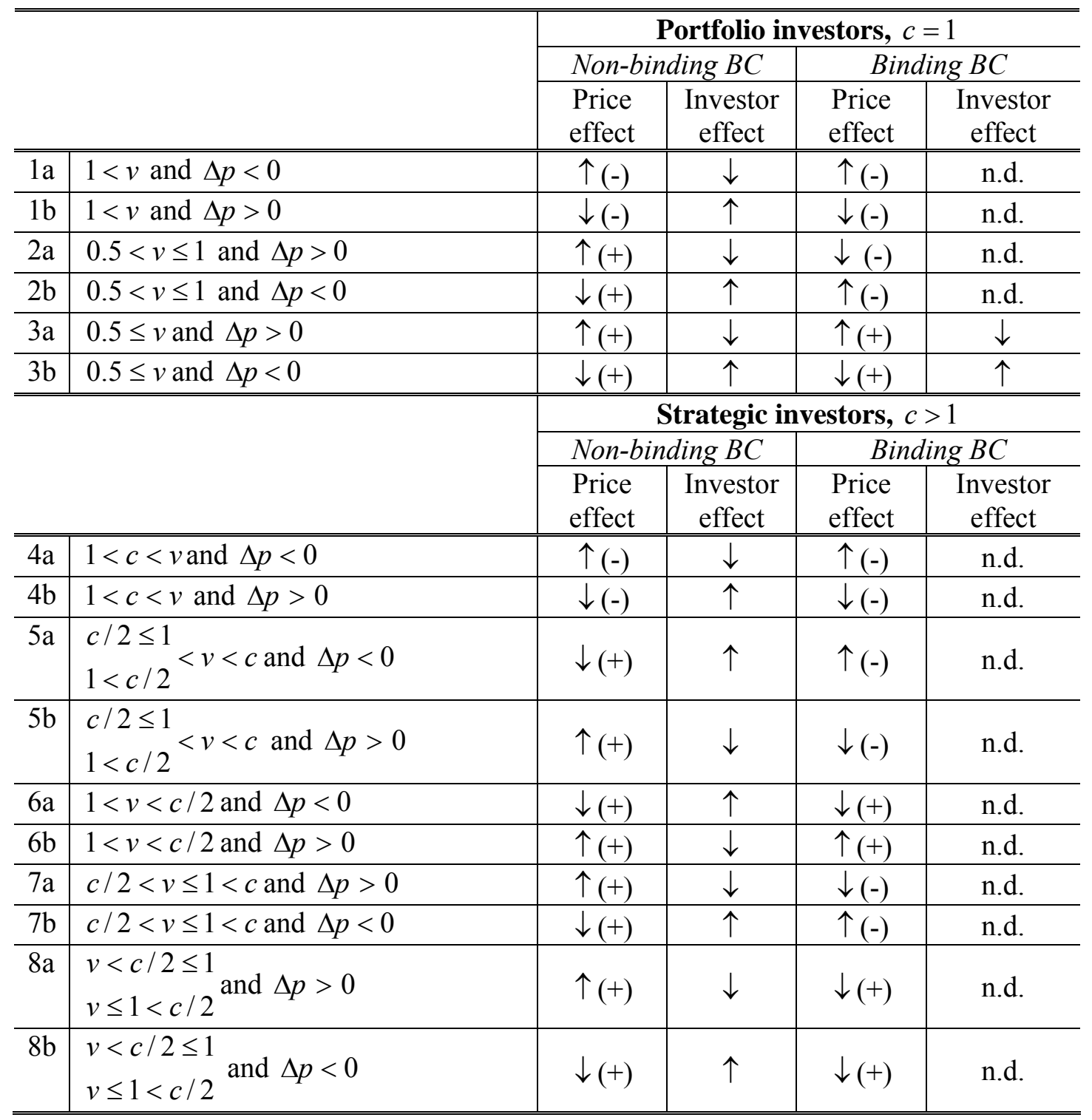

Note: For clarity subscripts $j, i ., r$ are skipped. $+/-$ denote the sign of the price elasticity of the share demand coefficient for given levels of the valuation parameter $v_{j i r}$; arrows indicate the impact of the price movements on $s d_{j i r}$. n.d. means that the overall effect was not possible to determine. The first column contains the numbers of individual situations with letters $a$ and $b$, where the letter $a$ shows the situations where the price was adjusted in the correct direction and $b$ when the price was adjusted in the incorrect direction. 
Let us have a look at the possible reasons for price distortions.

When the prices of shares in excess supply are increased because there are only a few shares left, even though they are already overpriced, the deepening of the share overvaluation declines the demand for these shares in the subsequent round. As a result, the change of the price variable drives down the share demand $s d_{j i r}$ (see for example the situations $1 \mathrm{~b}$ and $4 \mathrm{~b}$ in Table 1 , in particular for investors with a binding $\mathrm{BC}$ ). The problem of this inefficiency can be partially offset by strategic investors with a non-binding $\mathrm{BC}$ (if this type is present at all), who due to their control interests and efforts to allocate all points prefer these less lucrative opportunities, which have however a negligible probability of overbidding ( $5 \mathrm{~b}$ in Table 1).

The second distortion might be caused by the lack of the auctioneer's ability to correctly assess the signals sent by investors. For example, weaker bidding for relatively overvalued but absolutely undervalued shares leads to a price decrease; this event can happen mainly if most of the investors bidding for the firms are price-sensitive investors with a binding $\mathrm{BC}$ whose bids were moderate and who after a price decrease further increased their share demand (see situation $2 b$ or $7 b$ in Table 1). The consequences are similar. Diversification is replaced by stronger bidding on firm $i$, (unless the firm becomes strongly undervalued and the higher risk of overbidding decreases the bids ( $3 \mathrm{~b}$ or $8 \mathrm{~b})$ ), prices go further from the equilibrium and the wealth distribution is not efficient.

The third source of distortions comes from the presence of strategic investors. They tend to bid for firms that are less attractive for portfolio investors and for firms that they could get cheaper, being less sensitive to potential overpricing. As we write above, the type of investors and their price sensitivity determined the price change for the next round. If predominantly strategic investors bid for a particular firm that was overpriced but still stood well in a range of investors' investment opportunities and the auctioneer considered the interest of strategic investors as a signal that the shares were undervalued and increased the price, the investors decreased the demand (see $4 \mathrm{~b}$ and $5 \mathrm{~b}$ in Table 1). In this case the auctioneer might have been forced to move prices back down, which took place during Czech voucher privatization. This shortage might not be observed if the control interests 
were, due to some particular characteristics of the firm or its low price, very high (situation 6).

In addition to the previous point, low share demand does not give any precise guidelines how much the price should be adjusted downwards. As argued in Section 3, the low share demand might be caused simply by a lack of investor's resources and the nonnegativity constraint $s d_{j i r} \geq 0$ need not be binding. On the other hand, when the shares were perceived as strongly overvalued, $s d_{j i r}$ was null only due to the non-negativity constraint. Due to difficulties with distinguishing, pricing mistakes can occur. Consequently, a similar price adjustment of these two types of shares could cause an increase in the demand in the former case but no significant change in the latter case.

Our analysis supports the essence of Kraizberg's argument (1999), that price setting might cause distorting effects on the valuation of the resources in the economy. The lack of knowledge about the perceived values of firms could cause a bias in share pricing. As a result, in the case when investors with control interests held a significant proportion of the voucher points, many firms could have been sold at prices that were far from their fair market values.

The investor effect is more difficult to assess. For investors with a binding $\mathrm{BC}$ it generally has an ambiguous effect on the relevant term, i.e. there are more forces at play that determine the overall effect. For investors with a non-binding $\mathrm{BC}$, the investor effect has the opposite effect on the share demand than the price variable. ${ }^{36}$ It compensates too risky, very high or very low share demand determined by the prices and the price elasticity.

\section{Discussion of the results}

The insights of the model provide the basis for reflecting on investors according to their bidding strategies and identifying some shortcomings of the voucher privatization.

The analysis for both groups of investors shows that the bidding rules for the two categories vary and the impact of the analyzed variables on the share demand should also be different If both types of investors with a non-binding $\mathrm{BC}$ have the same perception of a firm's misvaluation, the difference is determined by the value of the parameter $c_{i r}$; also, the stronger the control interests of strategic investors, the lower the price sensitivity.

The situation is more interesting for investors with a binding BC. Strategic investors tend to be less price-sensitive, but their investor effect is lower and one cannot identify if the

\footnotetext{
${ }^{36}$ The reason is that the price affects the shadow price of the $\mathrm{LC}$, which is a component of the investor effect with a negative impact on share demand.
} 
share demand of strategic investors is higher compared to portfolio investors as one might expect. The economic intuition of this result is that strategic investors, in spite of their control interests, are careful about allocating their points. They are more afraid of overbidding, which would excessively increase the prices of the desired shares. Therefore they build higher blocks of shares gradually.

This analysis shows that if all types of investors are interested in the same firm and have the same perception of share misvaluation, the least price-elastic are strategic investors with a non-binding $\mathrm{BC}$ and the most price-elastic are portfolio investors with a binding $\mathrm{BC}$. The groups in between are determined by the extent of the control interest of strategic investors with a non-binding BC.

These results lead to the conclusion that strategic investors do not follow the same strategies as portfolio investors and do not have a tendency to compete with portfolio investors for the same shares. Generally, the interest of a skilled strategic investor is focused on cheaper firms in which it has a control interest while their relative undervaluation is only a secondary factor.

Ownership concentration was constrained by legally imposed limits. Coffee (1996) argued that the limit of ownership concentration was not indispensable. Our model supports his argument. The model demonstrates that fear of overbidding prevents very high bids in undervalued firms. Therefore no or a higher legal limit would enable those investors who value them to receive higher stakes, more in line with the efficient equilibrium derived by Katz and Owen (1997).

One could raise the argument that enforcing the limit was also supposed to induce diversification, which would help the auctioneer adjust prices correctly. However, this statement also requires further qualification. First, as the prices were set according to the ratio of demand and supply in the previous round, the firms with a low or zero degree of interest might have been unreasonably undervalued (Tríska, 2002). Second, we showed in the previous part that the presence of different investor types leads on one hand to differences between the final voucher price and what the fair market price would be and on the other hand to strategic investors absorbing the firms perceived by portfolio investors as overvalued given their bad governance and low expected liquidity. Therefore, the firms with the lowest demand in every round were those with negligible value for investors and the voucher privatization was not very suitable for improving their performance. 
Filer and Hanousek (2001) objected that the price was set below the reservation price at a supposed true equilibrium value. Besides, selection bias caused the best firms to be sold at a share price lower than the reservation price of the most interested investors. Therefore the mechanism resembled a Walras tatonnement process instead of a continuous clearing of supply and demand, which would (i) enable the most interested investors with the highest reservation price to get their desired firms, discouraging other investors by their constant bidding, and (ii) bring the prices of the most demanded firms closer to their expected market values. However, it is a subject for future research, if these expectations are realistic and if more efficient price-adjustment is not accompanied by a less favorable outcome.

The theoretical framework also partially explains the empirical result that medium firms often performed better in the post-privatization period compared to their bigger counterparts (Egerer, 1996). As the optimal bidding was influenced implicitly by the size of the investor (which co-determined its shadow price of wealth), the IPFs with control ambitions $\left(c_{j i r}>1\right)$ were less interested in the shares of bigger firms due to the large resources necessary to obtain a higher stake. The bigger firms were, on the other hand, more attractive for big investors, who diversified among all sizes of enterprises (Egerer, 1996). The big investment companies were not necessarily the most skilled, as Katz and Owen (1997; 2002) argued, and this resulted in the big firms being not as successful as medium firms in the hands of smaller and better skilled investment companies.

\section{Conclusions}

Voucher privatization in the Czech Republic provided a natural experiment of the ability of investors to construct their portfolio under conditions of asymmetric information and the absence of stock market prices. Our main aim was to provide a theoretical model explaining the portfolio choice made by investors maximizing their expected return.

The model is consistent with previous attempts to theoretically capture the bidding process and justifies the earlier empirical findings. The perception of share misvaluation and private information are revealed through the parameters, which help to determine the bidding rules for portfolio investors and investors with an interest in firm management. The prices of selected firms together with the overall price level of the portfolio and the firm size are the main factors of the share demand. Firm characteristics are incorporated in the investors' parameters and consequently into prices. The main result is that if investors followed a longer-term strategy of expected return maximization and if their information on the firms' 
future market values were correct, the investors who valued the firm the most received a higher stake.

The model also illustrates the harmful consequences of price adjustment based purely on the ratio of demand and supply and subject to the number of available shares and points. Whereas adjustments done in the correct direction and magnitude play an important role in assigning shares to those who value them higher and partially eliminates overbidding, when the auctioneer is not aware of the objective functions of investors and of the extent of share mispricing, price adjustment brings additional distortions to the process.

The future performance of firms could have been further improved by lifting the LC. This would enable strategic investors to get the firm control necessary for restructuring firms that were not suitable for portfolio investments. For portfolio investors and for most of the strategic investors with a binding BC, lifting the LC did not bring any considerable changes in their investment decisions, therefore the suspicions that unlimited stakes in firms can lead to an excessive concentration of power with harmful effects on firm governance are not justified.

From a longer-term perspective, the exact design of the voucher privatization is not the only crucial factor for firm development and its influence should not be exaggerated. However, well-organized voucher privatization can help to much faster overcome the challenges of the transition process because firms are on the right track from the beginning.

One can therefore conclude that, first, strategic investors who want to take care of firms should be attracted by dropping the legal limits on their stakes and by having higher proportions of firms' shares intended for privatization, and second, big investors can positively contribute to the development of institutional investing only when medium and bigger firms with better prospects and transparent ownership, where investors can count on their liquidity, prevail among privatized firms. 


\section{Bibliography:}

Aggarwal, R. and J.T. Harper, 2000, "Equity Valuation in the Czech Voucher Privatization Auctions", Financial Management, Vol. 29 (4), pp. 77-100.

Anderson, R., 1994, "Voucher Funds in Transitional Economies: The Czech and Slovak Experience", Policy Research Working Paper, No. 1324, The World Bank, Washington DC.

Ausubel, L. and P. Milgrom, 2002, "Ascending Auctions with Package Bidding”, Frontiers of Theoretical Economics, Vol. 1 (1).

Banks, J.S., Ledyard J.O. and D. Porter, 1989, "Allocating Uncertain and Unresponsive Resources: An Experimental Approach", RAND Journal of Economics, Vol. 20 (1), pp. $1-25$.

Bennett, J., Estrin S., Maw J.W. and G. Urga, 2004, "Privatization Methods and Economic Growth in Transition Economies", CEPR Discussion Paper, No. 4291, pp. 25.

Boycko, M., Shleifer A. and R.W. Vishny, 1994, "Voucher Privatization", Journal of Financial Economics, Vol. 35, pp. 249-266.

Boycko, M., Shleifer A. and R.W. Vishny, 1996, "A Theory of Privatization”, Economic Journal, Vol. 106, pp. 309-319.

Brada, J.C., 1992, "The Mechanics of the Voucher Plan in Czechoslovakia", RFE/RL Research Report, I, pp. 42-45.

Brzica, D., 1996, "Investment Funds and Voucher Privatization: Political and Economic Aspects", Working Papers Series on Transition from State Socialism, No. 96 (1), Cornell University.

Bykowski, M.M., Cull R. J. and J.O Ledyard, 1995, "Mutually Destructive Bidding: The FCC Auction Design Problem", Social science working paper, 916, California Institute of Technology, Ohio State University.

Carlin, W. and C. Mayer, 1992, "Restructuring Enterprises in Eastern Europe", Economic Policy, Vol. 15, pp. 311-346.

Clarke, E.H., 1971, “Multipart Pricing of Public Goods”, Public Choice, Vol. 11, pp. 17-33.

Coffee, J., 1996, "Institutional Investors in Transitional Economies: Lessons from the Czech Experience", in Frydman, R., C.W. Gray and A. Rapaczynski (eds.), Corporate Governance in Central Europe and Russia, CEU Press.

De Vries, S. and R.V. Vohra, 2003, "Combinatorial Auctions: A Survey", INFORMS Journal of Computation, Vol. 15 (3), pp. 284-309. 
Egerer, R., 1996, "The Influence of Privatization Strategies and Corporate Governance Options on the Development of Capital Markets in Central and Eastern Europe", Ph.D. Dissertation, No. 1806, University of St. Gallen.

Elmaghraby, W. and P. Keskinocak, 2003, "Technology for Transportation Biding at the Home Depot", in C Billingtom, T. Harrison, H. Lee and J. Neale (eds.), The Practice of Supply Chain Management: Where Theory and Applications Converge, Kluwer.

FCC, 2000, The Federal Communication Commission public notice DA00-1486, http://wireless.fcc.gov/auctions/31/releases/da001486.pdf.

Filer, R.K. and J. Hanousek, 2001, "Informational Content of Prices Set Using Excess Demand: The Natural Experiment of Czech Voucher Privatization", European Economic Review, Vol. 45, pp. 1619-1646.

Groves, T., 1973, “Incentives in Teams”, Econometrica, Vol. 41, pp. 617-631.

Harstad, R.M. and M.H. Rothkopf, 1995, “Combinatorial Auctions with Synergies”, Working Paper, RUTCOR, Rutgers University, New Brunswick, NJ.

Harstad, R.M. and M.H. Rothkopf, 2000, “An 'Alternating Recognition' Model of English Auctions", Management Science, Vol. 46, pp. 1-12.

Hillon, P. and S. D. Young, 1996, “The Czechoslovak Privatization Auction: An Empirical Investigation”, INSEAD Working Paper 96/57/FIN/AC, Paris.

Hingorani, A., Lehn K. and A.K. Makhija, 1997, "Investor Behavior in Mass Privatization: The case of the Czech Voucher Scheme", Journal of Financial Economics, Vol. 44, pp. 349-396.

Hohner, G., Rich J., Ng E., Reid G., Davenport A.J., Kalagnanam J.R., Lee H.S. and C. An, 2003, "Combinatorial and Quality-Discount Procurement Auctions with Mutual Benefits at Mars", Inc, Interfaces, Vol. 33 (1), pp. 23-35.

Hyclak, T.J and A. E., King, 1993, "The Privatization Experience in Eastern Europe" in Mejstř́k (chair), New Investment Opportunities in Eastern Europe and Latin America: The Impact of Liberalization, Privatization and Integration, Proceedings from the meeting of the Lehigh University, Bethlehem.

Katz, B.G. and J. Owen, 1997, "Optimal Voucher Privatization Fund Bids When Bidding Affects Firm Performance”, Journal of Comparative Economics, Vol. 24, pp. 25-43.

Katz, B.G. and J. Owen, 2002, "Voucher Privatization: A Detour on the Road to Transition", Economics of Transitions, Vol. 10 (3), pp. 553-583.

Koleva, P. and C. Vincensini, 2002, "The Evolution Trajectories of Voucher Funds: Towards Western-type Institutional Investors? The Case of the Czech Republic and Bulgaria", Economics of Planning, Vol. 59, pp. 79-105. 
Kraizberg, E., 1999, “The Voucher Privatization Process as a Price Discovery Mechanism”, European Finance Review, Vol. 3, pp. 175-203.

Krčmář, M., 1992, "Voucher Privatization", 10 $0^{\text {th }}$ CERGE Lecture on Practical Aspects of Privatization, CERGE, Charles University, Prague.

Krishna, K. and T. Tranaes, 2002, “Allocating Multiple Units”, Economic Theory, Vol. 20, pp. $733-750$

Kydland, F., 1977, "Equilibrium Solutions in Dynamic Dominant-Player Models", Journal of Economic Theory, Vol. 15, pp. 307-324.

Ma, C.-Y., 1994, "Bidders' Behavior and Strategy in the Czechoslovak Voucher Privatization Scheme", Ph.D. Dissertation, Lehigh University.

Marcinčin, A., and Shemetilo, 1995, "Performance of the Shares in the Investment Funds Portfolios and their Strategies", CERGE Working Paper, No. 83.

Maskin, E.S., 2000, "Auctions, Development and Privatization: Efficient Auctions with Liquidity-Constrained Buyers”, European Economic Review, Vol. 44, pp. 667-681.

Mejstř́k, M., 1994, "Czech Investment Funds as a Part of Financial Sector and Their Role in Privatization of the Economy", Reform Round Table Working, Paper No. 14, Charles University, Prague.

Mejstř́k, M., Marcinčin A. and R. Lastovička, 1997, "Voucher Privatization, Ownership Structures and Emerging Capital Market in the Czech Republic", in Mejstřík, Michal (ed.), The Privatization Process in East-Central Europe: Evolutionary Process of Czech Privatization, Kluwer Academic Publishers.

Milgrom, P.R. and R.B. Wilson, 1993, "Affidavit of Paul R. Milgrom and Robert B. Wilson before the Federal Communications Commission", Docket No. 93-253, November 8.

Nissan, N. and I. Segal, 2002, "The Communication Complexity of Efficient Allocation Problems", Working paper, Hebrew University, Jerusalem, Israel and Stanford University, Stanford, CA.

Otradovec, M., 1995a, "PPF a.s. (The First Private Investment Fund)”, WDI Working. Paper, No. 18, William Davidson Institute.

Otradovec, M., 1995b, "YSE Funds: A Story of Czech Investment Funds", WDI Working Paper, No. 20, William Davidson Institute.

Park, S. and M.H. Rothkopf, 2001, "Auctions with Endogenously Determined Allowable Combinations", RUTCOR Research Report, 3-2001, Rutgers University, New Brunswick, NJ.

Parkes, D.C., 2001, "Iterative Combinatorial Auctions: Achieving Economic and Computational Efficiency", Ph.D. Dissertation, Computer and Information Science, University of Pennsylvania, Philadelphia, PA. 
Pekeč, A. and M.H. Rothkopf, 2003, "Combinatorial Auction Design”, Management Science, Vol. 49, No. 11, November 2003, pp. 1485-1503.

Prescott, E.C., 1973, "Market Structure and Monopoly Profits: A Dynamic Theory", Journal of Economic Theory, Vol. 6, pp. 546-557.

Rassenti, S. J., V.L. Smith and R. L. Bulfin, 1982, “A Combinatorial Auction Mechanism for Airport Time Slot Allocation”, Bell Journal of Economics, Vol. 13, pp. 402-417.

Rees, R., 1988, "Inefficiency, Public Enterprise and Privatization", European Economic Review, Vol. 32, pp. 422-431.

Robinson, M.S., 1985, "Collusion and the Choice of Auction", Rand Journal of Economics, Vol. 16, pp. 141-145.

Rothkopf, M.H., Teisberg T.J. and E.P., Kahn, 1990, "Why are Vickrey Auctions Rare?", Journal of Political Economy, Vol. 98, No. 1, pp. 94-109.

Rothkopf, M.H, Pekeč A. and R. M. Harstad, 1998, "Computationally Manageable Combinational Auctions”, Management Science, Vol. 44, pp. 1131-1147.

Švejnar, J., 1993, "The Past and the Present of Czechoslovak Privatization", The 13th CERGE Lecture on Practical Aspects of Privatization, 26 p., January 1993.

Švejnar, J. and M. Singer, 1994, "Using Vouchers to Privatize Economy: The Czech and Slovak Case", Economics of Transition, Vol. 2 (1), pp. 43-69.

Takla, L., 1994, "The Relationship Between Privatization and the Reform of the Banking Sector: The Czech Republic and Slovakia”, London Business School Discussion Paper Series, No. 7, London Business School.

Tř́ska, D., 2002, Voucher Privatization, Workshop Proceedings no. 13/2002, Center for Economics and Politics, Prague.

Vickrey, W., 1961, "Counterspeculation, Auctions and Competitive Sealed Tenders", Journal of Finance, Vol. 16, pp. 8-37.

Vinogradov, V., 1999, "Cook-Book of Mathematics", CERGE-EI Lecture Notes No. 1, CERGE-EI, Prague.

von Stackelberg H., 1952, The Theory of Market Economy, Oxford University Press.

Wendelová P. and V. Bukáč, 1993, "Investment Privatization Funds as New Owners of Privatized Enterprises", Paper presented at the 15. CERGE Lecture on Practical Aspects of Privatization, Prague.

Yokoo M., Sakurai Y. and S. Matsubara, 2004, "The Effect of False-Name Bids in Combinatorial Auctions: New Fraud in Internet Auctions", Games and Economic Behavior, Vol. 46, No. 1, pp. 174-188. 


\section{Appendix:}

\section{Proofs and omitted calculations from Sections 3 and 4}

Solving the KT problem (7a)-(7c):

Simplifying the problem and solving it only for one representative demand $s d_{i r}$ of investor $j$, keeping in mind that similar calculations can be performed for all $\{i, r\}$, the problem shrinks to one FOC and two original constraints (5b) and (5c). We can distinguish four possible situations, $\left\{\lambda_{1 r}, \lambda_{2 i r}\right\}$.

$\lambda_{1 r}=0$ and $\lambda_{2 i r}=0$, since the objective function is strictly increasing in each variable. At least one constraint, other than the non-negativity constraint, must be binding. It can be shown by solving the KT conditions: $\frac{\partial L_{j}}{\partial s d_{i r}}=\mu_{i r} s d_{i r}^{\mu_{i r}-1} p_{i r}^{c_{i r}} v_{i r}-1 \leq 0, \quad s d_{i r} \geq 0 \quad$ and $\quad s d_{j i r}\left(\mu_{i r} s d_{i r}^{\mu_{i r}-1} p_{i r}^{c_{i r} / v_{i r}-1}\right)=0 \quad$ hold simultaneously if and only if $s d_{i r}=0$. As the zero vector cannot be a solution, this case is not possible and we are not going to analyze it further.

$\lambda_{1 r}=0$ and $\lambda_{2 i r} \neq 0$, i.e. the legal constraint is binding. For the budget constraint, this does not need to hold.

$$
\frac{\partial L_{j}}{\partial s d_{i r}}=\mu_{i r} s d_{i r}^{\mu_{i r}-1} p_{i r}^{c_{i r} / v_{i r}-1}-\lambda_{2 i r} / S_{i}=0 \Rightarrow \lambda_{2 i r}=\mu_{i r} s d_{i r}^{\mu_{i r}-1} p_{i r}^{c_{i r} / v_{i r}-1} \cdot S_{i} .
$$

If the second constraint is binding,

$$
\begin{aligned}
& I(r) \sum_{t=1}^{r-1} s a_{i t}+s d_{i r}=l . S_{i} \Rightarrow s d_{i r}=l S_{i}-I(r) \sum_{t=1}^{r-1} s a_{i t}, \text { the solution can be specified as } \\
& \left\{\lambda_{1 r}=0 ; \lambda_{2 i r}=\mu_{i r}\left(l S_{i}-I(r) \sum_{i=1}^{r-1} s a_{i t}\right)^{\mu_{i r}-1} p_{i r}^{c_{i r} / v_{i r}-1} . S_{i} ; s d_{i r}=l S_{i}-I(r) \sum_{i=1}^{r-1} s a_{j i t}\right\} .
\end{aligned}
$$

$\lambda_{1 r} \neq 0$ and $\lambda_{2 i r}=0$, i.e. the budget constraint is binding, for the legal constraint this does not need to hold.

$$
\frac{\partial L_{j}}{\partial s d_{i r}}=\mu_{i r} s d_{i r}^{\mu_{i r}-1} p_{i r}^{c_{i r} / v_{i r}-1}-\lambda_{1 r} p_{i r}=0 \Rightarrow \lambda_{1 r}=\mu_{i r} s d_{i r}^{\mu_{i r}-1} p_{i r}^{c_{i r} / v_{i r}-2} .
$$

If the budget constraint is binding, i.e.

$s d_{i r}=\left(B-I(r) \sum_{i=1}^{N} \sum_{t=1}^{r-1} s a_{i t} \cdot p_{i t}-\sum_{k=1, k \neq i}^{N} s d_{k r} \cdot p_{k r}\right) / p_{i r}$ and the solutions can be 
specified as follows:

$$
\begin{aligned}
& \left\{\lambda_{1 r}=\mu_{i r}\left(\left(B-I(r) \sum_{i=1}^{N} \sum_{t=1}^{r-1} s a_{i t} \cdot p_{i t}-\sum_{k=1, k \neq i}^{N} s d_{k r} \cdot p_{k r}\right) / p_{i r}\right)^{\mu_{j i r}-1} p_{i r}^{c_{i r} / v_{i r}-2} ;\right. \\
& \left.\lambda_{2 i r}=0 ; s d_{j i r}=\left(B-I(r) \sum_{i=1}^{N} \sum_{t=1}^{r-1} s a_{i t} \cdot p_{i t}-\sum_{k=1, k \neq i}^{N} s d_{k r} \cdot p_{k r}\right) / p_{i r}\right\} .
\end{aligned}
$$

$\lambda_{1 r} \neq 0$ and $\lambda_{2 i r} \neq 0$, which implies that both constraints are binding.

$$
\frac{\partial L_{j}}{\partial s d_{i r}}=\mu_{i r} s d_{i r}^{\mu_{i r}-1} p_{i r}^{c_{i r} / v_{i r}-1}-\lambda_{1 r} p_{i r}-\lambda_{2 i r} / S_{i}=0 \text { and the binding budget and legal }
$$

constraints enables us to express $s d_{i r}$ as $s d_{i r}=l S_{i}-I(r) \sum_{t=1}^{r-1} s a_{i t}$.

In this case, we are not able to derive the precise values of the shadow prices $\lambda_{1 r}$ and $\lambda_{2 i r}$ and the problem will be subject to empirical testing.

\section{Checking the concavity of the objective function}

The twice differentiable function is concave if and only if its Hessian matrix is everywhere negative semidefinite (Vinogradov, 1999, p.39). Let us define the symmetric Hessian matrix $\mathrm{H}$ of the second partial derivatives

$$
H=\left(\begin{array}{ccc}
\frac{\partial^{2} f}{\partial x_{1} \partial x_{1}} & \cdots & \frac{\partial^{2} f}{\partial x_{1} \partial x_{N}} \\
\frac{\partial^{2} f}{\partial x_{N} \partial x_{1}} & \cdots & \frac{\partial^{2} f}{\partial x_{N} \partial x_{N}}
\end{array}\right)
$$

The sign definiteness of the second derivative of the function is equivalent to the sign definiteness of the quadratic form of the Hessian matrix evaluated, in general terms, at $x^{*}$. Now we can apply either the principal minors test or eigenvalue test. If the FOC are met,

$$
x^{*} \text { is }\left\{\begin{array}{ll}
\text { local } & \text { minimum } \\
\text { local } & \text { maximum }
\end{array}\right\} \text { if }\left\{\begin{array}{l}
f_{x_{i} x_{i}}^{\prime \prime}\left(x^{*}\right)>0, f_{x_{i} x_{i}}^{\prime \prime}\left(x^{*}\right) f_{x_{k} x_{k}}^{\prime \prime}\left(x^{*}\right)-\left(f_{x_{k} x_{k}}^{\prime \prime}\left(x^{*}\right)\right)^{2}>0 \\
f_{x_{i} x_{i}}^{\prime}\left(x^{*}\right)<0, f_{x_{i} x_{i}}^{\prime \prime}\left(x^{*}\right) f_{x_{k} x_{k}}^{\prime \prime}\left(x^{*}\right)-\left(f_{x_{k} x_{k}}^{\prime \prime}\left(x^{*}\right)\right)^{2}>0
\end{array}\right\} .
$$

If $f_{x_{i} x_{i}}^{\prime \prime}\left(x^{*}\right) f_{x_{k} x_{k}}^{\prime \prime}\left(x^{*}\right)-\left(f_{x_{k} x_{k}}^{\prime \prime}\left(x^{*}\right)\right)^{2}<0, i \neq k$, we identify a stationary point as the saddle point.

For our specific problem $f_{j r}\left(s d_{1}, s d_{2}, \ldots, s d_{N}\right): \frac{\partial^{2} f}{\partial s d_{i r} \partial s d_{i r}}=\mu_{i r}\left(\mu_{i r}-1\right) s d_{i r}^{\mu_{i r}-2} p_{i r}^{c_{i r} / v_{i r}-1}$,

and since $\mu_{i r} \in(0,1)$, the derivative is, for every $s d_{i r}>0$, where $i \in\{1, \ldots, N\}$ and $r \in\{1, \ldots, R\}$, negative. 
$\frac{\partial^{2} f}{\partial s d_{i r} \partial s d_{k r}}=0$, because the objective function is separable, which implies

$\frac{\partial^{2} f}{\partial s d_{i r} \partial s d_{i r}} \cdot \frac{\partial^{2} f}{\partial s d_{k r} \partial s d_{k r}}-\left(\frac{\partial^{2} f}{\partial s d_{i r} \partial s d_{k r}}\right)>0$ for all $i \in\{1, \ldots, N\}$ where $s d_{i r}>0$. This shows that the Hessian matrix is negative semidefinite, the objective function is concave and $s d_{i r}^{*}$ for all $i \in\{1, \ldots, N\}$ and $r \in\{1, \ldots, R\}$ at which $f_{s d_{i r}}^{\prime}\left(s d_{1 r}^{*}, \ldots, s d_{N R}^{*}\right)=0$ is a local maximum.

\section{Derivation of equation ( $8 c)$}

We start with the F.O.C. of (6) with respect to $s d_{i r}$,

$$
\frac{\partial L_{j r}}{\partial s d_{i r}}=\mu_{i r} s d_{i r}^{\mu_{i r}-1} p_{i r}^{c_{i r} / v_{i r}-1}-\lambda_{1 r} \cdot p_{i r}-\lambda_{2 i r} / S_{i}=0
$$

where $\mu_{i r}=1-2 /\left(1+\exp \left(v_{i r} / \bar{v}_{p r}\right)\right)$.

We put the last two terms on the RHS and multiplied all the equations by $1 /\left(\lambda_{1 r} \cdot p_{i r}\right)$, as in this situation $\lambda_{1 r} \neq 0$ and we also assume that with price $p_{i r}>0$, we can perform the given manipulation

$$
\frac{\mu_{i r}}{\lambda_{1 r} \cdot p_{i r}} S d_{i r}^{\mu_{i r}-1} p_{i r}^{c_{i r} / v_{i r}-1}=1+\lambda_{2 i r} / S_{i} \lambda_{1 r} \cdot p_{i r}
$$

and consequently the logarithmic transformation of (A.2),

$$
\ln \left(\frac{\mu_{i r}}{\lambda_{1 j r}}\right)+\left(\mu_{i r}-1\right) \ln s d_{i r}+\left(\frac{c_{i r}}{v_{i r}}-2\right) \ln p_{i r}=\ln \left(1+\frac{\lambda_{2 i r}}{S_{i} \lambda_{1 r} p_{i r}}\right) .
$$

The term $\lambda_{2 i r} / S_{i} \lambda_{1 r} p_{i r}$ on the RHS contains the price and number of firm $i$ 's shares in the denominator, and the marginal value of the legal limit in the numerator.

When the term $\lambda_{2 i r} / S_{i} \lambda_{1 r} p_{i r} \rightarrow 0$, which is the case in big firms with expensive shares, which are realistic assumptions for investors with binding budget and legal constraints), ${ }^{37}$ we can approximate the RHS of (A.3) in the following manner: $\log \left(1+\lambda_{2 i r} / S_{i} \lambda_{1 r} p_{i r}\right) \approx \lambda_{2 i r} / S_{i} \lambda_{1 r} p_{i r}$. Finally, we rearrange the terms in (A.3) to get the specification (8c).

$$
\ln s d_{i r}^{*}=\frac{1}{\mu_{i r}-1}\left[\frac{\lambda_{2 i r}}{\lambda_{1 r} S_{i} p_{i r}}-\ln \left(\frac{\mu_{i r}}{\lambda_{1 r}}\right)\right]-\frac{c_{i r} / v_{i r}-2}{\mu_{i r}-1} \ln p_{i r} .
$$

\footnotetext{
${ }^{37}$ Though, when $S_{i}$ and/or $p_{i r}$ increases, it also effects the values of $\lambda$, and either increasing $S_{i}$ or increasing $p_{i r}$ negatively effect $\lambda_{2 i r}$ and/or positively effect $\lambda_{1 r}$. Therefore the overall effect holds.
} 


\section{Proof of Proposition 1:}

We look first at investors with a non-binding budget constraint. The coefficient consists of two terms: $\left(1 / v_{j i r}-1\right)$ and $\left(1+\exp \left(v_{j i r} / \bar{v}_{j p r}\right) / 2\right.$. The latter term is always bigger than 0 , therefore the sign of the coefficient is determined by the former one. $\left(1 / v_{j i r}-1\right)<0$ if and only if $v_{j i r}>1$, i.e. when the shares of the selected firm $i$ are overvalued. In the opposite case, when the shares of firm $i$ are undervalued, the price impact is positive.

As a next step, we investigate the size of the elasticity. For the share demand to be elastic we need $\left(1 / v_{j i r}-1\right)\left(1+\exp \left(v_{j i r} / \bar{v}_{j p r}\right) / 2<-1\right.$, at $v_{j i r}>1$. Solving the first inequality we come to the expression $\exp \left(v_{j i r} / \bar{v}_{v p r}\right)>\left(v_{j i r}+1\right) /\left(v_{j i r}-1\right)$, as $\exp \left(v_{j i r} / \bar{v}_{v p r}\right) \in(1, \infty)$, and $\left(v_{j i r}+1\right) /\left(v_{j i r}-1\right)>1$ for all $v_{j i r}>1$, converging to 1 as $v_{j i r}$ grows, one can see that the elasticity is largely determined by $\bar{v}_{v p r}$, growing as $\bar{v}_{v p r}$ declines. The inequality holds with greater probability when $v_{j i r}$ increases.

For positive elasticity $\left(1 / v_{j i r}-1\right)\left(1+\exp \left(v_{j i r} / \bar{v}_{j p r}\right) / 2>1\right.$ at $v_{j i r}<1$, we solved the first inequality, and the positive price elasticity exceeds 1 when $\exp \left(v_{j i r} / \bar{v}_{v p r}\right)>\left(3 v_{j i r}-1\right) /\left(1-v_{j i r}\right)$. Again as $\exp \left(v_{j i r} / \bar{v}_{v p r}\right) \in(1, \infty)$, assuming that the misvaluation parameter lies in the domain $\left\{v_{j i r}, \bar{v}_{v p r}\right\} \in(0, \infty)$, the demand is with certainty positive price-elastic when $\left(3 v_{j i r}-1\right) /\left(1-v_{j i r}\right) \leq 1$, i.e. when $v_{j i r} \leq 0.5$. If $v_{j i r} \in(0.5,1)$, our specification does not allow us to determine price elasticity with certainty and the impact of $\bar{v}_{v p r}$ co-determines how strongly prices affect share demand.

The impact of $v_{j i r}$ on the coefficient can be computed by differentiation of the coefficient with respect to $v_{j i r}$,

$$
\begin{aligned}
& \partial\left[\left(1 / v_{j i r}-1\right)\left(1+\exp \left(v_{j i r} / \bar{v}_{j p r}\right)\right) / 2\right] / \partial v_{j i r}= \\
& -1 / 2 v_{j i r}^{2}-1 / 2 v_{j i r}^{2} \exp \left(v_{j i r} / \bar{v}_{j p r}\right)+\exp \left(v_{j i r} / \bar{v}_{j p r}\right) / 2 v_{j i r} \bar{v}_{j p r}-\exp \left(v_{j i r} / \bar{v}_{j p r}\right) / 2 \bar{v}_{j p r} .
\end{aligned}
$$

By algebraic operations, we can show that for $v_{j i r} \geq 1$ or for $v_{j i r} / \bar{v}_{j p r} \leq 1$, the price elasticity coefficient declines with $v_{j i r}$. (Remark: one can compare this analytical solution with the graphical presentation in Figure 1.)

We do the same differentiation with respect o $\bar{v}_{j p r}$ : $\partial\left[\left(1 / v_{j i r}-1\right)\left(1+\exp \left(v_{j i r} / \bar{v}_{j p r}\right)\right) / 2\right] / \partial \bar{v}_{j p r}=\left(v_{j i r} / \bar{v}_{j p r}^{2}\right) \exp \left(v_{j i r} / \bar{v}_{j p r}\right)\left(v_{j i r}-1\right)$, which indicates 
that the coefficient grows with $\bar{v}_{j p r}$ when $v_{j i r}>1$ and the price impact is negative and declines or when $v_{j i r}<1$ and the price impact is positive. When $v_{j i r}=1$, the price impact on the share demand is 0 .

Now we proceed with the same analysis for investors with a binding budget constraint. The price coefficient consists of two terms: $\left(1 / v_{j i r}-2\right)$ and $\left(1+\exp \left(v_{j i r} / \bar{v}_{j p r}\right) / 2\right.$. The latter term is always bigger than 0 , therefore the sign of the coefficient is determined by the former one. $\left(1 / v_{j i r}-2\right)<0$ if and only if $v_{j i r}>0.5$, which is lower compared to investors with a non-binding BC. When $v_{j i r}<0.5$, the price impact is positive. When $v_{j i r}=0.5$, the elasticity of share demand to prices is 0 .

As a next step, we investigate the size of the elasticity. For the share demand to be elastic we need $\left(1 / v_{j i r}-2\right)\left(1+\exp \left(v_{j i r} / \bar{v}_{j p r}\right) / 2<-1\right.$ at $v_{j i r}>0.5$. Modifying the first inequality we get $\exp \left(v_{j i r} / \bar{v}_{v p r}\right)>1 /\left(2 v_{j i r}-1\right)$. As $\exp \left(v_{j i r} / \bar{v}_{v p r}\right) \in(1, \infty)$, in the domain where $1 /\left(2 v_{j i r}-1\right) \leq 1 \Rightarrow v_{j i r} \geq 1$, the share demand is always price-elastic for firms $i \in(1, \ldots, N)$ for which $v_{j i r} \geq 1$ holds. In the interval $v_{j i r} \in(0.5,1)$ the price elasticity is uncertain.

For positive elasticity we need $\left(1 / v_{j i r}-1\right)\left(1+\exp \left(v_{j i r} / \bar{v}_{j p r}\right) / 2>1\right.$ at $v_{j i r}<0.5$. Rearranging the terms, the positive price elasticity exceeds 1 when $\exp \left(v_{j i r} / \bar{v}_{v p r}\right)>\left(4 v_{j i r}-1\right) /\left(1-2 v_{j i r}\right)$. Again as $\exp \left(v_{j i r} / \bar{v}_{v p r}\right) \in(1, \infty)$, assuming that the misvaluation parameters lie in the domain $\left\{v_{j i r}, \bar{v}_{v p r}\right\} \in(0, \infty)$, the demand is positively priceelastic when $\left(4 v_{j i r}-1\right) /\left(1-2 v_{j i r}\right) \leq 1$, i.e. when $v_{j i r} \leq 0.3$. If $v_{j i r} \in(0.3,0.5)$, our specification does not allow us to determine price elasticity with certainty and the impact of $\bar{v}_{v p r}$ codetermines how strongly the prices affect the share demand.

The impact of $v_{j i r}$ on the coefficient can be computed by the differentiation of the coefficient with respect to $v_{j i r}$,

$$
\begin{aligned}
& \partial\left[\left(1 / v_{j i r}-2\right)\left(1+\exp \left(v_{j i r} / \bar{v}_{j p r}\right)\right) / 2\right] / \partial v_{j i r}= \\
& -1 / 2 v_{j i r}^{2}-1 / 2 v_{j i r}^{2} \exp \left(v_{j i r} / \bar{v}_{j p r}\right)+\exp \left(v_{j i r} / \bar{v}_{j p r}\right) / 2 v_{j i r} \bar{v}_{j p r}-\exp \left(v_{j i r} / \bar{v}_{j p r}\right) / \bar{v}_{j p r} .
\end{aligned}
$$

By algebraic operations, we can show that for $v_{j i r} \geq 1$ or for $v_{j i r} / \bar{v}_{j p r} \leq 1$, the price elasticity coefficient declines with $v_{j i r}$. 
To make the numerical solution more precise, we solved it graphically and as we can see in Figure 2, for a plausible range of values $v_{j i r}$ and $\bar{v}_{j p r}$, the price elasticity coefficient declines with $v_{j i r}$. (Remark: one can compare this analytical solution with the graphical presentation in Figure 2.)

We do the same differentiation with respect to $\bar{v}_{j p r}$ : $\partial\left[\left(1 / v_{j i r}-2\right)\left(1+\exp \left(v_{j i r} / \bar{v}_{j p r}\right)\right) / 2\right] / \partial \bar{v}_{j p r}=\left(1 / \bar{v}_{j p r}^{2}\right) \exp \left(v_{j i r} / \bar{v}_{j p r}\right)\left(v_{j i r}-0.5\right)$, which indicates that the coefficient grows with $\bar{v}_{j p r}$ when $v_{j i r}>0.5$ and the price impact is negative and declines when $v_{j i r}<0.5$ and the price impact is positive. When $v_{j i r}=0.5$, the price impact on the share demand is 0 .

\section{Proof of Proposition 2:}

The first part of the investor-specific effect $\left(1+\exp \left(v_{j i r} / \bar{v}_{j p r}\right)\right) / 2$ is always positive and affects only the magnitude of the effect. Its sign is therefore determined by the second part, which is $\left.\ln \mid\left(1-2 /\left(1+\exp \left(v_{j i r} / \bar{v}_{j p r}\right)\right)\right) / \lambda_{2 i r}\right\rfloor$ for investors with a non-binding BC and $\ln \left[\left(1-2 /\left(1+\exp \left(v_{j i r} / \bar{v}_{j p r}\right)\right)\right) / \lambda_{1 r}\right\rfloor$ for investors with a binding BC. We know that $\ln x<0$ if and only if $x<1$, which implies that if $x=a / b \Rightarrow a<b$.

Coming back to our problem, to achieve a positive impact we need $\left(1-2 /\left(1+\exp \left(v_{j i r} / \bar{v}_{j p r}\right)\right)\right)>\lambda_{2 i r} \Rightarrow \mu_{j i r}>\lambda_{2 i r}$ for investors with a non-binding budget constraint and correspondingly $\left(1-2 /\left(1+\exp \left(v_{j i r} / \bar{v}_{j p r}\right)\right)\right)>\lambda_{1 r} \Rightarrow \mu_{j i r}>\lambda_{1 r}$ for investors with a binding $\mathrm{BC}$.

To find out more precisely which factors affect the sign of the investor effect, we use the results of the KT conditions, where we derived $\lambda_{2 i r}$ and $\lambda_{1 r}$. For investors with a nonbinding $\mathrm{BC}$, the effect is positive if $\left|\mu_{j i r} / \lambda_{2 i r}\right|>1$, plugging in

$$
\begin{aligned}
& \lambda_{2 i r}=\mu_{i r}\left(l S_{i}-I(r) \sum_{t=1}^{r-1} s a_{i t}\right)^{\mu_{i r}-1} p_{i r}^{c_{i r} / v_{i r}-1} \cdot S_{i} \quad \text { and } \quad \mu_{i r}=1-2 /\left(1+\exp \left(v_{i r} / \bar{v}_{p r}\right)\right) \quad \text { implies } \\
& {\left[\mu_{i r} / \mu_{i r}\left(l S_{i}-I(r) \sum_{t=1}^{r-1} s a_{i t}\right)^{\mu_{i r}-1} p_{i r}^{1 / v_{i r}-1} \cdot S_{i}\right]>1}
\end{aligned}
$$


$\Rightarrow\left[\left(l S_{i}-I(r) \sum_{t=1}^{r-1} s a_{i t}\right)^{1-\mu_{i r}} / p_{i r}^{1 / v_{i r}-1} \cdot S_{i}\right]>1$, where $1-\mu_{i r} \in(0,1)$. The inequality shows that the fraction grows with the LC $l$ and firm $i$ 's relative share undervaluation, and declines with $I(r) \sum_{t=1}^{r-1} s a_{i t}$, the shares of firm $i$ received in previous rounds. The impact of firm price and firm size are ambiguous: (i) when $v_{j i r}>1$, the coefficient grows with firm $i$ 's voucher price, (ii) when $v_{j i r}<1$, the coefficient declines with firm $i$ 's voucher price and (iii) when $v_{j i r}=1$, the price has no effect on the coefficient. Regarding firm size, the investor specific effect grows with firm size if and only if $\left.1-\mu_{j i r}>l-I(r) \sum_{t=1}^{r-1} s a_{i t}\right) / S_{i}$, and the probability of this event decreases with $\mu_{j i r}$ and $l$.

For investors with a binding BC, the effect is positive if $\left\lfloor\mu_{j i r} / \lambda_{1 r}\right\rfloor>1$, plugging in $\lambda_{1 r}=\mu_{i r}\left(\left(B-I(r) \sum_{i=1}^{N} \sum_{i=1}^{r-1} s a_{i t} \cdot p_{i t}-\sum_{k=1, k \neq i}^{N} s d_{k r} \cdot p_{k r}\right) / p_{i r}\right)^{\mu_{j i r}-1} p_{i r}^{c_{i r} / v_{i r}-2}$ and $\mu_{i r}=1-2 /\left(1+\exp \left(v_{i r} / \bar{v}_{p r}\right)\right)$ implies $\left[\mu_{i r} / \mu_{i r}\left(\left(B-I(r) \sum_{i=1}^{N} \sum_{t=1}^{r-1} s a_{i t} \cdot p_{i t}-\sum_{k=1, k \neq i}^{N} s d_{k r} \cdot p_{k r}\right) / p_{i r}\right)^{\mu_{j i r}-1} p_{i r}^{c_{i r} / v_{i r}-2}\right]>1$ $\Rightarrow\left[\left(\left(B-I(r) \sum_{i=1}^{N} \sum_{t=1}^{r-1} s a_{i t} \cdot p_{i t}-\sum_{k=1, k \neq i}^{N} s d_{k r} \cdot p_{k r}\right) / p_{i r}\right)^{1-\mu_{i r}} p_{i r}^{1 / v_{i r}-2}\right]>1, \quad$ where $1-\mu_{i r} \in(0,1)$. The inequality shows that the fraction grows with $B$ and firm $i$ 's relative share undervaluation and declines with the points spent on shares in previous rounds. The impact of the price is ambiguous: (i) when $v_{j i r}>0.5$, the impact is ambiguous and (ii) when $v_{j i r} \leq 0.5$, the coefficient declines with firm $i$ 's voucher price.

\section{Derivation of $(13 b)$ :}

Starting with (8c),

$\ln s d_{i r}^{*}=\frac{1+\exp \left(v_{i r} / \bar{v}_{p r}\right)}{2}\left[\ln \left(\frac{\mu_{i r}}{\lambda_{1 r}}\right)-\frac{\lambda_{2 i r}}{\lambda_{1 r} S_{i} p_{i r}}\right]+\frac{1+\exp \left(v_{i r} / \bar{v}_{p r}\right)}{2}\left(\frac{c_{i r}}{v_{i r}}-2\right) \ln p_{i r}, \quad$ we $\quad$ can calculate the price elasticity. However, since we have the price in our equation twice and only once in $\log$ form, we have to express $\lambda_{2 i r} / \lambda_{1 r} S_{i} p_{i r}=\exp \left(\ln \left(1 / S_{i} p_{i r}\right)\right)=\exp \left(-\ln \left(S_{i} p_{i r}\right)\right)=\exp \left(\ln \lambda_{2 i r}-\ln \lambda_{1 r}-\ln p_{i r}-\ln S_{i}\right)$ 


$$
\begin{aligned}
& \frac{\partial \ln s d_{j i r}}{\partial \ln p_{i r}}=\left(\frac{1+\exp \left(v_{j i r} / \bar{v}_{j p r}\right)}{2}\right)\left(\frac{c_{j i r}}{v_{j i r}}-2\right)-\left(\frac{1+\exp \left(v_{j i r} / \bar{v}_{j p r}\right)}{2}\right) \exp \left(\ln \lambda_{2 i r}-\ln \lambda_{1 r}-\ln p_{i r}-\ln S_{i}\right) \\
& (-1)=\left(\frac{1+\exp \left(v_{j i r} / \bar{v}_{j p r}\right)}{2}\right)\left(\frac{c_{j i r}}{v_{j i r}}-2+\frac{\lambda_{2 i r}}{\lambda_{1 r} S_{i} p_{i r}}\right) .
\end{aligned}
$$

\section{Proof of Proposition 3:}

We look first at investors with a non-binding BC. The coefficient consists of two terms: $\left(c_{j i r} / v_{j i r}-1\right)$ and $\left(1+\exp \left(v_{j i r} / \bar{v}_{j p r}\right) / 2\right.$, which differs from the portfolio investors only by the term $c_{j i r}$. $\left(1+\exp \left(v_{j i r} / \bar{v}_{j p r}\right) / 2\right.$ is always bigger than 0 , therefore the sign of the coefficient is determined by $\left(c_{j i r} / v_{j i r}-1\right)$. The coefficient is negative only if $\left(c_{j i r} / v_{j i r}-1\right)<0 \Rightarrow 1<c_{j i r}<v_{j i r}$, i.e. when the shares of the selected firm $i$ are overvalued and the misvaluation parameter exceeds the parameter of control interest.

As a next step, we investigate the size of the elasticity. For the share demand to be elastic we need $\left(c_{j i r} / v_{j i r}-1\right)\left(1+\exp \left(v_{j i r} / \bar{v}_{j p r}\right) / 2<-1\right.$ at $v_{j i r}>c_{j i r}>1$. Rearranging the terms we get $\exp \left(v_{j i r} / \bar{v}_{v p r}\right)>\left(v_{j i r}+c_{j i r}\right) /\left(v_{j i r}-c_{j i r}\right)$. Since $\exp \left(v_{j i r} / \bar{v}_{v p r}\right) \in(1, \infty)$, $\left(v_{j i r}+c_{j i r}\right) /\left(v_{j i r}-c_{j i r}\right)>1$ for all $v_{j i r}>c_{j i r}$, converging to 1 as $v_{j i r}$ increases. The price elasticity grows with $v_{j i r}$ and declines with $\bar{v}_{v p r}$ and $c_{j i r}$.

For positive elasticity $\left(c_{j i r} / v_{j i r}-1\right)\left(1+\exp \left(v_{j i r} / \bar{v}_{j p r}\right) / 2>1\right.$ at $v_{j i r}<c_{j i r}$, we proceed similarly. The coefficient exceeds 1 when $\exp \left(v_{j i r} / \bar{v}_{v p r}\right)>\left(3 v_{j i r}-c_{j i r}\right) /\left(c_{j i r}-v_{j i r}\right)$. Since $\exp \left(v_{j i r} / \bar{v}_{v p r}\right) \in(1, \infty)$, assuming that the misvaluation parameters lie in the domain $\left\{v_{j i r}, \bar{v}_{v p r}\right\} \in(0, \infty)$, the demand is with certainty positive price-elastic, when $\left(3 v_{j i r}-1\right) /\left(1-v_{j i r}\right) \leq 1$, i.e. when $v_{j i r} \leq 0.5 c_{j i r}$. If $v_{j i r} \in\left(0.5 c_{j i r}, c_{j i r}\right)$, our specification does not allow us to determine price elasticity with certainty and the impact of $\bar{v}_{v p r}$ co-determines how strongly prices affect share demand.

The impact of $v_{j i r}$ on the coefficient can be found by the differentiation of the coefficient with respect to $v_{j i r}, \partial\left[\left(c_{j i r} / v_{j i r}-1\right)\left(1+\exp \left(v_{j i r} / \bar{v}_{j p r}\right)\right) / 2\right] / \partial v_{j i r}=$ $-c_{j i r} / 2 v_{j i r}^{2}-c_{j i r} / 2 v_{j i r}^{2} \exp \left(v_{j i r} / \bar{v}_{j p r}\right)+c_{j i r} \exp \left(v_{j i r} / \bar{v}_{j p r}\right) / 2 v_{j i r} \bar{v}_{j p r}-\exp \left(v_{j i r} / \bar{v}_{j p r}\right) / 2 \bar{v}_{j p r}$. Ву algebraic operations, we can show that unless $v_{j i r}<<1$ is very small and at the same time is 
relatively strongly overvalued, $v_{j i r} / \bar{v}_{j p r}>1$, the price elasticity coefficient declines with $v_{j i r}$. (Remark: one can compare the numerical solution with the graphical presentations in Figures 4-6.)

We do the same differentiation with respect to $\bar{v}_{j p r}$ : $\partial\left[\left(c_{j i r} / v_{j i r}-1\right)\left(1+\exp \left(v_{j i r} / \bar{v}_{j p r}\right)\right) / 2\right] / \partial \bar{v}_{j p r}=\left(1 / 2 \bar{v}_{j p r}^{2}\right) \exp \left(v_{j i r} / \bar{v}_{j p r}\right)\left(v_{j i r}-c_{j i r}\right), \quad$ which indicates that the coefficient grows with $\bar{v}_{j p r}$ when $v_{j i r}>c_{j i r}$ and the price impact is negative and declines when $v_{j i r}<c_{j i r}$ and the price impact is positive. When $v_{j i r}=c_{j i r}$, the price impact on share demand is 0 .

Now we proceed with the same analysis for strategic investors with a binding budget constraint. The price coefficient consists of two terms: $\left(c_{j i r} / v_{j i r}-2+\lambda_{2 i r} / \lambda_{1 r} S_{i} p_{i r}\right)$ and $\left(1+\exp \left(v_{j i r} / \bar{v}_{j p r}\right) / 2\right.$, which is always positive. $\left(c_{j i r} / v_{j i r}-2+\lambda_{2 i r} / \lambda_{1 r} S_{i} p_{i r}\right)<0$ if and only if $v_{j i r}>c_{j i r} /\left(2-\lambda_{2 i r} / \lambda_{1 r} S_{i} p_{i r}\right)$, which is lower for investors with a non-binding BC. In the opposite case, the price impact is positive. As a next step, we investigate the size of the elasticity. For share demand to be elastic we need $\left(c_{j i r} / v_{j i r}-2+\lambda_{2 i r} / \lambda_{1 r} S_{i} p_{i r}\right)\left(1+\exp \left(v_{j i r} / \bar{v}_{j p r}\right) / 2<-1 \quad\right.$ at $\quad v_{j i r}>c_{j i r} /\left(2-\lambda_{2 i r} / \lambda_{1 r} S_{i} p_{i r}\right)$. $\begin{array}{lllll}\text { Rearranging the terms tet } & \text { we }\end{array}$ $\exp \left(v_{j i r} / \bar{v}_{v p r}\right)>\left(c_{j i r} / v_{j i r}+\lambda_{2 i r} / \lambda_{1 r} S_{i} p_{i r}\right) /\left(2-c_{j i r} / v_{j i r}+\lambda_{2 i r} / \lambda_{1 r} S_{i} p_{i r}\right)>0$.

For sake of better illustration we assume that $\lambda_{2 i r} / \lambda_{1 r} S_{i} p_{i r} \approx 0$, which can be done mainly in the case of bigger and more expensive firms and investors with a limited endowment of voucher points as justified in derivation of $(8 \mathrm{c})$ in the Appendix . This allows us to simplify the RHS of the inequality $\left(c_{j i r} / v_{j i r}+\lambda_{2 i r} / \lambda_{1 r} S_{i} p_{i r}\right) /\left(2-c_{j i r} / v_{j i r}+\lambda_{2 i r} / \lambda_{1 r} S_{i} p_{i r}\right) \approx c_{j i r} /\left(2 v_{j i r}-c_{j i r}\right) . \quad$ Since $\exp \left(v_{j i r} / \bar{v}_{v p r}\right) \in(1, \infty)$, in the domain where $c_{j i r} /\left(2 v_{j i r}-c_{j i r}\right) \leq 1 \Rightarrow v_{j i r} \geq c_{j i r}$, the share demand is price-elastic for firm $i$, and in the interval $v_{j i r} \in\left(0.5 c_{j i r}, c_{j i r}\right)$ the price impact is negative but the price elasticity uncertain.

Positive price-elastic share demand requires $\left(1 / v_{j i r}-1\right)\left(1+\exp \left(v_{j i r} / \bar{v}_{j p r}\right) / 2>1\right.$ for $v_{j i r}>c_{j i r} /\left(2-1 / S_{i} p_{i r}\right), \quad$ which can be rearranged as $\exp \left(v_{j i r} / \bar{v}_{v p r}\right)>\left(4-c_{j i r} / v_{j i r}-\lambda_{2 i r} / \lambda_{1 r} S_{i} p_{i r}\right) /\left(c_{j i r} / v_{j i r}-2+\lambda_{2 i r} / \lambda_{1 r} S_{i} p_{i r}\right)$. Approximating $\lambda_{2 i r} / \lambda_{1 r} S_{i} p_{i r} \approx 0$, and keeping in mind that $\exp \left(v_{j i r} / \bar{v}_{v p r}\right) \in(1, \infty)$ for the misvaluation 
parameters $\left\{v_{j i r}, \bar{v}_{v p r}\right\} \in(0, \infty)$, the demand is positively price-elastic when $\left(4-c_{j i r} / v_{j i r}\right) /\left(c_{j i r} / v_{j i r}-2\right) \leq 1$, i.e. when $v_{j i r} \leq c_{j i r} / 3$. If $v_{j i r} \in\left(c_{j i r} / 3, c_{j i r} / 2\right)$, our specification does not allow us to determine price elasticity with certainty and the impact of $\bar{v}_{v p r}$ co-determines how strongly prices affect share demand.

The impact of $v_{j i r}$ on the coefficient can be found by the differentiation of the coefficient with respect to $v_{j i r}, \partial\left[\left(c_{j i r} / v_{j i r}-2+\lambda_{2 i r} / \lambda_{1 r} S_{i} p_{i r}\right)\left(1+\exp \left(v_{j i r} / \bar{v}_{j p r}\right)\right) / 2\right] / \partial v_{j i r}=$ $-c_{j i r} / 2 v_{j i r}^{2}-c_{j i r} / 2 v_{j i r}^{2} \exp \left(v_{j i r} / \bar{v}_{j p r}\right)+c_{j i r} \exp \left(v_{j i r} / \bar{v}_{j p r}\right) / 2 v_{j i r} \bar{v}_{j p r}-\exp \left(v_{j i r} / \bar{v}_{j p r}\right) / \bar{v}_{j p r}+$. $+\exp \left(v_{j i r} / \bar{v}_{j p r}\right) \lambda_{2 i r} / 2 \lambda_{1 r} S_{i} p_{i r} \bar{v}_{j p r}$. By algebraic operations, we can show that unless $v_{j i r} \rightarrow 0$ and at the same time $v_{j i r} / \bar{v}_{j p r}>1$, the investor has high control interest and the firm is very small and cheap, the price elasticity coefficient declines with $v_{j i r}$. (Remark: one can compare the numerical solution with the graphical representations in Figures 8-10.)

Then we proceed with differentiating the coefficient with respect to $\bar{v}_{j p r}$ : $\partial\left[\left(c_{j i r} / v_{j i r}-2+\lambda_{2 i r} / \lambda_{1 r} S_{i} p_{i r}\right)\left(1+\exp \left(v_{j i r} / \bar{v}_{j p r}\right)\right) / 2\right] / \partial \bar{v}_{j p r}=\left(1 / \bar{v}_{j p r}^{2}\right) \exp \left(v_{j i r} / \bar{v}_{j p r}\right)$ $\left\lfloor v_{j i r}-\left(c_{j i r} / 2+v_{j i r} \lambda_{2 i r} / 2 \lambda_{1 r} S_{i} p_{i r}\right)\right]$, which indicates that the coefficient grows with $\bar{v}_{j p r}$ when $v_{j i r}>c_{j i r} \lambda_{1 r} S_{i} p_{i r} /\left(2 \lambda_{1 r} S_{i} p_{i r}-\lambda_{2 i r}\right)$. For better illustration we replace $2 \lambda_{1 r} S_{i} p_{i r}-\lambda_{2 i r} \approx 2 \lambda_{1 r} S_{i} p_{i r}$, which can be justified by the same argument as above or in the Appendix, and leads to the conclusion that the coefficient grows when $v_{j i r}>0.5 c_{j i r}$ (the price impact is negative) and declines when $v_{j i r}<0.5 c_{j i r}$ (the price impact is positive).

\section{Proof of Proposition 4:}

Since $\left(1+\exp \left(v_{j i r} / \bar{v}_{j p r}\right)\right) / 2$ is always positive, the sign of the investor-specific effect is determined by $\ln \left[\left(1-2 /\left(1+\exp \left(v_{j i r} / \bar{v}_{j p r}\right)\right)\right) / \lambda_{2 i r}\right\rfloor$ for investors with a non-binding BC and $\ln \left[\left(1-2 /\left(1+\exp \left(v_{j i r} / \bar{v}_{j p r}\right)\right)\right) / \lambda_{1 r}\right\rfloor-\left(\lambda_{2 i r} / \lambda_{1 r} S_{i} p_{i r}\right)$ for investors with a binding BC. To find out more precisely which factors effect the investor effect, and how, we use the results of the KT conditions derived in the Appendix.

Investors with a non-binding budget constraint: To achieve a positive effect, $\ln \left(\mu_{j i r} / \lambda_{2 i r}\right)>0 \Rightarrow \mu_{j i r}>\lambda_{2 i r}$ $\Rightarrow\left(1-2 /\left(1+\exp \left(v_{j i r} / \bar{v}_{j p r}\right)\right)\right)>\lambda_{2 i r} \Rightarrow\left(1-2 /\left(1+\exp \left(v_{j i r} / \bar{v}_{j p r}\right)\right)\right) / \lambda_{2 i r}>1$. Plugging in $\lambda_{2 i r}$ 
and $\quad \mu_{i r} \quad \quad$ implies $\quad\left[\mu_{i r} / \mu_{i r}\left(l S_{i}-I(r) \sum_{i=1}^{r-1} s a_{i t}\right)^{\mu_{i r}-1} p_{i r}^{c_{j i r} / v_{i r}-1} \cdot S_{i}\right]>1$ $\Rightarrow\left[\left(l S_{i}-I(r) \sum_{t=1}^{r-1} s a_{i t}\right)^{1-\mu_{i r}} / p_{i r}^{1 / v_{i r}-1} \cdot S_{i}\right]>1$, where $1-\mu_{i r} \in(0,1)$. The inequality shows that the fraction grows with the legal constraint and firm $i$ 's relative share undervaluation, and declines with $I(r) \sum_{t=1}^{r-1} s a_{i t}$, the shares of firm $i$ received in previous rounds and firm size. The impact of the firm price and size are ambiguous: (i) when $v_{j i r}>1$, the coefficient grows with firm $i$ 's voucher price, (ii) when $v_{j i r}<1$, the coefficient declines with firm $i$ 's voucher price and (iii), when $v_{j i r}=1$, the price has no effect on the coefficient. Regarding firm size, the investor-specific effect grows with firm size if and only if $\left.1-\mu_{j i r}>l-I(r) \sum_{i=1}^{r-1} s a_{i t}\right) / S_{i}$, and the probability of this event decreases with $\mu_{j i r}$ and $l$.

Investors with a binding budget constraint: The investor effect is positive if $\ln \left(\mu_{j i r} / \lambda_{1 r}\right)-\lambda_{2 i r} / \lambda_{1 r} S_{i} p_{i r}>0 \Rightarrow \mu_{j i r}>\lambda_{1 r} \exp \left(\lambda_{2 i r} / \lambda_{1 r} S_{i} p_{i r}\right)$. For equation (8c) one cannot express explicitly $\lambda_{1 r}$ and $\lambda_{2 i r}$ as they are determined simultaneously, we restrict our analysis only to the impact of the shadow prices. The coefficient (20b) grows with the shadow price of the budget constraint $\lambda_{1 r}$ if $\partial\left(\ln \left(\mu_{j i r} / \lambda_{1 r}\right)-\lambda_{2 i r} / \lambda_{1 r} S_{i} p_{i r}\right) / \partial \lambda_{1 r}=-1 / \lambda_{1 r}+\lambda_{2 i r} / \lambda_{1 r}^{2} S_{i} p_{i r}>0 \Rightarrow \lambda_{2 i r} / S_{i} p_{i r}>\lambda_{1 r}$. When the derived inequality does not hold, i.e. when $\lambda_{2 i r} / S_{i} p_{i r}<\lambda_{1 r}$, the coefficient declines with $\lambda_{1 r}$. A similar analysis can be done for the shadow price of the legal constraint $\lambda_{2 i r}$ : $\partial\left(\ln \left(\mu_{j i r} / \lambda_{1 r}\right)-\lambda_{2 i r} / \lambda_{1 r}\right) / \partial \lambda_{2 i r}=-1 / \lambda_{1 r} S_{i} p_{i r}<0$; i.e. the term (20b) decreases with $\lambda_{2 i r}$.

\section{Proof of Proposition 5:}

Strategic investors with a non-binding BC: The investor effect expressed in (20a) shows potential reasons for the change in the outcome for strategic investors when the LC is lifted leading to $l=1$. Solving the KT problem in the Appendix provides $\lambda_{2 i r}=\mu_{i r}\left(l S_{i}-I(r) \sum_{t=1}^{r-1} s a_{i t}\right)^{\mu_{i r}-1} p_{i r}^{c_{i r} / v_{i r}-1} . S_{i}$, because $\mu_{i r}-1<0$ and $\partial \lambda_{2 i r} / \partial l<0$, i.e. for any investors with a non-binding $\mathrm{BC}$, an increase in $l$ causes a decrease in the shadow price of the 
LC, $\lambda_{2 i r}$, for every $i \in\{1, \ldots, N\}$. Its impact on the value of term (20a) is negative, $\partial\left[1+\exp \left(v_{j i r} / \bar{v}_{j p r}\right) / 2 .\left(1-2 /\left(1+\exp \left(v_{j i r} / \bar{v}_{j p r}\right)\right) / \lambda_{2 i r}\right)\right\rfloor / \partial \lambda_{2 i r}<0$, i.e. a decline in $\lambda_{2 i r}$ (caused by an increase in $l$ ) brings an increase in the value of term (20a), which means a higher share demand of investors with a non-binding BC.

Strategic investors with a binding BC: The investor effect expressed in (20b) incorporates both $\lambda^{\prime} s$ whose values are determined together. $\partial\left[1+\exp \left(v_{j i r} / \bar{v}_{j p r}\right) / 2 .\left(\ln \left(1-2 /\left(1+\exp \left(v_{j i r} / \bar{v}_{j p r}\right)\right)\right) / \lambda_{1 r}-\lambda_{2 i r} / \lambda_{1 r} S_{i} p_{i r}\right)\right] / \partial \lambda_{2 i r}=$ $=1+\exp \left(v_{j i r} / \bar{v}_{j p r}\right) / 2\left(-1 / \lambda_{1 r} S_{i} p_{i r}\right)<0$. This indicates that, ceteris paribus, when $\lambda_{2 i r}$ declines, the share demand of investors increases. However, since for this group of investors both constraints are binding and both $\lambda^{\prime} s$ are determined together (the solution of the KT shows $\left.\left(\mu_{j i r} s d_{i r}^{\mu_{i r}-1} p_{i r}^{c_{i j i r} / v_{i r}-1}-\lambda_{2 i r} / S_{i}\right) p_{i r}=\lambda_{1 r}\right)$, a potential decrease in $\lambda_{2 i r}$ caused by a higher $l$, which makes the legal constraint less binding, leads to an increase in $\lambda_{1 r}$. As a result we also have to investigate the impact of its changes on (20b). The first part of the term $1+\exp \left(v_{j i r} / \bar{v}_{j p r}\right) / 2$ moves independently from the height of the LC, so it is sufficient to look at $\partial\left(\ln \mu_{i r} / \lambda_{1 r}-\lambda_{2 i r} / \lambda_{1 r} S_{i} p_{i r}\right) / \partial \lambda_{1 r}=-1 / \lambda_{1 r}+\lambda_{2 i r} / \lambda_{1 r}^{2} S_{i} p_{i r}$, which is

$-1 / \lambda_{1 r}+\lambda_{2 i r} / \lambda_{1 r}^{2} S_{i} p_{i r}>0$, if $\lambda_{2 i r}>\lambda_{1 r} S_{i} p_{i r}$ and the share demand increases with the shadow price of the $\mathrm{BC}$, and

$-1 / \lambda_{1 r}+\lambda_{2 i r} / \lambda_{1 r}^{2} S_{i} p_{i r}<0$, if $\lambda_{2 i r}<\lambda_{1 r} S_{i} p_{i r}$, and the share demand decreases with the shadow price of the $\mathrm{BC}$.

As a result, lifting the $\mathrm{LC}$ on the stakes in individual firms has an ambiguous effect on the share demand of investors with a binding BC, depending on the mutual relations between $\lambda_{1 r}$ and $\lambda_{2 i r}$.

\section{Derivation of the impact of variable changes in 4.3:}

Let us simplify the equation of the optimal share demand (8a) as

$$
\ln s d_{j i r}=\frac{c_{j i r} / v_{j i r}-1}{\left(1-\mu_{j i r}\right)} \ln p_{i r}+X_{i r}^{\prime} \beta_{j r}^{\prime},
$$


where $X$ is the vector of other relevant variables as specified in (4) and $\beta_{j}$ stands for the vector of corresponding coefficients. ${ }^{38}$ So, for the first and second round the optimal share demand is

$$
\begin{aligned}
& \ln s d_{j i 1}=\frac{c_{j i 1} / v_{j i 1}-1}{\left(1-\mu_{j i 1}\right)} \ln p_{i 1}+X_{i 1}^{\prime} \beta_{j 1}^{\prime} \\
& \ln s d_{j i 2}=\frac{c_{j i 2} / v_{j i 2}-1}{\left(1-\mu_{j i 2}\right)} \ln p_{i 2}+X_{i 2}^{\prime} \beta_{j 2}^{\prime} .
\end{aligned}
$$

Subtracting (C.2a) from (C.2b), we get

$$
\Delta \ln s d_{j i 21}=\frac{c_{j i 2}+\widetilde{v}_{j i 2}}{c_{j i 2}\left(v_{j i 2}-1\right)} \ln p_{i 2}-\frac{c_{j i 1}+\widetilde{v}_{j i 1}}{c_{j i 1}\left(v_{j i 1}-1\right)} \ln p_{i 1}+\beta_{j}^{\prime} \Delta X_{i 21}^{\prime}
$$

where $\frac{c_{j i 1}+\widetilde{v}_{j i 1}}{c_{j i 1}\left(v_{j i 1}-1\right)}=\beta_{j 1}$ and $\frac{c_{j i 2}+\widetilde{v}_{j i 2}}{c_{j i 2}\left(v_{j i 2}-1\right)}=\beta_{j 2}$.

For illustrative purposes we can drop the indexes $i$ and $j$ and replace $\ln s d_{r}=y_{r}$ and $\ln p_{r}=x_{r}$. (C.2a) and (C.2b) can be replaced by

$$
\begin{aligned}
& y_{1}=\beta_{1} x_{1}+\beta^{\prime} X_{1}^{\prime} \text { and } \\
& y_{2}=\beta_{2} x_{2}+\beta^{\prime} X_{2}^{\prime} .
\end{aligned}
$$

Subtracting these two terms yields $y_{2}-y_{1}=\beta_{2} x_{2}-\beta_{1} x_{1}+\beta^{\prime}\left(X_{2}-X_{1}\right)$. Denoting $\Delta \beta_{21}=\beta_{2}-\beta_{1}$ and $\Delta x_{21}=x_{2}-x_{1}$ implies $\Delta x_{21} \beta_{1}+x_{2} \Delta \beta_{21}+\Delta X_{21} \beta=\Delta y_{21}$. However, if we run a regression skipping the second term $\Delta x_{21} \alpha_{21}+\Delta X_{21} \beta=\Delta y_{21}$, we get the coefficient $\alpha_{21}$. Multiplying each term by $\left(\Delta x_{21}^{\prime} \Delta x_{21}\right)^{-1} \Delta x_{21}^{\prime}$ gives $\beta_{1}+\left(\Delta x_{21}^{\prime} \Delta x_{21}\right)^{-1} \Delta x_{21}^{\prime} x_{2} \Delta \beta_{21}+\left(\Delta x_{21}^{\prime} \Delta x_{21}\right)^{-1} \Delta x_{21}^{\prime} \Delta X_{21} \beta=\left(\Delta x_{21}^{\prime} \Delta x_{21}\right)^{-1} \Delta x_{21}^{\prime} \Delta y_{21}=\alpha_{21}$.

Under the assumption that the changes in explanatory variables are not mutually correlated, i.e. $\Delta x_{21}^{\prime} \Delta X_{21}=0, \alpha_{21}=\beta_{1}+\left(\Delta x_{21}^{\prime} \Delta x_{21}\right)^{-1} \Delta x_{21}^{\prime} x_{2} \Delta \beta_{21}$ holds. This can be rearranged as $\alpha_{21}=\left(\Delta x_{21}^{\prime} \Delta x_{21}\right)^{-1} \Delta x_{21}^{\prime}\left(\Delta x_{21}-x_{2}\right) \beta_{1}+\left(\Delta x_{21}^{\prime} \Delta x_{21}\right)^{-1} \Delta x_{21}^{\prime} x_{2} \beta_{2}$.

Returning to our original variable, the impact of the price change on the share demand, under the assumption of no correlation between price change and other variables in vector $X_{i 21}$, is as follows and holds, correspondingly, for all explanatory variables:

$$
\Delta \ln s d_{j i 21}=\left[\frac{\Delta \ln p_{i 21}^{\prime}\left(\Delta \ln p_{i 21}-\ln p_{i 2}\right)}{\Delta \ln p_{i 21}^{\prime} \Delta \ln p_{i 21}} \beta_{j 1}+\frac{\Delta \ln p_{i 21}^{\prime} \ln p_{i 2}}{\Delta \ln p_{i 21}^{\prime} \Delta \ln p_{i 21}} \beta_{j 2}\right] \Delta \ln p_{i 21}+\beta_{j}^{\prime} \Delta X_{i 21}^{\prime} .
$$

\footnotetext{
${ }^{38}$ The same transformation can be done for the share demand of other types of investors expressed by (8b) and (8c).
} 
Individual researchers, as well as the on-line and printed versions of the CERGE-EI Working Papers (including their dissemination) were supported from the following institutional grants:

- Center of Advanced Political Economy Research [Centrum pro pokročilá politicko-ekonomická studia], No. LC542, (2005-2009),

- Economic Aspects of EU and EMU Entry [Ekonomické aspekty vstupu do Evropské unie a Evropské měnové unie], No. AVOZ70850503, (2005-2010);

- Economic Impact of European Integration on the Czech Republic [Ekonomické dopady evropské integrace na ČR], No. MSM0021620846, (2005-2011);

Specific research support and/or other grants the researchers/publications benefited from are acknowledged at the beginning of the Paper.

(c) Elena Yusupová, 2006

All rights reserved. No part of this publication may be reproduced, stored in a retrieval system or transmitted in any form or by any means, electronic, mechanical or photocopying, recording, or otherwise without the prior permission of the publisher.

Published by

Charles University in Prague, Center for Economic Research and Graduate Education (CERGE) and

Economics Institute (EI), Academy of Sciences of the Czech Republic

CERGE-El, Politických vězňu 7, 11121 Prague 1, tel.: +420 224005 153, Czech Republic.

Printed by CERGE-EI, Prague

Subscription: CERGE-El homepage: http://www.cerge-ei.cz

Editors: Directors of CERGE and EI

Managing editors: Deputy Directors for Research of CERGE and EI

ISSN 1211-3298

ISBN 80-7343-097-5 (Univerzita Karlova. Centrum pro ekonomický výzkum a doktorské studium) ISBN 80-7344-086-5 (Akademie věd České republiky. Národohospodářský ústav) 
CERGE-EI

P.O.BOX 882

Politických vězňů 7

11121 Praha 1

Czech Republic http://www.cerge-ei.cz 